Aus der Poliklinik für Zahnärztliche Prothetik

(Prof. Dr. med. dent. R. Bürgers)

im Zentrum Zahn-, Mund- und Kieferheilkunde

der Medizinischen Fakultät der Universität Göttingen

\title{
Nachweis potenziell parodontopathogener Bakterien bei gesunden und erkrankten Implantaten in der unterstützenden Implantattherapie -Ergebnisse einer praxisbasierten Querschnittsstudie-
}

\author{
INAUGURAL - DISSERTATION \\ zur Erlangung des Doktorgrades \\ für Zahnheilkunde \\ der Medizinischen Fakultät der \\ Georg-August-Universität zu Göttingen
}

vorgelegt von

Daniel Gollasch, geb. Fischer

aus

Oranienburg

Göttingen 2019 
Dekan:

Referent:

Ko-Referent/in:

Drittreferent/in:
Prof. Dr. med. W. Brück

PD Dr. med. dent. S. Rinke

Prof. Dr. M. Hülsmann 
Hiermit erkläre ich, die Dissertation mit dem Titel

"Nachweis potenziell parodontopathogener Bakterien bei gesunden und erkrankten Implantaten in der unterstützenden Implantattherapie -Ergebnisse einer praxisbasierten Querschnittsstudie-" eigenständig angefertigt und keine anderen als die von mir angegebenen Quellen und Hilfsmittel verwendet zu haben.

Göttingen, den

(Unterschrift) 


\section{Inhaltsverzeichnis}

Abkürzungsverzeichnis ....................................................................... III

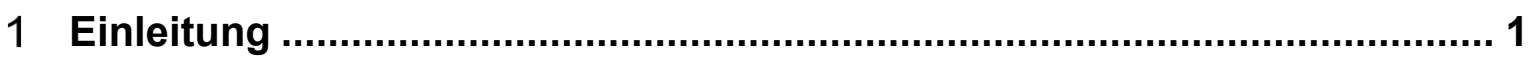

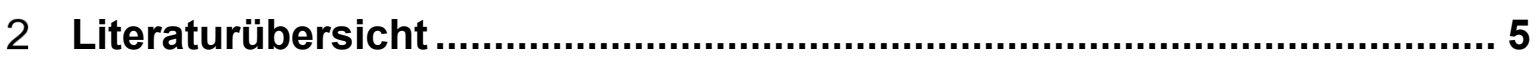

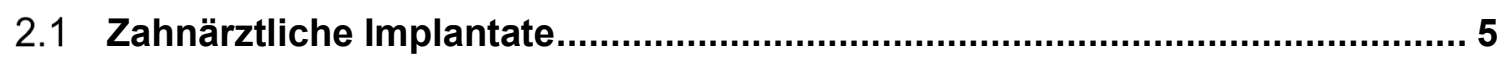

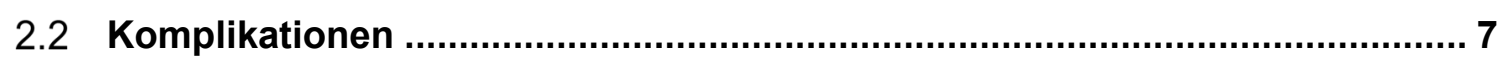

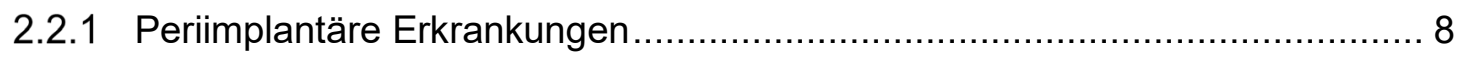

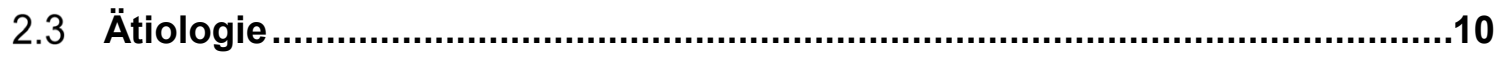

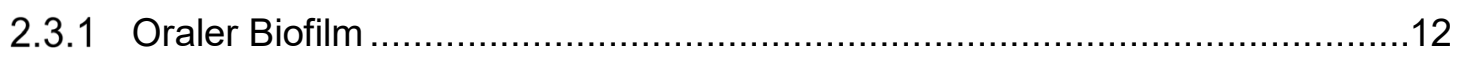

2.4 Aktuelle Erkenntnisse zu mikrobiologischen Befunden an Implantaten.......16

2.5 Diagnostik periimplantärer Erkrankungen.................................................17

2.5.1 Klinische Diagnostik periimplantärer Erkrankungen .................................18

2.5.2 Erweiterte Diagnostik periimplantärer Erkrankungen.................................19

3 Material und Methoden ...................................................................... 20

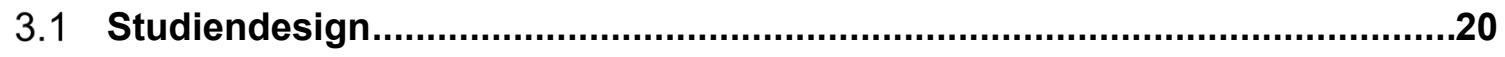

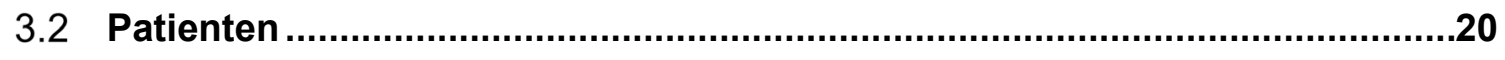

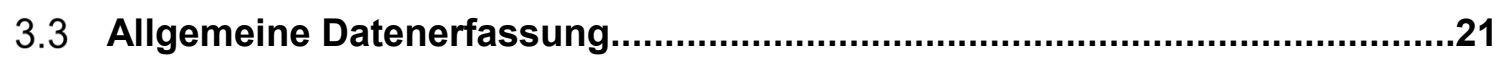

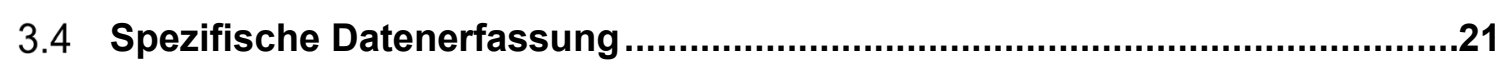

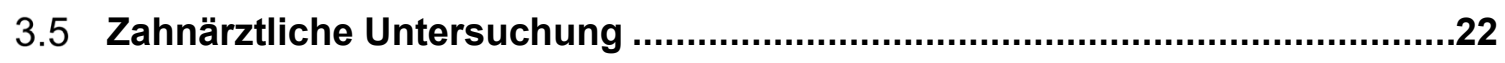

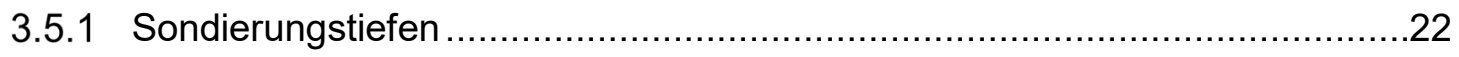

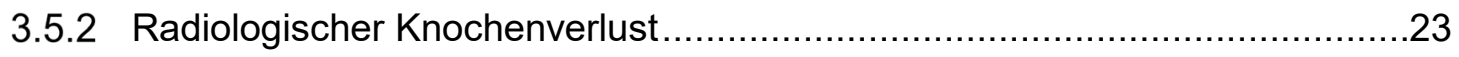

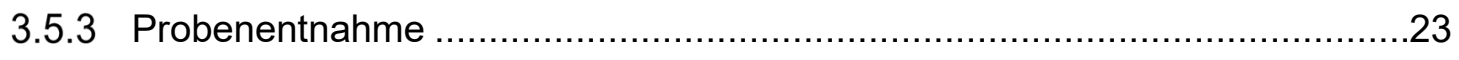

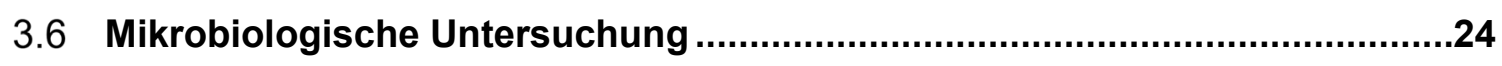

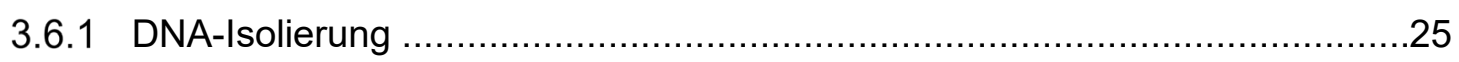

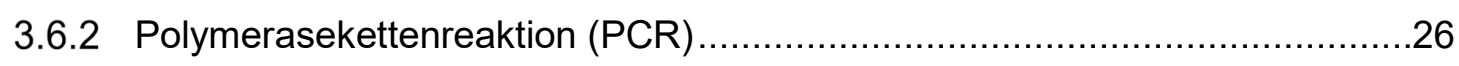

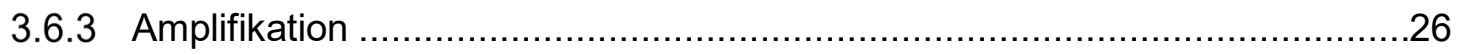

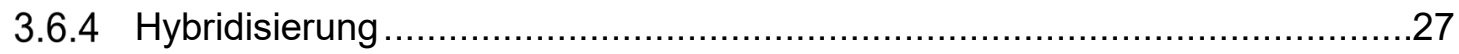

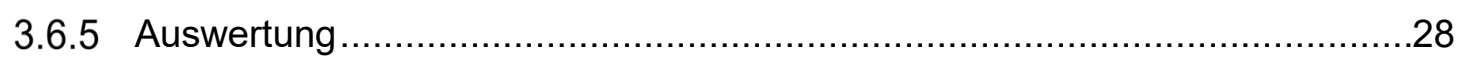

3.7 Datenerfassung und statistische Auswertung …......................................29

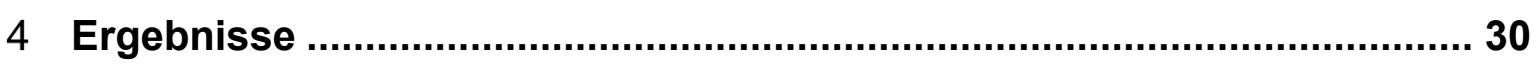

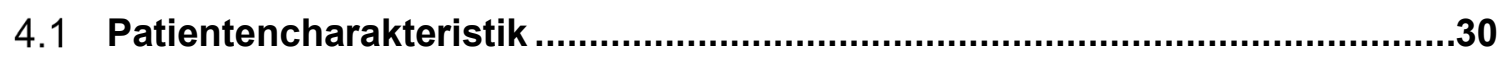

4.2 Mikrobiologische Befunde ......................................................................

4.2.1 Bakteriennachweis von Aggregatibacter actinomycetemcomitans ................31

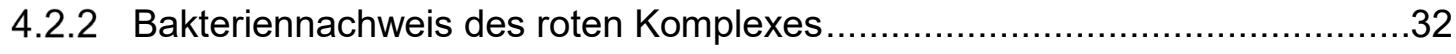

4.2.3 Bakteriennachweis des orangen Komplexes ........................................34 


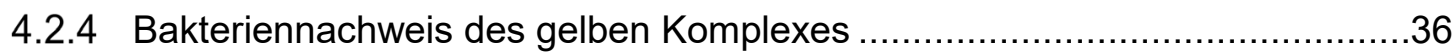

4.2.5 Bakteriennachweis des grünen Komplexes ............................................37

4.3 Klinische Prävalenz von Mukositis und Periimplantitis unter

Berücksichtigung von Risikofaktoren und sonstigen Einflussfaktoren ................39

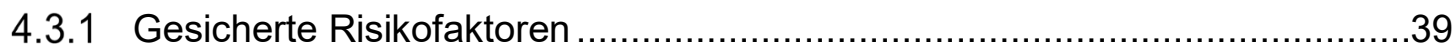

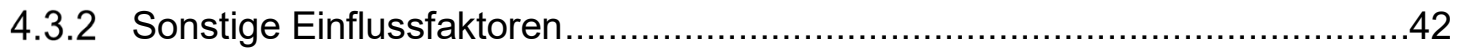

4.4 Zusammenfassung der wichtigsten Ergebnisse ..........................................45

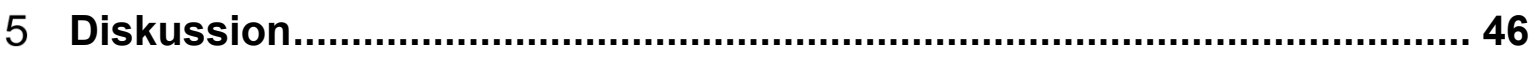

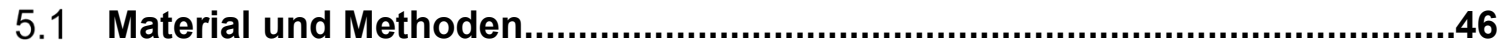

5.2 Der Zusammenhang zwischen potentiell parodontopathogenen Bakterien und dem Auftreten periimplantärer Erkrankungen .............................................47

5.3 Risikofaktoren und deren Einfluss auf periimplantäre Erkrankungen ..........50

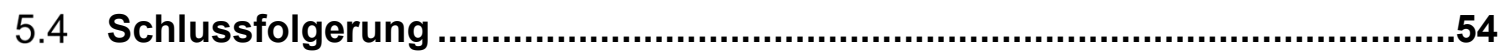

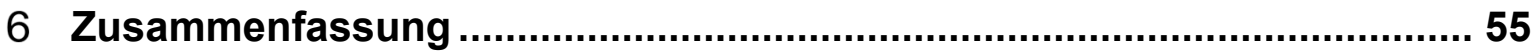

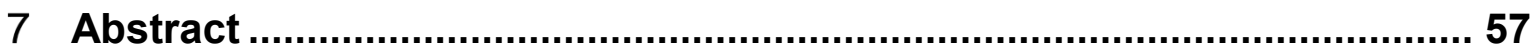

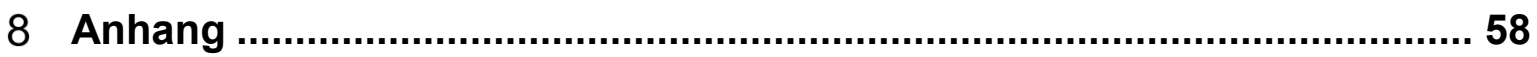

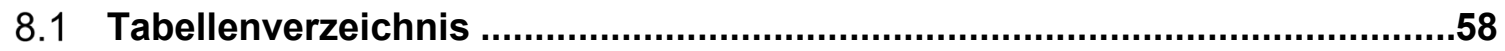

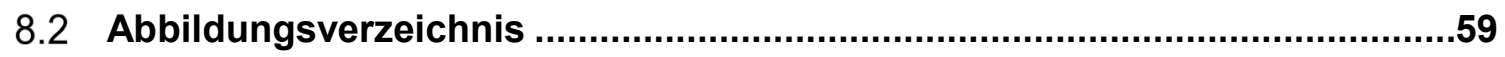

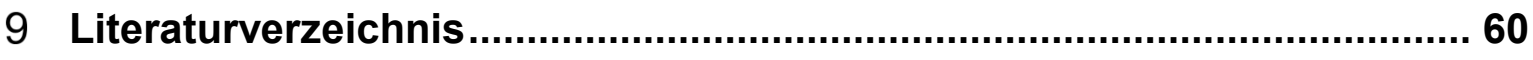




\section{Abkürzungsverzeichnis}

Aa

Aac

AC

aMMP-8

BL

BOP

CC

CON-C

CON-D

$\mathrm{Cr}$

Cs

CT

DEN

DMF-T

Ec

En

Fn

GAP

$\mathrm{HBO}$

HYB

IL-1

ITI

PCR

$P g$

Pi

PI
Actinobaccilus

Aggregatibacter Actinomycetemcomitans

Amplifikationskontrolle

aktive Matrix-Metalloproteinasen 8

bone-level

bleeding on probing

Konjugatkontrolle

Konjugat-Konzentrat

zugehöriger Puffer zum Konjugat-

Konzentrat

Campylobacter rectus

Capnocytophaga species

Computertomographie

Denaturierungsreagenz

decayed, missing, filled, teeth

Eikenella corrodens

Eubacterium nodatum

Fusobacterium nucleatum

generalisierte aggressive Parodontitis

hyperbare Sauerstoffbehandlung

Hybridisierungspuffer

Interleukin 1

International Team for Implantology

Polymerasekettenreaktion

Porphyromonas gingivalis

Prevotella intermedia

Plaque-Index 
Abkürzungsverzeichnis

\begin{tabular}{|c|c|}
\hline PIM & Studiencode \\
\hline$P m$ & Peptostreptococcus micros \\
\hline PNM & Primer/Nukleotid-Mix \\
\hline py & pack years \\
\hline rhBMP-2 & $\begin{array}{l}\text { recombinant human bone morphogenetic } \\
\text { protein-2 }\end{array}$ \\
\hline rhbFGF & $\begin{array}{l}\text { recombinant human basic fibroblast growth } \\
\text { factor }\end{array}$ \\
\hline rh-IGF-I & $\begin{array}{l}\text { recombinant human insulin-like growth } \\
\text { factor }\end{array}$ \\
\hline RIN & Rinselösung \\
\hline $\mathrm{SBI}$ & Sulkus-Blutungs-Index \\
\hline $\mathrm{Sr}-\mathrm{HA}$ & Strontium-Hydroxylapatit \\
\hline ST & Sondierungstiefen \\
\hline STR & Stringent-Waschlösung \\
\hline STRIPS & nummerierte Membranstreifen \\
\hline SUB-C & Substrat-Konzentrat \\
\hline SUB-D & $\begin{array}{l}\text { zugehöriger Puffer zum Substrat- } \\
\text { Konzentrat }\end{array}$ \\
\hline Sys-Paro & parodontale Vorerkrankung \\
\hline Taq Polymerase & $\begin{array}{l}\text { thermostabile DNA-Polymerase des } \\
\text { Bakteriums Thermus aquaticus }\end{array}$ \\
\hline$T d$ & Treponema denticola \\
\hline$T f$ & Tannerella forsythia \\
\hline UPT & unterstützende Parodontitistherapie \\
\hline
\end{tabular}




\section{$1 \quad$ Einleitung}

Seit der Versorgung des ersten Patienten mit einem dentalen Implantat im Jahr 1965 an der Universität Lund in Schweden hat die dentale Implantologie eine beständige Weiterentwicklung erfahren. Dentale Implantate sind mittlerweile eine wissenschaftlich abgesicherte Therapieform zum Ersatz einzelner Zähne im teilbezahnten Kiefer und auch bei der Versorgung des zahnlosen Patienten mit festsitzendem oder abnehmbarem Zahnersatz (Klinge et al. 2018).

In mehreren klinischen Studien konnte gezeigt werden, dass dentale Implantate eine Überlebensrate von mehr als 95\% nach Funktionsperioden von zehn Jahren aufweisen (Buser et al. 2012; Degidi et al. 2012; Fischer und Stenberg 2013; Gotfredsen 2012; Jemt 2016). Dies bedeutet, dass nach dieser Beobachtungszeit noch 19 von 20 inserierten Implantaten in Funktion sind.

In systematischen Übersichtsarbeiten und Metaanalysen konnte gezeigt werden, dass ca. 2-3\% der inserierten Implantate während der Einheilphase verloren gehen. Darüber hinaus wurde eine jährliche Verlustrate von 0,3-1,3\% kalkuliert (Jung et al. 2012; Pjetursson et al. 2012; Sailer et al. 2012).

Dieser primär hohe Wert für in Funktion befindliche Implantate lässt jedoch eventuell aufgetretene Komplikationen unberücksichtigt (Pjetursson und Heimisdottir 2018). Entsprechend konnten in den systematischen Reviews zwar hohe Überlebensraten identifiziert werden, gleichzeitig zeigte sich aber, dass nur ca. zwei Drittel der versorgten Implantate in einem Beobachtungszeitraum von fünf Jahren frei von Komplikationen waren (Jung et al. 2012; Pjetursson et al. 2012; Sailer et al. 2012). Komplikationen, die während der Funktionsphase einer implantatprothetischen Versorgung auftreten können, werden unterteilt in:

- Biologische Komplikationen: Verlust in der Einheilphase, Erkrankungen der periimplantären Weich- und Hartgewebe (Mombelli et al. 2012)

- Technische Komplikationen: Materialfrakturen im Bereich der Suprakonstruktionen oder bei Implantatkomponenten oder auch Lockerungen von Schraubverbindungen

- Technische Komplikationen: Materialfrakturen im Bereich der Suprakonstruktionen oder bei Implantatkomponenten oder auch Lockerungen von Schraubverbindungen

Pjetursson et al. (2014) untersuchten in einer Übersichtsarbeit, ob die Häufigkeit von Verlusten und Komplikationen im Zuge der Weiterentwicklung der dentalen Implantologie 
reduziert werden konnte. Die Autoren konnten zwar in Publikationen, die nach 2000 erschienen sind, eine Reduktion der Komplikationsraten feststellen, dennoch zeigten sich insbesondere für Verblendkeramikfrakturen und biologische Komplikationen weiterhin sehr hohe Prävalenzraten. Die Evaluation der Ursachen und Strategien zur Vermeidung derartiger Komplikationen ist daher in den letzten zehn Jahren in den Fokus der klinischen Forschung gerückt (Klinge et al. 2018).

Bereits seit mehr als 20 Jahren ist bekannt, dass der Langzeiterfolg implantatprothetischer Versorgungen insbesondere durch biologische Komplikationen verringert werden kann (van Steenberghe et al. 1993). Die European Federation of Periodontolgy definierte zwei Ausprägungsformen biologischer Komplikationen bei dentalen Implantaten (Lang und Berglundh 2011; Sanz et al. 2012): Mukositis und Periimplantitis.

Mukositis ist als reversible Entzündung der periimplantären Mukosa definiert. Die Entzündung ist dabei auf die Weichgewebe begrenzt und ein periimplantärer Knochenverlust lässt sich nicht nachweisen (Mombelli et al. 2012). Es gibt eine starke Evidenz tierexperimenteller und klinischer Studien, dass die Biofilmakkumulation der primäre ätiologische Faktor der Mukositis ist. Durch die Entfernung des Biofilms können wieder gesunde, entzündungsfreie Verhältnisse der periimplantären Mukosa erzielt werden. Typische klinische Symptome der Mukositis sind Schwellung, Rötung und Blutung auf Sondieren (bleeding on probing =BOP) (Berglundh et al. 2018).

Periimplantitis wird als plaqueassoziierte pathologische Veränderung der periimplantären Weich- und Hartgewebe definiert (Lafaurie et al. 2017; Lasserre et al. 2018). Sie ist charakterisiert durch eine Entzündung der periimplantären Weichgewebe und einen progressiven Verlust des periimplantären Knochens während der Funktionsphase. Klinische Zeichen einer Periimplantitis sind BOP und/oder Suppuration, eine Zunahme der Sondierungstiefen und zusätzlich ein progressiver Knochenverlust im Vergleich zu vorangegangenen radiologischen Befunden (Renvert et al. 2018).

Das wissenschaftliche Interesse für den Bereich der biologischen Komplikationen hat insbesondere in den letzten zehn Jahren stark zugenommen. So konnten bei einer Recherche im Web of Science im Februar 2018 allein 1.932 Artikel mit dem Keyword „periimplantitis“ identifiziert werden. Diese Artikel wiesen für das Jahr 2017 mehr als 7.000 Zitate auf. Im Jahr 2007 betrug die Anzahl der Zitate für wissenschaftliche Artikel mit dem Suchbegriff „periimplantitis“ lediglich 1.000 (Klinge et al. 2018).

In einer systematischen Übersichtsarbeit von Derks und Tomasi (2015) konnten Prävalenzraten für Mukositis von $19-65 \%$ bestimmt werden. Die Häufigkeit der 
Periimplantitis schwankte zwischen 1 und 47\%. Im Rahmen einer Metaanalyse konnte eine mittlere Prävalenz für die Mukositis von $43 \%$ und für die Periimplantitis von $22 \%$ bestimmt werden. Dies ist auch in Übereinstimmung mit den Ergebnissen anderer Übersichtarbeiten und zeigt die hohe Relevanz biologischer Komplikationen für den klinischen Langzeiterfolg implantatprothetischer Versorgungen (Lee et al. 2017; Munoz et al. 2018; Salvi et al. 2017).

Der Erfolg einer Periimplantitistherapie ist nach den bislang vorliegenden Daten aus systematischen Übersichtsarbeiten und Metaanalysen nur schwer vorhersagbar (Daugela et al. 2016; Ramanauskaite et al. 2016; Roccuzzo et al. 2018). Im Vergleich zu einer Therapie bei einem bereits fortgeschrittenen und ausgeprägten Knochenabbau (Daugela et al. 2016; Ramanauskaite et al. 2016; Roccuzzo et al. 2018) konnte jedoch gezeigt werden, dass eine Therapie der Periimplantitis effektiver ist, wenn sie in einem möglichst frühen Stadium erfolgt. Daher erscheint es wichtig, einerseits effektive Präventionsstrategien für die Entstehung einer Periimplantitis zu untersuchen, andererseits aber auch klinisch validierte und routinemäßig einsetzbare Diagnoseverfahren zu etablieren, die eine frühzeitige Diagnostik der Periimplantitis ermöglichen (Derks und Tomasi 2015). Für die Entwicklung effizienter Präventionsstrategien ist in erster Linie die Generierung von Daten zur Prävalenz und zum Schweregrad periimplantärer Erkrankungen erforderlich. Hierbei sind auch patientenspezifische und/oder implantatspezifische Risikofaktoren zu berücksichtigen (Renvert und Quirynen 2015).

Im Rahmen mehrerer klinischer Studien konnten bislang Daten zu potentiellen Risikofaktoren, die eine Assoziation mit einer periimplantären Erkrankung aufweisen, identifiziert werden. So konnten Zementüberschüsse, eine parodontale Vorerkrankung, aber auch Rauchen als Risikofaktoren identifiziert werden. Bislang sind keine eindeutigen Aussagen zum Einfluss von Allgemeinerkrankungen (z. B. Diabetes oder kardiovaskuläre Erkrankungen) oder einer genetischen Prädisposition auf das Erkrankungsrisiko für Periimplantitis möglich (Dreyer et al. 2018; Renvert und Quirynen 2015). Demgegenüber zeigen die Ergebnisse systematischer Übersichtsarbeiten, dass durch die regelmäßige Teilnahme an einem strukturierten Vorsorgeprogramm das Risiko für biologische Komplikationen reduziert werden kann (Dreyer et al. 2018; Renvert und Polyzois 2015).

Widersprüchliche Ergebnisse wurden für den potentiellen Einfluss spezifischer Mikroorganismen und die Progression periimplantärer Erkrankungen publiziert (Lafaurie et al. 2017). Übereinstimmung besteht lediglich hinsichtlich der Tatsache, dass die Mikroflora in parodontalen und periimplantären Läsionen eine komplexe Zusammensetzung mit überwiegend anaeroben Mikroorganismen aufweist (Renvert und 
Quirynen 2015). Zudem konnten auch Mikroorganismen, die primär nicht mit einer parodontalen Erkrankung assoziiert sind (S. aureus und Candida albicans) gehäuft in periimplantären Läsionen nachgewiesen werden (Lafaurie et al. 2017). Parodontale Läsionen und periimplantäre Erkrankungen scheinen unterschiedliche Erkrankungsformen in Bezug auf die vorherrschende Mikroflora darzustellen (Lafaurie et al. 2017).

Bei parodontalen Erkrankungen konnte durch den Nachweis spezifischer Mikroorganismen und deren Häufigkeit eine Korrelation zur Progression der Erkrankung nachgewiesen werden (Wang et al. 2016). Für periimplantäre Läsionen liegen demgegenüber jedoch nur sehr wenige Erkenntnisse vor, die durch den qualitativen und quantitativen Nachweis von Mikroorganismen prognostische Aussagen zum Fortschreiten einer periimplantären Läsion erlauben. Dies gilt in analoger Weise für Testverfahren, mit denen durch den Nachweis spezifischer Biomarker (z. B. Metallomatrixpeptidasen) eine Korrelation zum Progressionsrisiko einer periimplantären Erkrankung nachgewiesen werden soll (Wang et al. 2016). 


\section{Literaturübersicht}

\subsection{Zahnärztliche Implantate}

In der Zahn-, Mund- und Kieferheilkunde bezeichnet man einen aus alloplastischem Material bestehenden Körper, der die Funktion einer Zahnwurzel übernimmt, als Implantat. Das Implantat dient dem Ersatz verloren gegangener Zähne und der Befestigung von Kronen, Brücken, Prothesen und Epithesen (Glauser et al. 2007; Jung et al. 2008; Klinge et al. 2018; Sailer et al. 2009) und hat sich vor allem im Bereich der Totalprothetik zur Verbesserung der Retention bewährt (Roccuzzo et al. 2012) Die nachfolgende Abbildung 2.1 zeigt ein Implantat vom Typ Ankylos (Dentsply Friadent, Mannheim).

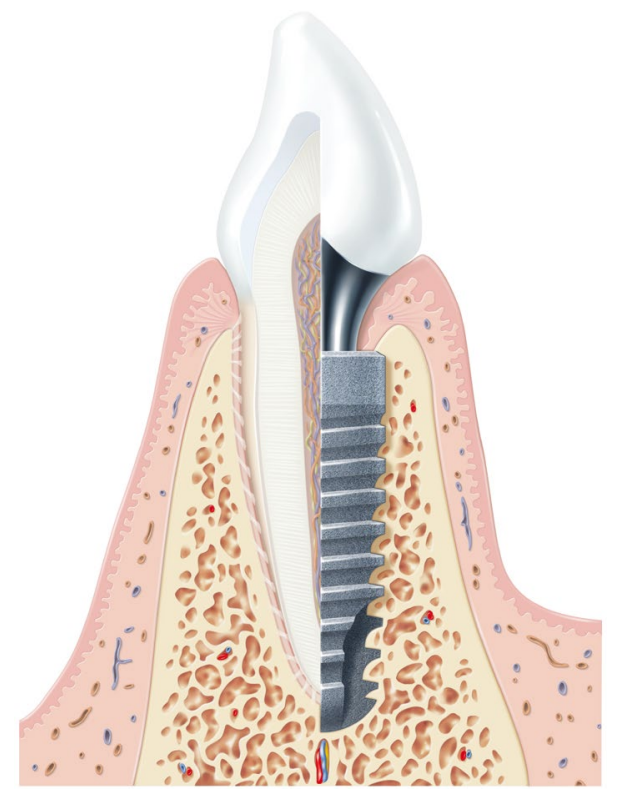

Abbildung 2.1 Implantat vom Typ Ankylos (Dentsply Sirona, Mannheim)

(mit freundlicher Genehmigung von Dentsply Sirona Implants, Mannheim, Deutschland)

Indikationen für orale Implantate sind in erster Linie ein zahnloser Kiefer bzw. ein Lückengebiss mit Schaltlücke oder Freiendsituation (Avila et al. 2009). Weitere mögliche Indikationen für dentale Implantate sind nachfolgend aufgelistet (Wehrbein 1994):

1. Sie sollten die Invasivität (Pfeilerpräparation) bei konventionellen prothetischen Versorgungsmöglichkeiten herabsetzen, um intakte Zahnhartsubstanz zu erhalten,

2. Zur Möglichkeit der Segmentierung einer konventionellen Brückenversorgung bei großen Spannweiten, wenn entweder nicht genügend Pfeilerzähne vorhanden 
sind, diese zu ungünstig verteilt sind oder qualitativ nicht mit eingebunden werden können,

3. Bei fragwürdigen Pfeilerkonstruktionen oder bei Pfeilerzähnen mit ungewisser Prognose,

4. Bei dem Wunsch des Patienten nach festsitzendem Zahnersatz,

5. Zur orthodontischen Verankerung bei unzureichender dentaler Verankerungs möglichkeit.

Implantate haben sich zur Verbesserung der Retention von Prothesen im zahnlosen Kiefer bewährt (Pjetursson et al. 2008; Roccuzzo et al. 2012). Aber auch im Bereich von Einzelzahnimplantaten finden sie aufgrund der Substanzschonung von Nachbarzähnen in den letzten Jahren eine weite Anwendung (Glauser et al. 2007; Jung et al. 2008; Sailer et al. 2009). Aufgrund ihrer hohen wissenschaftlich belegten Überlebensrate von $96 \%$ nach fünf Jahren (Sailer et al. 2009) und 94,9\% nach zehn Jahren (Albrektsson et al. 2012; Buser et al. 2012; Degidi et al. 2012; Fischer und Stenberg 2013; Gotfredsen 2012; Jemt 2016) werden Implantate in der Zukunft einen immer größer werdenden Stellenwert in der Zahnmedizin bekommen und sind schon jetzt ein etabliertes Mittel der Wahl bei zu ersetzenden Zähnen (Lin et al. 2006).

Derzeit sind die wissenschaftlichen klinischen Daten für keramische Implantate im Allgemeinen und für Zirkonoxid-Implantate im Besonderen nicht ausreichend, um keramische Implantate für die routinemäßige klinische Anwendung zu empfehlen (Andreiotelli et al. 2009). Obwohl einige kurzfristige klinische Berichte verfügbar sind und zufriedenstellende Ergebnisse liefern, sollten kontrollierte klinische Studien mit einer Nachuntersuchung von fünf Jahren oder länger durchgeführt werden (Ozkurt und Kazazoglu 2011). In Zukunft geht man jedoch davon aus, dass Zirkonoxid vor allem im ästhetisch relevanten Bereich zunehmend mehr in den Vordergrund tritt, momentan aber noch zu wenig aussagekräftige Studien vorliegen, um die Beständigkeit eindeutig nachweisen zu können (Andreiotelli et al. 2009).

Auch Titan-Zirkon-Legierungen (Roxolid, Institut Straumann AG) versprechen sehr gute Ergebnisse. Die Meta Analyse von Altuna et al. 2016 zeigt Überlebensraten von 98,4\% und $97,8 \%$ ein Jahr nach Insertation und $97,7 \%$ und $97,3 \%$ nach zwei Jahren. Allerdings erwähnt er auch, dass Langzeitergebnisse fehlen, um die klinische Leistungsfähigkeit zu bestätigen.

Kontraindikationen lassen sich in temporäre und permanente Kontraindikationen unterteilen. $\mathrm{Zu}$ den temporär allgemeinmedizinischen Kontraindikationen zählen vorrübergehende Infekte, Erkrankungen und Therapien, die zwar temporär das 
Immunsystem beeinflussen, aber durch ihre zeitliche Begrenzung keine absolute Kontraindikation darstellen (Chrcanovic und Albrektsson und et al. 2016; Ouanounou et al. 2016). Kritischer sind Stoffwechselerkrankungen zu betrachten. Aber auch Allergien, Systemerkrankungen des Knochens oder des endokrinen Systems können absolute allgemeinmedizinische Kontraindikationen darstellen. Lange Zeit galt Diabetes mellitus noch als relative Kontraindikation für Implantatversorgungen, da das Risiko periimplantärer Infektionen und sogar fehlender Osseointegration zweifellos höher ist (Dreyer et al. 2018; Ferreira et al. 2006). Jedoch ist man heute in der Lage, auch Patienten mit gut eingestelltem Diabetes mellitus durch chirurgische Techniken und einer sorgfältig ausgewählten Platzierung implantologisch zu versorgen. (Abadzhiev und Balcheva 2009; Naujokat et al. 2016; Turkyilmaz 2010). Eine signifikant erhöhte Verlustgefahr von Implantaten haben Patienten nach radiatio. Eine Studie von Granstrom et al. (1999) über einen Zeitraum von 16 Jahren ergab, dass die Bestrahlung bei 53,7\% der Implantate zum Misserfolg führte. Zusätzlich fanden sie jedoch heraus, dass dieser Misserfolg durch eine unterstützende hyperbare Sauerstoffbehandlung (HBO) die Erfolgsrate entscheidend verbesserte. Das Fazit der Studie ist jedoch, dass eine Implantatinsertion im bestrahlten Knochen mit einer erhöhten Ausfallrate einhergeht, man dieser durch eine adjuvante HBO-Behandlung aber zumindest teilweise entgegenwirken kann. Unklar scheint das Risiko bei Patienten $\mathrm{zu}$ sein, welche sich in einer Bisphosphonattherapie befinden. Hierzu fehlen randomisierte klinische Langzeitstudien mit einem längeren Beobachtungszeitraum (de-Freitas et al. 2016)

\subsection{Komplikationen}

Komplikationen lassen sich in technische, biologische und sonstige Komplikationen einteilen. Liaw et al. (2015) unterscheiden in ihrer Studie zwischen biomechanischen Überbelastungen, Infektionen, Entzündungen und anderen Gründen. Tabelle 2.1 gibt einen Überblick über häufig aufgeführte Komplikationen. Die folgende Arbeit beschäftigt sich im Anschluss ausschließlich mit den biologischen Komplikationen. 
Tabelle 2.1 Komplikationen

\begin{tabular}{|c|c|c|}
\hline Komplikationen & Art & Literatur \\
\hline technische & $\begin{array}{l}\text { Überkonturierung -> Blutungen } \\
\text { Kronen-/ Abutmentfrakturen } \\
\text { Dezementierung / Schraubenlockerung } \\
\text { Implantatfraktur } \\
\text { Platzierung und Restauration }\end{array}$ & $\begin{array}{l}\text { (Calderon et al. 2014) } \\
\text { (Romeo und Storelli 2012) } \\
\text { (Romeo und Storelli 2012) } \\
\text { (Tagger Green et al. 2002) } \\
\text { (John et al. 2013) }\end{array}$ \\
\hline biologische & $\begin{array}{l}\text { Mukositis } \\
\text { Periimplantitis }\end{array}$ & $\begin{array}{l}\text { (Rodrigo et al. 2012) } \\
\text { (Lang et al. 2000) }\end{array}$ \\
\hline sonstige & $\begin{array}{l}\text { Zementreste } \\
\text { Bruxismus }\end{array}$ & $\begin{array}{l}\text { (Quaranta et al. 2017) } \\
\text { (Chrcanovic und Kisch und } \\
\text { et al. 2016) }\end{array}$ \\
\hline
\end{tabular}

\subsubsection{Periimplantäre Erkrankungen}

Als periimplantäre Erkrankungen bezeichnet man eine periimplantäre Mukositis und eine Periimplantitis. Dabei handelt es sich um entzündliche Erkrankungen (Sanchez-Perez et al. 2011) grundsätzlich multifaktorieller Erkrankungsgenese (Mombelli et al. 2012; Tomasi und Derks 2012). Der Begriff periimplantäre Erkrankungen wurde erstmals von Mombelli im Jahr 1987 erwähnt (Mombelli et al. 1987). Definitionsgemäß ist eine periimplantäre Mukositis eine reversible Entzündung des periimplantären Weichgewebes (Mukosa) ohne ein Anzeichen von Knochenverlust (Ata-Ali et al. 2011; Salvi et al. 2012). Heute nimmt man an, dass sich die periimplantäre Mukositis von der Gingivitis nicht grundlegend unterscheidet und eine Immunantwort auf bakterielle Belastungen der Gingiva ist (Lang und Berglundh 2011). Zudem sind beide Erkrankungen reversibel (Salvi et al. 2012). Allerdings ist anzumerken, dass die typischen Entzündungszeichen, wie Rötung und Schwellung, aufgrund der veränderten Vaskularisierung an Implantaten geringer ausgeprägt sind als an natürlichen Zähnen. An Implantaten gehen sie lediglich vom Periost des umgebenden Knochens und nicht von parodontalen und supraperiostalen Gefäßen wie bei der Gingivitis aus (Berglundh et al. 1994).

Die Periimplantitis ist eine irreversible Entzündung des periimplantären Gewebes, bei der es zu einem radiologisch erkennbarem krestalen Knochenabbau um das Implantat herum kommt (Lafaurie et al. 2017; Lang und Berglundh 2011; Lasserre et al. 2018; Rinke et al. 2011). Sie hingegen unterscheidet sich im Umfang, in der Zusammensetzung der Läsion sowie der Progression entscheidend von der Parodontitis. Die Parodontitis dominiert ein sich selbst begrenzender Prozess mit einer „sich schützenden“ Bindegewebskapsel, welcher bei periimplantären Läsionen gelegentlich fehlt (Lang und Berglundh 2011). Die Periimplantitis verläuft zirkulär um das Implantat und bildet häufig schüsselförmige erkennbare Defekte aus (Schwarz et al. 2007). Tabelle 2.2 gibt einen Überblick über aktuelle Studien, welche die Inzidenz und Prävalenz von Mukositis und Periimplantitis 
angeben.

Tabelle 2.2 Inzidenz und Prävalenz von Mukositis / Periimplantitis

\begin{tabular}{|c|c|c|c|}
\hline Quelle & $\begin{array}{l}\text { Beobachtungs- } \\
\text { zeit }\end{array}$ & Material & Ergebnisse \\
\hline Marrone et al. 2013 & 5 Jahre & $\begin{array}{l}103 \text { Patienten } \\
266 \text { Implantate }\end{array}$ & \begin{tabular}{|l|} 
Prävalenz: \\
Mukositis: $38 \%$ \\
Periimplantitis: $23 \%$
\end{tabular} \\
\hline Duque et al. 2016 & $1 \mathrm{Jahr}$ & $\begin{array}{l}25 \text { Patienten } \\
64 \text { Implantate }\end{array}$ & $\begin{array}{l}\text { Prävalenz: } \\
\text { Mukositis: } 81,2 \% \\
\text { conventional implants } \\
\text { (Cls) / 90\% platform } \\
\text { switching implants (PSIs) } \\
\text { Periimplantitis: } 15,6 \% \\
\text { (Cls) / 6,6\% (PSIs) } \\
\end{array}$ \\
\hline $\begin{array}{l}\text { van Velzen et al. } \\
2015\end{array}$ & 10 Jahre & $\begin{array}{l}177 \text { Patienten } \\
374 \text { Implantate }\end{array}$ & $\begin{array}{l}\text { Inzidenz: } \\
\text { Periimplantitis: } 7 \%\end{array}$ \\
\hline Derks et al. 2015 & Meta-Analyse & 11 Studien & $\begin{array}{l}\text { Prävalenz: } \\
\text { Mukositis: 19\% - 65\% } \\
\text { (mittlere Prävalenz 43\%) } \\
\text { Periimplantitis: 1\% - 47\% } \\
\text { (mittlere Prävalenz 22\%) } \\
\end{array}$ \\
\hline Daubert et al. 2015 & 11 Jahre & $\begin{array}{l}96 \text { Patienten } \\
225 \text { Implantate }\end{array}$ & $\begin{array}{l}\text { Prävalenz: } \\
\text { Mukositis: } 33 \% \\
\text { Periimplantitis: } 16 \% \\
\end{array}$ \\
\hline Rinke et al. 2011 & $\begin{array}{l}68,2 \pm 24,8 \\
\text { Monate }\end{array}$ & 89 Patienten & \begin{tabular}{|l|} 
Prävalenz: \\
Mukositis: $45 \%$ \\
Periimplantitis: $11 \%$ \\
\end{tabular} \\
\hline Dierens et al. 2012 & 16 bis 22 Jahre & $\begin{array}{l}46 \text { Patienten } \\
46 \text { Implantate }\end{array}$ & $\begin{array}{l}\text { Inzidenz: } \\
\text { Periimplantitis } 5 \%\end{array}$ \\
\hline $\begin{array}{l}\text { Koldsland et al. } \\
2010\end{array}$ & 8,4 Jahre & 109 Patienten & \begin{tabular}{|l|} 
Prävalenz: \\
Mukositis $47,1 \%$ \\
Periimplantitis: $11,3 \%$
\end{tabular} \\
\hline
\end{tabular}

Wie der Tabelle $2.2 \mathrm{zu}$ entnehmen ist, zeigen sich größere Varianzen in der Prävalenz und der Inzidenz von Mukositis und Periimplantitis bei entsprechend unterschiedlichen Beobachtungszeiten. Die Prävalenz von Mukositis und Periimplantitis erstreckt sich von 19 bis $65 \%$ und von 1 bis $47 \%$ (Derks und Tomasi 2015). Bei der Betrachtung der Daten bleibt zu berücksichtigen, dass unterschiedliche Definitionen für Mukositis und Periimplantitis verwendet wurden, was die Aussagen zur tatsächlichen Häufigkeit von Mukositis und Periimplantitis sehr erschwert. Zukünftige Studien zur Epidemiologie periimplantärer Erkrankungen sollten daher einheitliche Definition und Patientenparameter beinhalten, um sie vergleichbar und aussagekräftig zu machen (Derks und Tomasi 2015; Munoz et al. 2018). 


\section{3 Ätiologie}

Nach heutigem Kenntnisstand ist die Ätiologie periimplantärer Erkrankungen, genau wie die parodontaler Erkrankungen, multifaktoriell (Mombelli et al. 2012; Tomasi und Derks 2012). Das heißt, dass neben dem primär biofilminduzierten Einfluss des Erkrankungsgeschehens, auch den Risikofaktoren ein modulierender Effekt zugesprochen wird (Abbildung 2.2). Mikrobielle Einflussgrößen nehmen, genau wie genetische Risikofaktoren, Umwelt- und erworbene Risikofaktoren, Einfluss auf periimplantäre Erkrankungen und können diese negativ beeinflussen (Kotsovilis et al. 2008; Mombelli et al. 2012; Park et al. 2017).

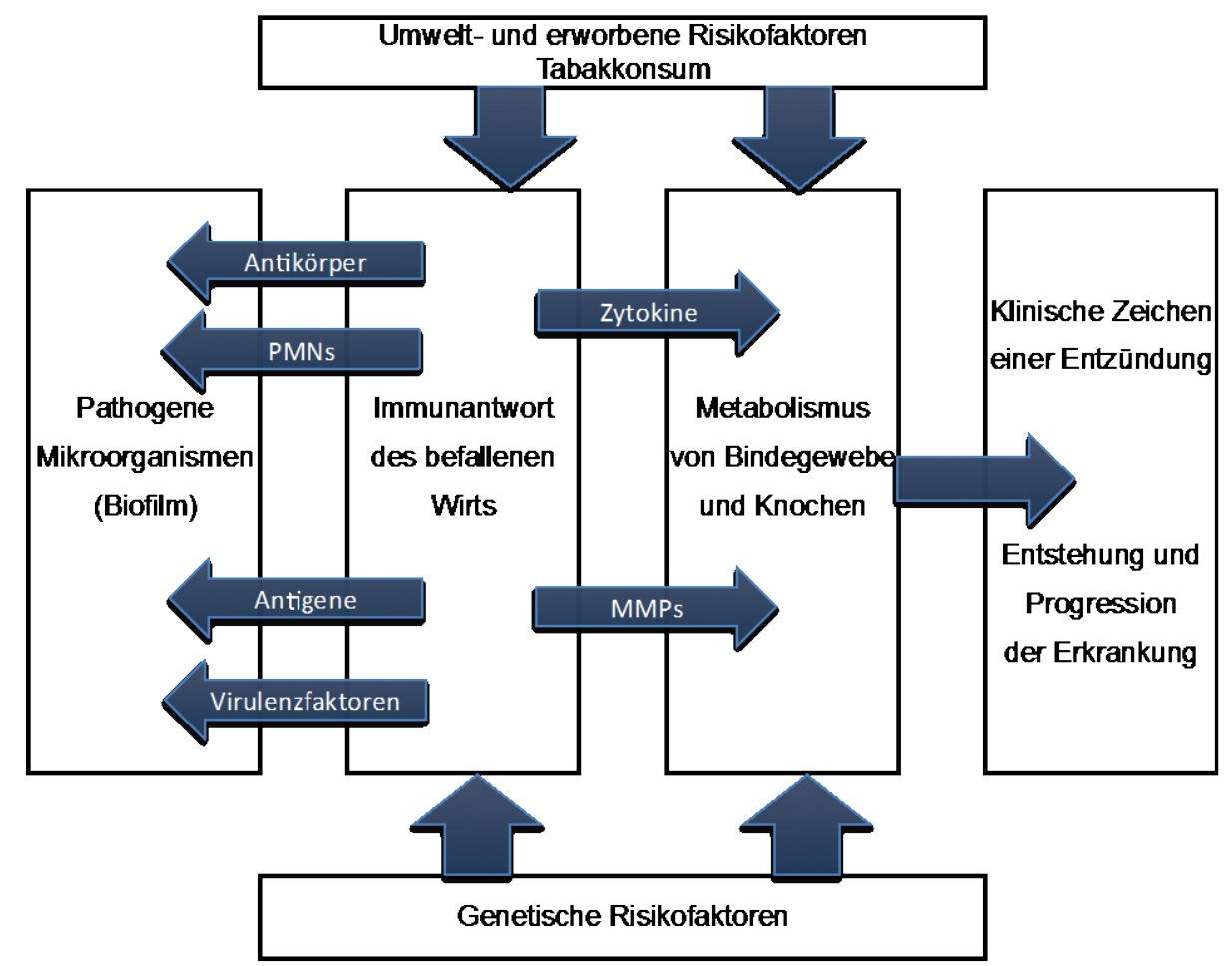

Abbildung 2.2 Ätiologisches Modell der Parodontitis, übertragbar auch für Periimplantitis (modifiziert nach Saxer et al. 2007)

Risikofaktoren lassen sich in gesicherte, allgemeine und iatrogene Risikofaktoren für periimplantäre Erkrankungen unterscheiden (Heitz-Mayfield 2008; Tomasi und Derks 2012). Zu den gesicherten Risikofaktoren werden

- parodontale Vorerkrankungen,

- eine schlechte Compliance / Mundhygiene

- und das Rauchen gezählt.

Durch die Patienten beeinflussbare Risikofaktoren sind vor allem das Rauchen und die Mundhygiene (Dreyer et al. 2018; Renvert und Polyzois 2015; Smeets et al. 2014). So 
führt das Rauchen zu einem doppelt so hohen Implantatverlust (Johnson und Hill 2004; Park et al. 2017). Andere Studien belegen, dass Raucher ein bis zu 32fach erhöhtes Risiko haben eine Periimplantitis zu bekommen (Rinke et al. 2011; Roos-Jansaker et al. 2006). Allerdings sollten nach aktuellen Studien diese Ergebnisse mit Vorsicht interpretiert werden, da das Rauchen zwar die Ausfallrate nach Insertion signifikant beeinträchtigt und auch das Risiko postoperativer Infektion erhöht, oftmals aber unkontrollierte Störfaktoren vorkommen (Chrcanovic et al. 2015; Stacchi et al. 2016). Eine weiterer Hauptrisikofaktor für die Entstehung periimplantärer Erkrankungen bleibt eine schlechte Mundhygiene / Compliance (Dreyer et al. 2018). Der somit einhergehende orale pathogene Biofilm begünstigt die Entstehung einer Mukositis und damit auch langfristig die Entstehung einer Periimplantitis (Heitz-Mayfield 2008; Leonhardt et al. 1992; Mombelli und Lang 1998). Eine schlechte Mundhygiene erhöht das Risiko einer Periimplantitis um das 2,5fache (Heitz-Mayfield 2008). Als weiterer nicht zu vernachlässigender Risikofaktor wird eine parodontale Vorerkrankung angesehen (Casado et al. 2011; Dreyer et al. 2018; Renvert et al. 2014; Renvert und Quirynen 2015; Stacchi et al. 2016). Patienten mit einer parodontalen Vorerkrankung bekommen mit $28,8 \%$ deutlich häufiger eine Periimplantitis als Patienten ohne diese (5,8\%) (Karoussis et al. 2003). Auch in anderen Studien wurde dieser Zusammenhang bestätigt (Cho-Yan Lee et al. 2012; Hardt et al. 2002; HeitzMayfield 2008; Smith et al. 2017) und ein statistisch signifikanter Zusammenhang zwischen parodontalen Vorerkrankungen und periimplantären Erkrankungen nachgewiesen (Casado et al. 2013). 56\% der Patienten mit einer parodontalen Vorerkrankung hatten im Anschluss an die Implantation eine periimplantäre Mukositis und $26 \%$ bekamen eine Periimplantitis, die im parodontal gesunden Gebiss bei etwa $10 \%$ liegt (Swierkot et al. 2012). Demzufolge haben Patienten mit einer parodontalen Vorerkrankung ein fünffach höheres Risiko eines Implantatversagens, ein dreifach höheres Risiko einer Mukositis und ein 14 mal höheres Risiko einer Periimplantitis (Swierkot et al. 2012). Andererseits bleibt zu erwähnen, dass das Risiko periimplantärer Erkrankungen bei Patienten mit parodontaler Vorgeschichte durch eine adäquate Parodontitis-Therapie deutlich gesenkt werden kann (Goh et al. 2017).

Allgemeine Risikofaktoren, welche mit einer schwachen Evidenz belegt sind, werden folgend aufgelistet:

- Diabetes mellitus

- Alkoholkonsum

latrogene und sonstige mögliche Risikofaktoren werden durch teilweise sehr widersprüchliche Ergebnisse zwar erwähnt, es fehlen allerdings aussagekräftige Studien (Dreyer et al. 2018). 
Einige dieser sind folgend aufgeführt und beschrieben:

- Augmentation

- Fehlpositionierung des Implantats

- Implantatoberfläche/-design

- Zementüberschüsse

- Interaktionen von Medikamenten

- Biomechanische Einflüsse (Bruxismus / Fehlbelastung)

- Technische Komplikationen (Schraubenlockerung)

Die Augmentation an der Implantationsstelle hat scheinbar wenig Einfluss auf die klinischen Zeichen periimplantärer Erkrankungen (Karbach et al. 2009). Auch die Oberflächenrauhigkeit von Implantaten hat keinen Einfluss auf die Einheilung und die bakterielle Besiedlung der Implantate (Karbach et al. 2009; Lang und Berglundh 2011). Durch die wachsende Anzahl zementierter Implantatkronen und die Tendenz zur submukösen Platzierung der Kronenränder in ästhetisch anspruchsvollen Bereichen steigt allerdings die Anzahl an Periimplantitiserkrankungen vor allem durch Zementüberschüsse stark an (Linkevicius et al. 2013; Pesce et al. 2015; Quaranta et al. 2017; Weng 2011). Auch Bruxismus ist ein nicht zu vernachlässigender Faktor für Komplikationen. Allerdings ist auch dieser Risikofaktor mit einer eher schwachen Evidenz belegt. So legen Studien nahe, dass Bruxismus die Rate des Implantatversagens, wie auch die von mechanischen und technischen Komplikationen signifikant erhöht (Chrcanovic und Kisch und et al. 2016; Papi et al. 2017).

\subsubsection{Oraler Biofilm}

Der orale Biofilm ist definiert als eine weiche, zähe, dreidimensionale mikrobielle Besiedlung mit fester Anhaftung der Bakterien an den Oberflächen der Mundhöhle. In der Mundhöhle konnten weit mehr als 500 Bakterienspezies isoliert und nachgewiesen werden, von denen allerdings nur eine geringe Anzahl mit parodontalen Erkrankungen assoziiert sind (Moore und Moore 1994). Hierbei werden sehr stark, stark und moderat pathogene Bakterien unterschieden. Entsprechend ihrer Pathogenität kann man potentiell parodontopathogene Bakterien in verschiedene mikrobielle Komplexe einteilen. Jeder dieser Komplexe enthält Bakterien ähnlicher Pathogenität und Charakteristika. Die Komplexe arbeiten untereinander synergistisch (Socransky et al. 1998). In Abbildung 2.3 werden die Bakterien aufgrund ihrer Pathogenität dargestellt. 

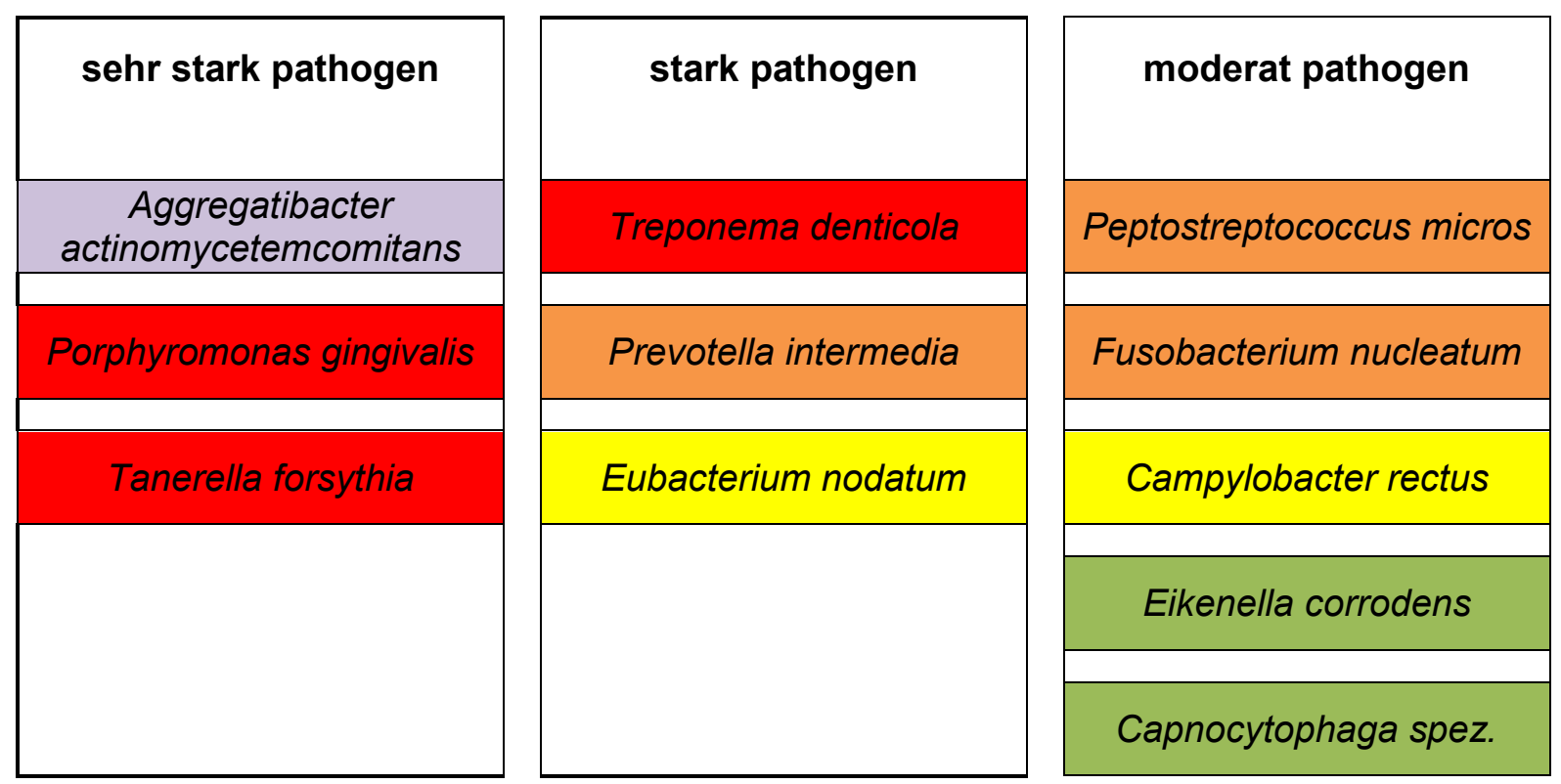

Abbildung 2.3 Pathogenität der Bakterien

Entsprechend ihrer Pathogenität können fünf verschiedene Komplexe unterschieden werden (Abb.2.4):

- roter Komplex: Tannerella forsythia (Tf), Porphyromonas gingivalis (Pg) und Treponema denticola $(T d)$

- $\quad$ orangener Komplex: Fusobacterium nucleatum (Fn), Prevotella intermedia (Pi) und Peptostreptococcus micros (Pm)

- gelber Komplex: Eubacterium nodatum (En) und Campylobacter rectus (Cr),

- grüner Komplex: Capnocytophaga Spezies (Cs) und Eikenella corrodens (Ec),

- violetter Komplex: Aggregatibacter actinomycetemcomitans (Aac).

Der rote Komplex ist auffallend häufig bei parodontalen Erkrankungen anzufinden (Socransky et al. 1998). 


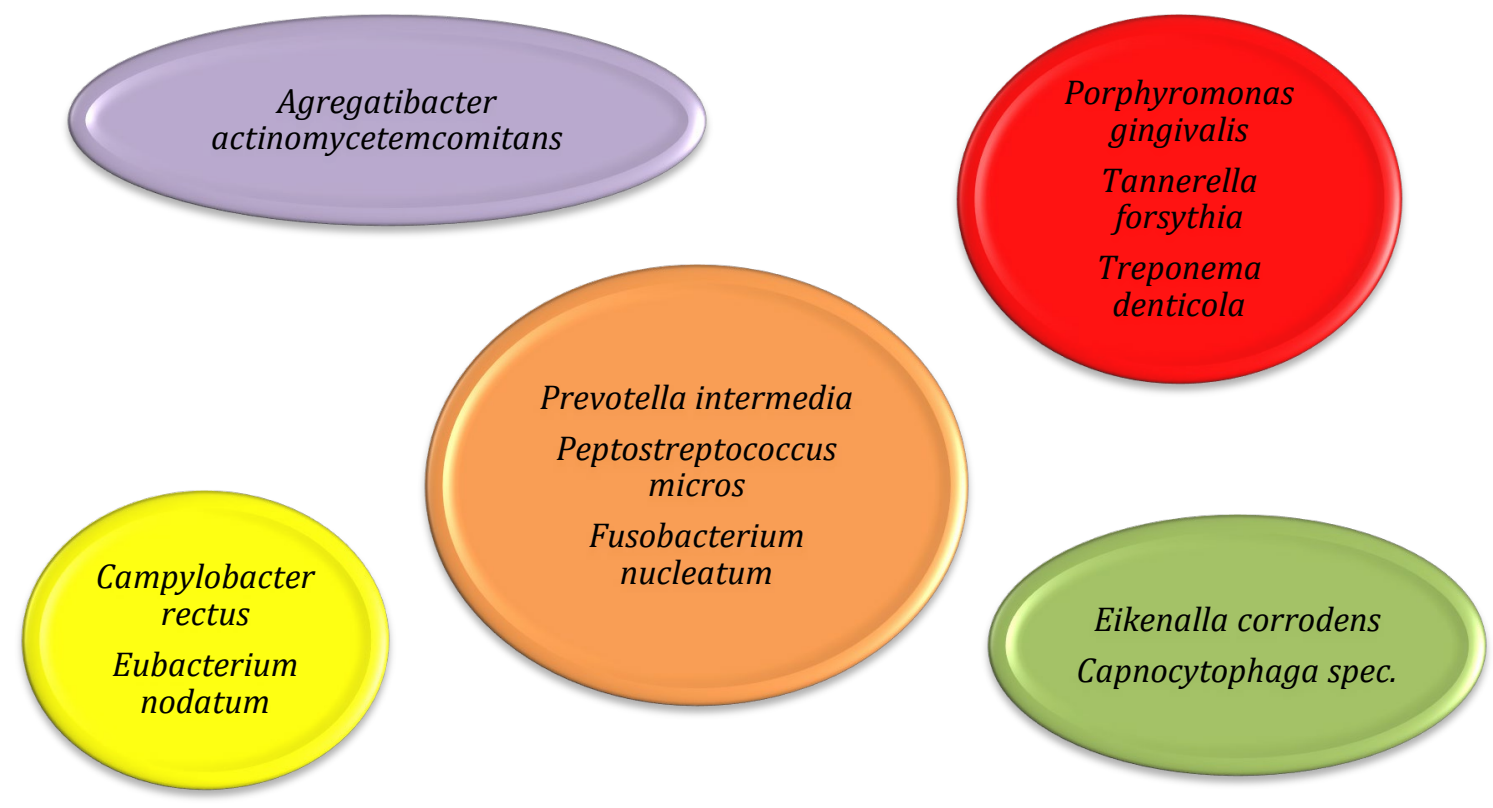

Abbildung 2.4 Darstellung der Bakterien in Komplexen bei der Etablierung parodontaler Erkrankungen nach Socransky et al. 1998

Die bedeutendsten potentiell parodontopathogenen Bakterien $\mathrm{Aac}, \mathrm{Pg}, \mathrm{Td}, \mathrm{Tf}, \mathrm{Pi}, \mathrm{Pm}$ und Fn werden folgend näher charakterisiert.

Aggregatibacter Actinomycetemcomitans (Aac) ist ein motiles, fakultativ anaerobes, gramnegatives Stäbchen und zählt zum violetten Komplex. Es kommt vor allem bei Patienten mit einer aggressiven Parodontitis gehäuft vor (Sanchez et al. 2015; Timmerman und van der Weijden 2006). Es ist bekannt, dass Aac auch bei gesunden Patienten auftritt, hier allerdings in deutlich geringerer Konzentration als bei einer Parodontitis (Torrungruang et al. 2015).

Porphyromonas gingivalis $(P g)$ ist ein anaerobes, gramnegatives, nicht sporenbildendes Stäbchen, welches ähnlich wie Aac als Leitkeim der Parodontitis fungiert (Diaz et al. 2006; Socransky et al. 1998). Pg versucht das angeborene Immunsystem zu umgehen und in einer Wirtszelle zu überleben (Olsen und Yilmaz 2016). Pg ist an der Pathogenese einer Parodontitis stark beteiligt. Jüngste Ergebnisse haben die Rolle von $P g$ als wichtigen und einzigartigen Pathogen belegt (Sakanaka et al. 2015). Dieses Bakterium besitzt die Fähigkeit in unterschiedlichen Umgebungen auf verschiedene Art und Weise zu wirken. $P g$ erhöht die Virulenz der parodontalen Mikroflora und schafft so ein günstiges Zusammenspiel anderer Spezies. Außerdem kann $P g$ in gingivale Epithelzellen eindringen und die epitheliale Barriere in tiefere Gewebe passieren, von wo aus $P g$ persistierende Infektionen im Zahnfleischgewebe steuert (Sakanaka et al. 2015). Wie 
auch $A a c$ ist bei $P g$ eine enge Korrelation zu Parodontitis bekannt (Faghri et al. 2007; Puig-Silla et al. 2012; Torrungruang et al. 2015).

Treponema denticola $(T d)$ ist eine anaerobe, gramnegative Spirochäte. $T d$ ist vorwiegend in tiefen parodontalen Taschen anzufinden (Socransky et al. 1998). Es ist bekannt, dass $P g$ und $T d$ synergistisch die Immunantwort eines Wirtes stimulieren und somit einen alveolaren Knochenabbau induzieren (Orth et al. 2011).

Tannerella forsythia (Tf) ist ein obligat anaerobes, gramnegatives Stäbchen (Socransky et al. 1998). Die Prävalenz von $P g$ und $T f$ ist mit über $60 \%$ bei Parodontitispatienten auffällig hoch. Beide Keime werden auch sehr häufig zusammen nachgewiesen, weshalb davon auszugehen ist, dass auch sie synergistisch arbeiten. Außerdem lässt sich zweifelsohne eine positive Korrelation zwischen einer chronischen Parodontitis und $T f$ herstellen (Settem et al. 2012; Tomita et al. 2013). Ebenfalls bekannt ist, dass $T f$ sehr eng mit Fn assoziiert ist und diese beiden synergistisch die Immunantwort des Wirtes stimulieren, welche einen alveolaren Knochenverlust induziert (Settem et al. 2012).

Prevotella intermedia (Pi) ist ein gramnegatives, obligat anaerobes, bewegliches Stäbchen, welches stark mit einer Parodontitis assoziiert ist und als Wegbereiter für den roten Komplex benannt wird. Außerdem wird Pi als Leitkeim des orangenen Komplexes bezeichnet (Socransky et al. 1998). Bei Jugendlichen erhöht sich die Anzahl von Pi in der subgingivalen Plaque mit zunehmendem Fortschritt der parodontalen Entzündung signifikant (Yang et al. 2014).

Peptostreptococcus micros (Pm) ist eine anaerobe, grampositive, nicht sporenbildende Kokke (Kugelbakterium) (Socransky et al. 1998). Pm ist eng mit einer Parodontitis assoziiert und ist altersunabhängig. Deutlich wird, dass $P m$ in einer aktiven Parodontitis mit $47 \%$ häufiger als bei einer inaktiven Parodontitis (14\%) vorkommt (Rams et al. 1992). Außerdem ist bekannt, dass $P m$ mit $F n$ und $P g$ koaggregiert (Kremer und van Steenbergen 2000).

Fusobacterium nodatum ( $F n$ ) ist ein nicht motiles, obligat anaerobes, gramnegatives, spindelförmiges Stäbchen, welches sich vermehrt bei parodontalen Erkrankungen nachweisen lässt und genau wie $P i$ und $P m$ zum orangenen Komplex gehört (Socransky et al. 1998). Fn ist ein opportunistischer Krankheitserreger, von dem angenommen wird, dass er als Brücke zwischen Früh- und Spätkolonisation der Plaque fungiert. Wie schon erwähnt, arbeitet $F n$ bei der Biofilmbildung und Pathogenese synergistisch mit $T f$ (Settem et al. 2012).

Der Zusammenhang zwischen Plaqueakkumulation und Mukositis wurde in verschiedenen Studien nachgewiesen (Ericsson et al. 1992; Pontoriero et al. 1994). Die 
mikrobiologische Besiedlung bzw. das Keimspektrum von Implantaten entspricht annähernd dem von natürlichen Zähnen (Lang et al. 1993; Leonhardt et al. 1992). Bei vielen Implantaten, welche wieder entfernt werden mussten, wurden dieselben mikrobiologischen Komplexe festgestellt, die auch bei einer Parodontitis vorherrschen (Augthun und Conrads 1997; Becker et al. 1990; Rams und Link 1983). Vorherrschende subgingivale Spezies sind hier, wie bei Zähnen auch, Pg, Tf, Fn, Campylobacter gracilis, Streptococcus intermedius und Pm (Persson und Renvert 2014; Tanner et al. 1997). Bei der Periimplantitis ist die Zusammensetzung des subgingivalen Biofilms ähnlich der einer chronischen Parodontitis (Mombelli und Decaillet 2011), welcher vorwiegend aus gramnegativen Bakterien besteht. Periimplantäre Erkrankungen weisen außerdem gelegentlich eine hohe Anzahl an Peptostreptokokken oder Staphylokokken auf (Mombelli und Decaillet 2011).

Die parodontopathogenen Bakterien $\mathrm{Aac}, \mathrm{Pg}, \mathrm{Td}$, $T f$ und $\mathrm{Pi}$ konnten in kranken, wie auch in gesunden Implantaten festgestellt werden (Ata-Ali et al. 2011). Allerdings nur bei Patienten mit periimplantären Erkrankungen in einer Konzentration größer als $10^{6}$. Man kam zu der Schlussfolgerung, dass vor allem $A a c$ und $P g$ die vorherrschenden Erreger periimplantärer Zerstörung sind (Ata-Ali et al. 2011). Zu ähnlichen Ergebnissen kamen auch Hultin et al. (2002) und Shibli et al. (2008).

\subsection{Aktuelle Erkenntnisse zu mikrobiologischen Befunden an Implantaten}

Der orale Biofilm, der am häufigsten mit der Periimplantitis einhergeht, ist gekennzeichnet durch Spirochäten und bewegliche Formen von gramnegativen Anaerobiern (SanchezGarces und Gay-Escoda 2004). Es ist allerdings nicht möglich, erkrankungsspezifische Bakterien eindeutig zuzuordnen, da hierzu teilweise sehr widersprüchliche Ergebnisse vorliegen. Dies liegt vor allem an der Komplexität der Struktur und dem breiten Spektrum der Bakterien periimplantärer Erkrankungen (Belibasakis 2014; Charalampakis und Belibasakis 2015; Lafaurie et al. 2017; Mombelli und Decaillet 2011). Und obwohl bei periimplantären Erkrankungen potentiell parodontopathogene Bakterien vorliegen (wie zum Beispiel $P g, T f, P i$ und $T d$ ), existiert eine Vielzahl an weiteren Bakterien, welche nach aktuellen Erkenntnissen bei der Entstehung und der Progression der Parodontitis eine eher untergeordnete Rolle spielen, periimplantäre Erkrankungen jedoch fördern (Albertini et al. 2015; Persson und Renvert 2014).

Die Periimplantitis stellt eine heterogene Mischinfektion dar, die parodontopathologische Mikroorganismen, nicht kultivierbare asaccharolytische anaerobe gram-positive Stäbchen und andere nicht kultivierbare gramnegative Stäbchen sowie selten opportunistische 
Mikroorganismen wie enterische Stäbchen und Staphylococcus aureus enthält. (Lafaurie et al. 2017).

Tabelle 2.3 gibt einen Überblick über parodontitistypische und nicht parodontitistypische Bakterien, welche an gesunden wie auch erkrankten Implantaten vorliegen.

\begin{tabular}{|l|l|}
\hline Parodontitistypische Bakterien & Nicht parodontitistypische Bakterien \\
\hline Aggregatibacter actinomycetemcomitans & Actinomyces odotolyticus \\
Campylobacter rectus & Campylobacter gracilis \\
Fusobacterium nucleatum & Campylobacter showae \\
Parvimonas micra & Fusobacterium periodonticum \\
Prevotella intermedia & Haemophilus influenza \\
Porphyromonas gingivalis & Helicobacter pylori \\
Tannerella forsythia & Pseudomonas aeruginosa \\
Treponema denticola & Staphylococcus anaerobius \\
& Staphylococcus aureus \\
& Staphylococcus haemolyticus \\
& Staphylococcus intermedius \\
& Streptococcus mitis \\
& Treponema socranskii \\
& Veillonella parvula \\
\hline
\end{tabular}

Tabelle 2.3 parodontitistypische / nicht parodontitistypische Bakterien gesunder und erkrankter Implantate (nach Persson und Renvert 2014)

Letztendlich ist davon auszugehen, dass die Komplexität und Heterogenität periimplantärer Erkrankungen sehr umfangreich ist und die Bedeutung der verschiedenen Mikroorganismen nach aktuellem Kenntnisstand noch unklar erscheint (Charalampakis und Belibasakis 2015; Faveri et al. 2015; Lasserre et al. 2018; Mombelli und Decaillet 2011; Padial-Molina et al. 2016).

\subsection{Diagnostik periimplantärer Erkrankungen}

Nachfolgend wird auf die Diagnostik zur Erkennung periimplantärer Erkrankungen eingegangen. Hierzu wird in klinische und erweiterte Diagnostik unterteilt. Tabelle 2.4 gibt einen Überblick über die aktuellen klinisch-diagnostischen Kriterien periimplantärer Erkrankungen. 


\begin{tabular}{|l|l|l|}
\hline Kriterium & Mukositis & Periimplantitis \\
\hline Reversibilität & Ja & bedingt \\
\hline Zunahme der Sondierungstiefen & Nein & ja \\
\hline Blutung auf Sondierung (BOP positiv) & Ja & ja \\
\hline Pus / Suppuration & nein & fakultativ \\
\hline röntgenologischer Knochenabbau & nein & ja \\
\hline Implantatlockerung & nein & Finalstadium \\
\hline Schmerzen & fakultativ & fakultativ \\
\hline
\end{tabular}

Tabelle 2.4 Klinisch-diagnostische Kriterien periimplantärer Erkrankungen

\subsubsection{Klinische Diagnostik periimplantärer Erkrankungen}

Die klinische Diagnostik gilt nach wie vor als Standardverfahren zur Detektion periimplantärer Erkrankungen (Heitz-Mayfield 2008; Lang und Berglundh 2011). Diagnostische Kriterien sind dabei die Blutung auf Sondierung, erhöhte Sondierungstiefen periimplantärer Taschen, Suppuration und radiologisch auffälliger Knochenverlust am Implantat (Renvert et al. 2018; Sanchez-Garces und Gay-Escoda 2004). Entscheidend für die Verlaufskontrollen sind die Ausgangsbefunde. Allen voran die Sondierungstiefen und ein Ausgangsröntgenbild, welches möglichst zum Zeitpunkt der Eingliederung der Suprakonstruktion bzw. mit Abformpfosten erhoben werden sollte. Im weiteren Verlauf ist darauf zu achten, dass die Sondierungstiefen möglichst an den gleichen Referenzstellen erhoben werden und dass bei Röntgenbildern zur Verlaufskontrolle stets dieselbe Aufnahmetechnik zur Röntgendiagnostik verwendet wird (Berglundh et al. 2018; HeitzMayfield 2008).

Klinisch spricht man von einer periimplantären Mukositis, wenn die Blutung auf Sondierung positiv ist (Berglundh et al. 2018; Lang und Berglundh 2011; Renvert et al. 2018). Das Hauptkriterium einer Periimplantitis ist der radiologisch festgestellte Knochenabbau mit einer einhergehenden Blutung auf Sondierung (BOP) und möglichen erhöhten Taschentiefen (Berglundh et al. 2018; Elemek und Almas 2014; Lang und Berglundh 2011; Renvert et al. 2018). Klinisch sind die Patienten häufig schmerzfrei (Mombelli 1997). Obwohl bei einer Periimplantitis koronal die knöcherne Unterstützung verloren geht, bleibt das Implantat meist osseointegriert und damit klinisch stabil. Aus diesem Grund ist die Mobilität ein unspezifisches diagnostisches Merkmal (Elemek und Almas 2014). 


\subsubsection{Erweiterte Diagnostik periimplantärer Erkrankungen}

Zusätzlich zur klinischen Diagnostik besteht die Möglichkeit periimplantäre Erkrankungen mit Hilfe einer mikrobiologischen Diagnostik und dem Nachweis von Metalloproteinasen (aMMP-8) zu untersuchen. Die vorliegende Arbeit beschäftigt sich mit der mikrobiologischen Diagnostik genauer und untersucht deren Sinnhaftigkeit bzw. Mehrgewinn für die Diagnostik periimplantärer Erkrankungen.

Da periimplantäre Erkrankungen primär bakterielle Infektionserkrankungen sind (Mombelli et al. 2012), liegt die Annahme nahe, dass die Beurteilung der Zusammensetzung des periimplantären Biofilms, u. a. der potentiell parodontopathogenen Bakterien, sinnvoll erscheint. Aktuelle Studien weisen jedoch sehr widersprüchlich Ergebnisse auf (Belibasakis 2014; Charalampakis und Belibasakis 2015; Lafaurie et al. 2017; Lasserre et al. 2018). Schwierig macht es hierbei vor allem die Tatsache, dass gesunde und erkrankte Implantate eine ähnliche Zusammensetzung der Bakterien aufweisen. Zwar gibt es quantitative Unterschiede in der Zusammensetzung der Bakterien, aber auch diese führen in verschiedenen Studien zu unterschiedlichen Ergebnissen (Albertini et al. 2015; Belibasakis 2014; Charalampakis und Belibasakis 2015; Mombelli und Decaillet 2011; Persson und Renvert 2014). Entsprechend der aktuellen Lage der Literatur, erscheint eine mikrobiologische Diagnostik vorerst nicht aussagekräftig zu sein. Dieser Aspekt soll im Folgenden näher betrachtet werden. Aus diesem Grund beschäftigt sich die vorliegende Arbeit eingehend mit der Beurteilung der Sinnhaftigkeit und des Nutzens mikrobiologischer Tests als erweitertes diagnostisches Verfahren zur Erkennung periimplantärer Erkrankungen. Außerdem wird der Einfluss von möglichen Risikofaktoren auf periimplantäre Erkrankungen untersucht. 


\section{Material und Methoden}

\subsection{Studiendesign}

Bei der vorliegenden Arbeit handelt es sich um eine praxisbasierte klinische Querschnittsstudie zur Untersuchung potentiell parodontopathogener Keime an Implantaten mit unterschiedlichen Krankheitszuständen: gesund, Mukositis und Periimplantitis. Die genutzten Proben stammen aus einem Patientenklientel einer klinischen Studie (Rinke et al. 2011). Diese Studie wurde von der Ethikkommission der Georg-August-Universität Göttingen genehmigt (Nr.3/1/09). Die Patienten wurden mündlich über die Studie aufgeklärt und gaben eine schriftliche Einverständniserklärung zur Teilnahme an der Studie ab. Sie nahmen freiwillig an der Studie teil.

\subsection{Patienten}

Im Rahmen einer klinischen Studie wurden Patienten der Zahnarztpraxis Priv.-Doz. Dr. Rinke, Dr. Jablonski \& Kollegen in Hanau untersucht. Diese wurden im Zeitraum vom 01.01.1998 bis zum 31.12.2005 mit Implantaten ausschließlich vom Typ Ankylos (Dentsply Sirona, Mannheim) im teilbezahnten Kiefer und zementierter Suprakonstruktion versorgt. Untersucht wurden gesunde Implantate und Implantate mit periimplantären Erkrankungen wie Mukositis und Periimplantitis. Mukositis wurde entsprechend der Kriterien von Roos-Jansaker et al. (2006) definiert (PDD $4 \mathrm{~mm}$ und positiver BOP). Entsprechend der Definition von Karoussis et al. (2004) und Roos-Jansaker et al. (2006) wurde eine Periimplantitis diagnostiziert, wenn zusätzlich zu den Symptomen der periimplantären Mukositis ein progressiver Knochenverlust röntgenologisch festgestellt werden konnte.

Die Teilnehmer waren sowohl männlich als auch weiblich im Alter von 18 bis 75 Jahren und haben risikoorientiert, bis zu viermal jährlich, an einer Mundhygienebetreuung mit professioneller Zahnreinigung teilgenommen. Eine Prophylaxe/UPT wurde im ersten Jahr nach Implantation alle drei Monate und später alle sechs Monate durchgeführt. Patienten, bei denen sich eine ineffektive Plaquekontrolle in der posttherapeutischen Phase herausstellte (> 35\%) wurden weiterhin alle drei Monate zur Prophylaxe / UPT einbestellt. Dieses Intervall wurde anschließend beibehalten, bis die Plaquekontrolle unter $20 \%$ fiel. Patienten, deren Prophylaxeabstände innerhalb des Intervalls lagen, wurden in regelmäßige PZR/UPT klassifiziert. 
Die Behandlung umfasste folgende Elemente:

- Einschätzung des Gingivablutungsindex (GBI) (Ainamo und Bay 1975) und der Plaquekontrolle (O'Leary et al. 1972)

- Mundhygieneinstruktion

- Motivation zu einer effektiven Plaquekontrolle

- Professionelle Zahnreinigung mit abschließender Politur

- Fluoridierung

Folgende Ausschlusskriterien wurden für die Patienten definiert:

- Probanden unter 18 Jahren

- immunsupprimierte Patienten

- organtransplantierte Patienten

- Patienten, bei denen eine Endokarditisprophylaxe erforderlich ist

- Vorliegen von Hepatitis A, B, C, TBC, HIV

- Patienten mit Niereninsuffizienz

- Patienten mit Anfalls- oder Nervenleiden

- suchtkranke Patienten

- bekannte Unverträglichkeit/Überempfindlichkeit

- vorliegende Schwangerschaft

- $\quad$ keine regelmäßige Teilnahme an der professionellen Mundhygienebetreuung

- prothetische Versorgung der Implantate erfolgte mit einer abnehmbaren Suprakonstruktion

\subsection{Allgemeine Datenerfassung}

Zu Beginn wurde eine allgemeine Anamnese erhoben. Besonderes Augenmerk wurde hier auf die Rauchgewohnheiten, die parodontale Vorgeschichte und Allgemeinerkrankungen wie z. B. Diabetes mellitus gelegt. Zusätzlich wurden die Ein- und Ausschlusskriterien abgeklärt und die Aufklärung des Patienten und dessen schriftliche Einverständniserklärung überprüft. Als Raucher wurden Patienten definiert, welche zum Zeitpunkt der Implantation rauchten bzw. weniger als fünf Jahre zuvor aufgehört hatten (Lang und Tonetti 2003). Eine parodontale Vorerkrankung (Sys-Paro) wurde bei Patienten erfasst, die innerhalb der letzten fünf Jahre vor Implantation eine Parodontitistherapie (scaling und root planing bzw. chirurgische Therapie) bekamen.

\subsection{Spezifische Datenerfassung}

Die spezifische Datenerfassung umfasste die implantatbezogenen Angaben und die Nachsorge der einzelnen Implantate. Hierfür wurden bei jedem Patient für jedes Implantat 
Material und Methoden

folgende Parameter mindestens drei Jahre nach prothetischer Versorgung erfasst:

- Lokalisation des Implantates

- Implantationszeitpunkt

- Zeitpunkt der letzten Mundhygienebetreuung

- technische Komplikationen des Implantates

- Mobilität

- Verlust

- Schmerzsymptomatik

\subsection{Zahnärztliche Untersuchung}

Im Rahmen eines Nachsorgetermins erfolgte eine systematische Nachuntersuchung der Implantate sowie die Aufnahme folgender Parameter:

- Kariesindex (DMF-T)

- Entzündungsindex (PBI)

- Plaqueindex (PI)

- $\quad$ kompletter Parodontalstatus mit bleeding on probing (BOP) und Sondierungstiefen (ST) der Restbezahnung

- gingivale Rezession mit Implantatexposition

- metrische Auswertung des PSAs zum Zeitpunkt drei Jahre nach prothetischer Versorgung

Zusätzlich wurden Proben zur Bestimmung der Bakterienlast an den Implantaten entnommen. Zweimal jährlich wurde ein Zahnstatus aufgenommen und Taschentiefen an vier Stellen der Zähne / Implantate gemessen.

Nachfolgend werden die wichtigsten Untersuchungsparameter kurz beschrieben.

\subsubsection{Sondierungstiefen}

Zur Erhebung der Sondierungstiefen wurde an vier Stellen jedes Implantates mit einer millimeterskalierten Parodontalsonde gemessen (mesio-buccal, mesio-oral, disto-buccal und disto-oral). Der jeweils höchste Wert wurde notiert. Hierfür wurde bei gleichbleibendem Druck von ca. 0,25 N der Abstand vom Gingivarand bis zum Sulkusbzw. Taschenboden gemessen. Die Sonde wurde dabei parallel zur Implantatachse in 
den Sulkus eingebracht. 30 Sekunden nach dem Sondieren wurde der BOP erhoben. Taschen $>4 \mathrm{~mm}$ wurden anschließend mit Hilfe von Ultraschall und Handinstrumenten subgingival gereinigt. Für das subgingivale Scaling an Implantaten wurde ein spezieller Ultraschallaufsatz (Kavo Sonicflex Implant, Kava Dental GmbH, Biberach, Deutschland) verwendet.

\subsubsection{Radiologischer Knochenverlust}

Der Knochenverlust wurde durch eine metrische Analyse der Panoramaschichtaufnahmen (PSA) festgestellt. Alle PSAs wurden unter Verwendung der gleichen digitalen Röntgenstrahleinheit angefertigt (Orthophos, Sirona Dental Systems, Bensheim, Deutschland). Die Daten wurden mit Hilfe eines Computerprogramms (Sidexis XG, Sirona Dental Systems) und eines kalibrierten Monitors (SyncMaster 2443SW, Samsung, Schwalbach, Deutschland) analysiert. Alle Röntgenbilder wurden von derselben Person ausgewertet. Der Abstand zwischen Implantatschulter und marginaler Knochenstufe wurde am mesialen und distalen Rand jedes Implantats gemessen. Die marginale Knochenstufe wurde als der koronalste Punkt der Knochenkante, welche an die Implantatoberfläche angrenzt, definiert. Die Seite mit dem höchsten ermittelten Knochenverlust wurde für den jeweiligen Patienten notiert. Als Grenzwert für einen progressiven Knochenverlust wurde ein Knochenabbau von mehr als 3,5 mm apikal der Implantatschulter zur letzten vorhandenen Röntgenaufnahme angesehen. Ausgangsröntgenbilder der Implantatsetzung wurden zum Vergleich des Knochenniveaus herangezogen. Das originale Protokoll des Implantatsystems empfiehlt eine etwas krestalere Position $(0,5 \mathrm{~mm})$ der Implantatschulter. Implantate mit einer subkrestal platzierten Implantatschulter wurden aus der Studie ausgeschlossen (Rinke et al. 2011).

Von zehn Patienten mit insgesamt 46 Implantaten wurden die Röntgenbilder für eine zweite Analyse des marginalen Knochenniveaus ausgewählt, um Prüfschwankungen festzusetzen. Diese Röntgenbilder wurden aus einer Zufallszahlentabelle ausgewählt. 83\% der analysierten Implantate zeigten einen messbaren Unterschied von weniger als $0,5 \mathrm{~mm}$, während die restlichen Unterschiede zwischen $0,5 \mathrm{~mm}$ und $0,8 \mathrm{~mm}$ lagen (Rinke et al. 2011).

\subsubsection{Probenentnahme}

Die Proben des subgingivalen Biofilms wurden mit sterilen Papierspitzen an allen vorhandenen Implantaten entnommen. Vorab entfernte man den supragingivalen Biofilm. 
Die entsprechenden Implantatkonstruktionen wurden mit Hilfe von Watterollen trocken gelegt und isoliert. Anschließend schob man die Papierspitze mit einer zahnärztlichen Pinzette in die betroffene Tasche vor. Hier verblieb sie für ca. zehn Sekunden. Nach der Entnahme isolierte man die Papierspitze in einem Transportröhrchen. Dieses Procedere wurde mesial und distal an jedem untersuchten Implantat mit zwei unterschiedlichen Papierspitzen durchgeführt, die abschließend für jedes Implantat gepoolt wurden.

\subsection{Mikrobiologische Untersuchung}

Der Nachweis bakterieller DNA erfolgte mit Hilfe der Polymerasekettenreaktion (PCR) im Labor der Poliklinik für Präventive Zahnmedizin, Parodontologie und Kariologie der Universitätsmedizin Göttingen.

Der Laborteil wurde mit zwei molekulargenetischen Testsystemen, micro-IDent ${ }($ und micro-IDent $®$ plus der Firma HAIN Lifescience (Nehren, Deutschland) durchgeführt. Diese unterschieden sich jedoch nur in der Bakterien-Spezies, wobei das Verfahren identisch ist. Beide Verfahren beruhen auf einer DNA-STRIP-Technologie und erlauben die gemeinsame molekulargenetische Identifizierung von insgesamt 11 potentiell parodontopathogenen Bakterien-Spezies.

- Aggregatibacter Actinomycetemcomitans (Aac),

- Porphyromonas gingivalis (Pg),

- Tannerella forsythia (Tf),

- Treponema denticola $(T d)$,

- Prevotella intermedia (Pi),

- Peptostreptococcus micros (Pm),

- Fusobacterium nucleatum/ periodonticum (Fn),

- Campylobacter rectus (Cr),

- Eubacterium nodatum (En),

- Eikenella corrodens (Er)

- Capnocytophaga spec. (Cs).

Die Aufbereitung der Proben und deren Auswertung gliederte sich in drei Phasen, welche anschließend ausführlich beschrieben werden:

1. der DNA-Isolierung aus subgingivalen Plaqueproben und anschließender PCR,

2. der Multiplex-Amplifikation mit biotinmarkierten Primern,

3. und der reversen Hybridisierung. 


\subsubsection{DNA-Isolierung}

Der Arbeitsraum sollte hierbei völlig frei von amplifizierter DNA sein. Ausgangsmaterial der DNA-Isolierung sind die Papierspitzen der entnommenen Proben, mit denen die subgingivalen Plaqueproben entnommen wurden. Nach der Entnahme sind die Papierspitzen bis zu sieben Tage lagerbar. Für die DNA-Isolierung verwendete man das QIAamp DNA Mini Kit ${ }^{\circledR}$ (Firma Qiagen, Hilden, Deutschland), welches alle im Folgenden verwendeten Puffer und Lösungen beinhaltet. Die folgenden Arbeitsschritte wurden basierend auf dem Protokoll des Herstellers durchgeführt (Lyse, Adsorption und Waschung) und nachfolgend beschrieben:

Lyse: für jede Probe wurden $180 \mu \mathrm{l}$ ATL-Puffer (Lysepuffer) und $20 \mu \mathrm{l}$ Proteinase KLösung in einem dafür geeigneten Gefäß zusammengeführt und vermischt. Das entstandene Gemisch bewirkt die vollständigen Lyse der zellulären Bestandteile des subgingivalen Biofilms. Anschließend wurde in jedes Proberöhrchen mit innen liegender Papierspitze $200 \mu \mathrm{l}$ der Mischung hinzugefügt und $30 \mathrm{~s}$ mit Hilfe eines Vortexmischers gründlich gevortext. Dieses Gemisch wurde im Anschluss $10 \mathrm{~min}$ bei $70{ }^{\circ} \mathrm{C}$ inkubiert und abschließend anzentrifugiert.

Adsorption: Im Anschluss an die Lyse wurde den Proben je $200 \mu \mathrm{l}$ AL-Puffer (enthält chaotrope Salze) hinzu gegeben, gevortext und $5 \mathrm{~min}$ bei $95^{\circ} \mathrm{C}$ inkubiert. Über die chaotropen Salze des AL-Puffers, wird die Adsorption der DNA-Bestandteile von den übrigen Bestandteilen der Proteine bewirkt. Im Anschluss wurde das Gemisch kurz anzentrifugiert und $200 \mu \mathrm{l}$ Ethanol (96-100\%ig) hinzugefügt. Abermals wurde das Gemisch $15 \mathrm{~s}$ gevortext und anzentrifugiert. In ein Auffanggefäß setzte man danach ein beschriftetes Filter-Tube ein. Hierbei entstand eine Lösung, welche in das obere Reservoir des Filter-Tubes pipettiert wurde.

Waschung: Abschließend mussten die letzten Verunreinigungen, wie z.B. Lipide und Proteine, ausgewaschen werden. Das verschlossene Filter-Tube wurde hierzu für eine Minute bei $6000 \times$ g (ca. $8000 \mathrm{U} / \mathrm{m}$ ) in einer Standardzentrifuge zentrifugiert. Im Anschluss verwarf man den Durchlauf. Nun wurde das Filter-Tube wieder in das Anfangsgefäß gestellt und $500 \mu \mathrm{l}$ AW1-Puffer zupipettiert (erster Waschpuffer). Dieses wurde wie im vorausgegangenen Schritt erneut zentrifugiert und der Durchlauf wiederum verworfen. Anschließend wurde das Filter-Tube nochmals in das Anfangsgefäß gestellt und dem zweiten Waschpuffer, $500 \mu$ AW2-Puffer, zupipettiert. Im Anschluss wurde das Gemisch 3 min. bei maximaler Geschwindigkeit zentrifugiert. Nun setzte man das Filter-Tube in ein frisches Auffanggefäß und zentrifugierte nochmals $1 \mathrm{~min}$. bei maximaler Geschwindigkeit zentrifugiert. Das Auffanggefäß wurde anschließend verworfen und das Filter-Tube in ein 
sauberes beschriftetes $1,5 \mathrm{ml}$ Reaktionsgefäß eingesetzt. $\mathrm{Zu}$ der DNA-Evolution pipettierte man $200 \mu \mathrm{l}$ AE-Puffer (Elutionspuffer). Gelagert wurden die gewonnen Proben nach der Beschriftung bei $-20^{\circ} \mathrm{C}$ im Gefrierschrank.

Der AW1 und AW2 Puffer wurden, wie es das Protokoll der Herstellers (Firma Qiagen, Hilden, Deutschland) verlangt, mit Ethanol versetzt. Zwei Heizblöcke auf je $70^{\circ} \mathrm{C}$ und $95^{\circ} \mathrm{C}$ wurden vorgewärmt, um den ATL-Puffer (Lysepuffer, Qiagen, Hilden, Deutschland) zum Lösen in warmes Wasser stellen zu können.

\subsubsection{Polymerasekettenreaktion (PCR)}

Anschließend wurde die DNA mittels PCR vervielfältigt. Die PCR unterteilt sich in zwei Schritte. Anfangs wird die bereits isolierte DNA wie beschrieben repliziert, bzw. mittels eines biotin-markierten Primers amplifiziert. Diese Vervielfältigung ist erforderlich, um anschließend die vorkommenden Bakterien qualitativ und semiquantitativ bestimmen zu können. Hier kommt es im Anschluss zur sogenannte Hybridisierung. Die replizierte DNA lagert sich an den membrangebundenen Sonden an. Diese speziell von der Firma Hain Lifescience (Nehren, Deutschland) hergestellten Sonden sind spezifisch für das jeweilige Bakterium. Die Bindung einer Bakterien-DNA, wird durch einen Farbumschlag auf einem Teststreifen nachgewiesen. Hierdurch kann man das entsprechende Bakterium identifizieren. Die relative Menge des Bakteriums spiegelt sich im Anschluss durch die Intensität des Farbumschlages wieder. Dieses Testverfahren wurde gemäß dem Protokoll des Testverfahrens Micro-IDent ${ }^{\circledR}$ bzw. Micro-IDent ${ }^{\circledR}$ (plus) (Hain Lifescience, Nehren, Deutschland) durchgeführt. Nachfolgend wird auf die einzelnen Schritte des Tests näher eingegangen.

\subsubsection{Amplifikation}

Der Amplifikations-Mix von $45 \mu$ wurde gesondert in einem Raum hergestellt, der frei von DNA war. Alle folgenden Pipettierschritte wurden auf Eis durchgeführt.

Pro Probe benötigt man $35 \mu \mathrm{l}$ PNM (Primer/Nukleotid-Mix), $5 \mu \mathrm{l}$ 10-fach PCR-Puffer für Taq DNA Polymerase (enthält 15 mM MgCl ), $2 \mu \mathrm{l} 25$ mM MgCl 2 -Lösung, 0,2 $\mu \mathrm{l}$ (1 U) Taq DNA Polymerase, $3 \mu \mathrm{l}$ Wasser (molecular biology grade) zum Auffüllen auf $45 \mu \mathrm{l}$ und $5 \mu \mathrm{l}$ DNA-Lösung. Das ergibt ein Endvolumen von $50 \mu$ l.

Nun berechnet man die zu amplifizierenden Proben, welche sich aus der Zahl der zu untersuchenden Proben zuzüglich der Zahl der gewünschten Kontrollproben ergibt und erstellt sich einen Master-Mix. Dieser enthielt alle zur Amplifikation benötigten 
Material und Methoden

Reagenzien, bis auf die DNA-Lösung.

Amplifikationsprodukte können bei $+4{ }^{\circ} \mathrm{C}$ bis $-20^{\circ} \mathrm{C}$ gelagert werden.

\subsubsection{Hybridisierung}

Die anfangs amplifizierte DNA musste anschließend identifiziert und einem Bakterium zugeordnet werden. Hierzu wurden für die Hybridisierung membrangebundene Sonden verwendet. Alle nachfolgend verwendeten Materialien stammen vom gleichen Hersteller (Hain Lifescience, Nehren, Deutschland) und sind im Micro-IDent ${ }^{\circledR}$ bzw. dem MicroIDent $₫$ (plus) Test enthalten. Auch diese wurden streng nach dem Protokoll verwendet.

Für die Hybridisierung sind einige Vorbereitungen zu treffen. Es ist darauf zu achten, dass das Schüttelwasserbad auf $45^{\circ} \mathrm{C}$ vorgewärmt ist, wobei die maximal zulässige Abweichung bei $+/-1{ }^{\circ} \mathrm{C}$ liegt. Der Hybridisierungspuffer (HYB) und die StringentWaschlösung (STR) sind vor Gebrauch auf $37-45^{\circ} \mathrm{C}$ aufzuwärmen, was sich in einem Brutkasten gut erledigen lässt. Alle anderen Reagenzien, bis auf CON-C und SUB-C, sind auf Raumtemperatur zu bringen. Das Konjugat-Konzentrat CON-C (orange) und das Substrat-Konzentrat SUB-C werden nun in der benötigten Menge im Verhältnis 1:100 mit dem dazugehörigen Puffer verdünnt, sprich CON-C mit CON-D und SUB-C mit SUB-D, und gut vermischt. Beide sind lichtgeschützt zu lagern.

Sind alle Vorbereitungen getroffen, sind es 14 Schritte bis zur Auswertung, welche genauestens eingehalten werden müssen.

1. Für jede zu untersuchende Probe wird in die untere Ecke einer Wannenkavität $20 \mu$ l Denaturierungsreagenz (DEN) pipettiert.

2. Zu dieser gibt man jeweils $20 \mu \mathrm{l}$ Amplifikat dazu, mischt diese durch Auf- und Abpipettieren gut durch und lässt sie $5 \mathrm{~min}$ bei Raumtemperatur inkubieren

3. Anschließend gibt man jeweils $1 \mathrm{ml}$ vorgewärmten und gut gemischten HYB dazu und schwenkt die Wanne vorsichtig bis die Lösung eine homogene Färbung aufweist.

4. Nun legt man in jede Kavität einen schon möglichst vorher nummerierten Membranstreifen (STRIPS).

5. Jetzt wird die Wanne für $30 \mathrm{~min}$ bei $45^{\circ} \mathrm{C}$ im Schüttelwasserbad inkubiert.

6. Nach 30 min wird der Hybridisierungspuffer vollständig entfernt.

7. Jeweils $1 \mathrm{ml}$ STR zugeben und die Wanne für $15 \mathrm{~min}$ unter leichtem Schütteln im Wasserbad inkubieren lassen. 
8. Nach 15 min wird STR vollständig entfernt. Ab diesem Schritt wird nur noch bei Raumtemperatur gearbeitet.

9. Nun werden die Membranstreifen für $1 \mathrm{~min}$ mit $1 \mathrm{ml}$ Rinse-Lösung im Horizontalschüttler gewaschen, anschließend wird die Rinse-Lösung abgeschüttelt.

10. $1 \mathrm{ml}$ verdünntes Konjugat kommt jetzt zu jedem Membranstreifen hinzu und wird für 30 min auf dem Horizontalschüttler inkubiert.

11. Danach wird die Lösung abgeschüttelt und jeder Membranstreifen zweimal für je $1 \mathrm{~min}$ mit $1 \mathrm{ml}$ Rinse-Lösung und einmal mit ca. $1 \mathrm{ml}$ destilliertem Wasser gewaschen.

12. Anschließend gibt man $1 \mathrm{ml}$ verdünntes Substrat zu jedem Membranstreifen und lässt es lichtgeschützt und ohne Schütteln inkubieren.

13. Nach ca. 8 min entfernt man das Substrat und wäscht die Membranstreifen wie schon oben beschrieben zweimal mit destilliertem Wasser.

14. Letztendlich entfernt man die Membranstreifen mit einer Pinzette aus der Kavität und lässt sie auf saugfähigem Papier ca. 5 min trocknen.

\subsubsection{Auswertung}

Nachdem die Membranstreifen getrocknet sind, befestigt man sie auf eine geeignete Unterlage und bewahrt sie lichtgeschützt auf. Die Hybridisierung ergibt ein Bandenmuster, welches mit Hilfe einer Schablone visuell ausgewertet wird. Ein Farbumschlag auf dem Teststreifen weist die Bindung der speziellen Bakterien-DNA mit der Sonde nach, wodurch das Bakterium identifiziert wird. Die Intensität des Farbumschlags gibt die relative Menge des Bakteriums an. Die Einschätzung der Tiefenfärbung erfolgt hierbei subjektiv. Diese Auswertung lässt sich in fünf Bereiche unterteilen:

Bereich 0: die Keimkonzentration liegt unter der Nachweisgrenze keine Entzündungsreaktion

Bereich 1: Keimkonzentration gering, ca. $10^{3}$ normale Entzündungsreaktion, kein erhöhtes genetisches Risiko

Bereich 2: $\quad$ Keimkonzentration erhöht, $<10^{4}$ erhöhte Entzündungsreaktion, erhöhtes genetisches Risiko für progressive Parodontitis

Bereich 3: $\quad$ Keimkonzentration stark erhöht, $<10^{5}$ stark erhöhte Entzündungsreaktion, stark erhöhtes genetisches Risiko für progressive Parodontitis

Bereich 4: $\quad$ Keimkonzentration sehr stark erhöht, $<10^{6}$ verminderte genetische Entzündungshemmung 
Auf dem Membranstreifen sind neben den sechs Reaktionszonen für die parodontopathogenen Markerkeime noch zusätzlich zwei Kontrollzonen. Die Konjugatkontrolle (CC), welche die Effizienz der Konjugatbindung und der Substratreaktion dokumentiert, und die Amplifikationskontrolle, an der sich bei korrekter Durchführung während der Amplifikation das entstehende Kontrollprodukt bindet.

Beide Banden müssen erkennbar und angefärbt sein. Ist dies nicht der Fall, liegt eine falsch-negative Reaktion vor, und der Test muss wiederholt werden.

\subsection{Datenerfassung und statistische Auswertung}

Die Ergebnisse wurden in codierter Form mit Hilfe eines Tabellenkalkulationsprogrammes (Microsoft EXCEL, Version 2011) archiviert. Die statistische Auswertung erfolgte in Kooperation mit dem Institut für Medizinische Statistik der Universitätsmedizin Göttingen.

Ebenfalls mit Hilfe des Tabellenkalkulationsprogrammes (Microsoft EXCEL, Version 2011) wurden tabellarische Darstellungen, Säulendiagramme sowie Abbildungen erstellt. Außerdem wurde das Programm genutzt, um anfallenden Berechnungen durchzuführen.

Die statistischen Angaben wurden mit Hilfe des Fisher Exact Probability Test (www.vassarstats.de) durchgeführt. Als statistisch signifikant wurde dabei ein pWert $<0,05$ angesehen. 


\section{$4 \quad$ Ergebnisse}

\subsection{Patientencharakteristik}

Es konnten 87 Personen (weiblich $=51$; männlich $=36$ ) mit insgesamt 168 Implantaten in die Studie eingeschlossen werden. Von den 168 Implantaten waren nach den vorher definierten Kriterien:

- 113 Implantate gesund,

- 55 hatten eine Mukositis

- 16 eine Periimplantitis.

Das Durchschnittsalter der Patienten betrug 57,11 \pm 10,96 Jahre. In der folgenden Tabelle 4.1 werden die Patienten charakterisiert und die Verteilung periimplantärer Erkrankungen bezogen auf verschiedene Risikofaktoren betrachtet. Zum Zeitpunkt der Analyse hatten 54 der 87 Patienten eine parodontale Vorerkrankung (Sys-Paro). 52 Patienten nahmen regelmäßig an einer professionellen Zahnreinigung (PZR) teil bzw. erhielten regelmäßig eine unterstützende Parodontitistherapie (UPT). 18 Patienten wurden als Raucher quantifiziert.

Tabelle 4.1 Patientencharakteristik

\begin{tabular}{|c|c|c|c|c|c|c|c|c|c|}
\hline \multirow[t]{2}{*}{ Parameter } & & \multicolumn{2}{|c|}{ gesamt } & \multicolumn{2}{|c|}{ Mukositis } & \multicolumn{2}{|c|}{ Periimplantitis } & \multicolumn{2}{|c|}{ gesund } \\
\hline & & $\mathrm{n}$ & $\%$ & $\mathrm{~N}$ & $\%$ & $\mathrm{n}$ & $\%$ & $\mathrm{n}$ & $\%$ \\
\hline Implantate & & 168 & & 55 & 33 & 16 & 10 & 113 & 67 \\
\hline \multirow{2}{*}{ Geschlecht } & männlich & 66 & 39 & 19 & 29 & 4 & 6 & 47 & 71 \\
\hline & weiblich & 102 & 61 & 36 & 35 & 12 & 12 & 66 & 65 \\
\hline \multirow{2}{*}{$\begin{array}{l}\text { Rauch- } \\
\text { verhalten }\end{array}$} & Raucher & 43 & 26 & 20 & 47 & 11 & 26 & 23 & 53 \\
\hline & Nichtraucher & 125 & 74 & 35 & 28 & 5 & 4 & 90 & 72 \\
\hline \multirow{2}{*}{$\begin{array}{l}\text { systemische } \\
\text { Parodontitis }\end{array}$} & ja & 104 & 62 & 33 & 32 & 13 & 13 & 71 & 68 \\
\hline & nein & 64 & 28 & 22 & 34 & 3 & 5 & 42 & 66 \\
\hline \multirow{2}{*}{ UPT/PZR } & regelmäßig & 93 & 55 & 30 & 32 & 7 & 8 & 63 & 68 \\
\hline & unregelmäßig & 75 & 45 & 25 & 33 & 9 & 12 & 50 & 67 \\
\hline
\end{tabular}


Tabelle 4.2 gibt einen Überblick über die Positionen der Implantate. Hierbei fällt auf, dass lediglich zwei Implantate in der regio der Inzisivi vorkommen und sich der Großteil in der regio der ersten Molaren befindet $(51,2 \%)$.

Tabelle 4.2 Positionierung der Implantate nach FDI-Schema

\begin{tabular}{c|c|c|c|c|c|c|c|c|c|c|c|c|c|c|c|c} 
Zahn & $\mathbf{1 8}$ & $\mathbf{1 7}$ & $\mathbf{1 6}$ & $\mathbf{1 5}$ & $\mathbf{1 4}$ & $\mathbf{1 3}$ & $\mathbf{1 2}$ & $\mathbf{1 1}$ & $\mathbf{2 1}$ & $\mathbf{2 2}$ & $\mathbf{2 3}$ & $\mathbf{2 4}$ & $\mathbf{2 5}$ & $\mathbf{2 6}$ & $\mathbf{2 7}$ & $\mathbf{2 8}$ \\
\hline \multirow{3}{*}{$\mathrm{n}$} & 1 & 1 & 11 & $\mathbf{9}$ & $\mathbf{9}$ & 0 & 0 & 1 & 0 & 0 & 0 & 13 & 11 & 17 & 1 & 0 \\
\cline { 2 - 30 } & 0 & $\mathbf{7}$ & $\mathbf{3 1}$ & 5 & 6 & 1 & 0 & 0 & 0 & 0 & 0 & 4 & 7 & 27 & 6 & 0 \\
\hline Zahn & $\mathbf{4 8}$ & $\mathbf{4 7}$ & $\mathbf{4 6}$ & $\mathbf{4 5}$ & $\mathbf{4 4}$ & $\mathbf{4 3}$ & $\mathbf{4 2}$ & $\mathbf{4 1}$ & $\mathbf{3 1}$ & $\mathbf{3 2}$ & $\mathbf{3 3}$ & $\mathbf{3 4}$ & $\mathbf{3 5}$ & $\mathbf{3 6}$ & $\mathbf{3 7}$ & $\mathbf{3 8}$
\end{tabular}

\subsection{Mikrobiologische Befunde}

Tabelle 4.3 gibt einen ersten Überblick über die Verteilung der Prävalenzen der Bakterien an gesunden und periimplantär erkrankten Implantaten. Hierzu werden die potentiell parodontopathogenen Bakterien in ihre fünf Komplexe unterteilt. Die Nachweisgrenze der Bakterien für folgende Untersuchungen lag bei $10^{3}$.

Tabelle 4.3 Verteilung der Prävalenzen der Bakterien an gesunden Implantaten, bei Mukositis und Periimplantitis

\begin{tabular}{c|c|c|c} 
& Gesund & Mukositis & Periimplantitis \\
\cline { 2 - 4 }$A a c$ & $9,73 \%$ & $21,82 \%$ & $25,00 \%$ \\
\hline$P g$ & $61,06 \%$ & $67,27 \%$ & $68,75 \%$ \\
$T f$ & $45,13 \%$ & $58,18 \%$ & $62,50 \%$ \\
$T d$ & $25,66 \%$ & $32,73 \%$ & $50,00 \%$ \\
\hline$P i$ & $16,81 \%$ & $25,45 \%$ & $50,00 \%$ \\
$P m$ & $15,04 \%$ & $23,64 \%$ & $31,25 \%$ \\
$F n$ & $81,42 \%$ & $89,09 \%$ & $93,75 \%$ \\
\hline$C r$ & $3,54 \%$ & $7,27 \%$ & $6,25 \%$ \\
$E n$ & $0,88 \%$ & $0,00 \%$ & $0,00 \%$ \\
\hline Ec & $7,08 \%$ & $5,45 \%$ & $6,25 \%$ \\
$C s$ & $13,27 \%$ & $9,09 \%$ & $6,25 \%$
\end{tabular}

\subsubsection{Bakteriennachweis von Aggregatibacter actinomycetemcomitans}

Aac lag an $10 \%$ der gesunden Implantate vor. Bei einer Mukositis (22\%) und einer Periimplantitis (25\%) war Aac im Vergleich zu gesunden Implantaten jeweils erhöht. Wie der Abbildung $4.1 \mathrm{zu}$ entnehmen, lässt sich jedoch kein signifikanter Unterscheid zwischen dem Auftreten von Aac an gesunden und periimplantär erkrankten Implantaten feststellen. 


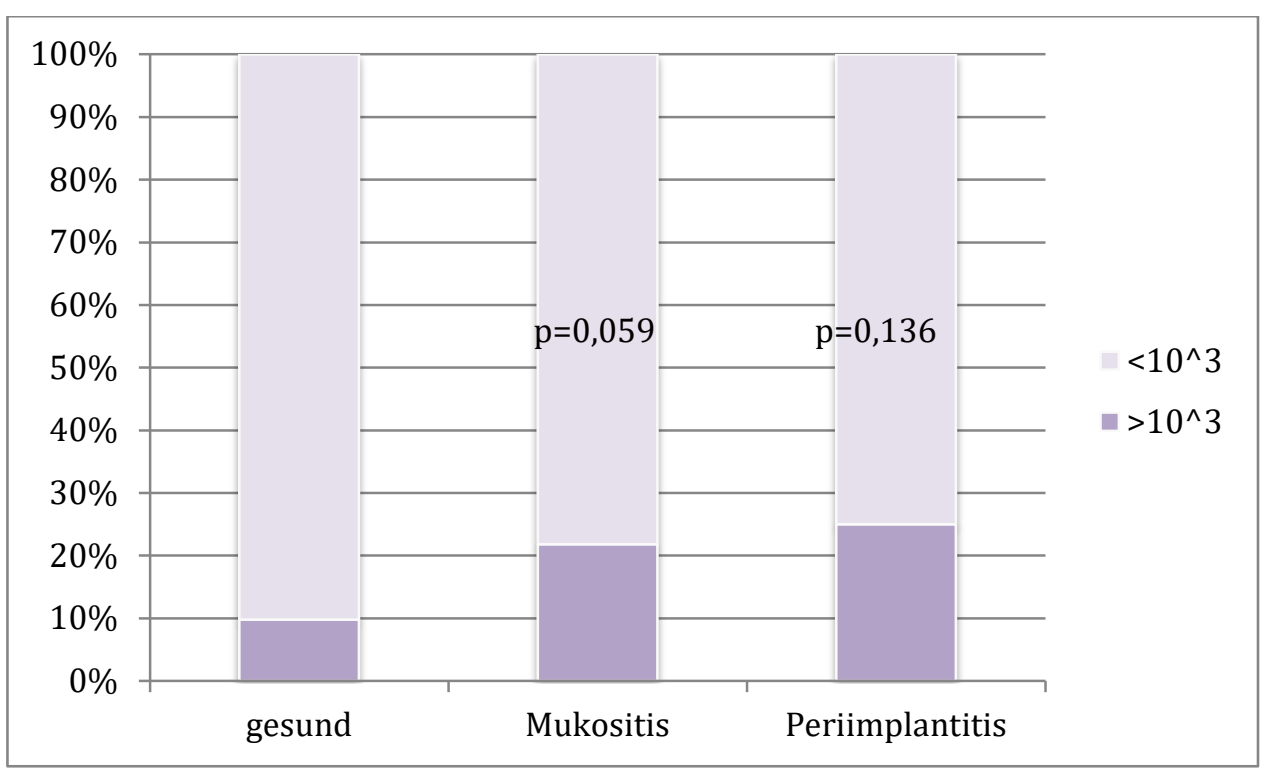

Abbildung 4.1 Verteilung der Prävalenz von Aggregatibacter actinomycetemcomitans nach gesund, Mukositis und Periimplantitis

Tabelle 4.4 gibt die Verteilung der Konzentrationen für $A a c$ an gesunden und periimplantär erkrankten Implantaten an. $86 \%$ der Proben lagen unterhalb der Nachweisgrenze. 14\% wurden oberhalb der Nachweisgrenze detektiert. Hierbei fällt auf, dass vor allem bei der Mukositis Aac zu 12,73\% im sehr stark erhöhten Bereich liegt und hier ein signifikanter Unterscheid im Vergleich zu gesunden Implantaten vorliegt $(p=0.026)$.

Tabelle 4.4 Verteilung der Konzentrationen für $A a c$

\begin{tabular}{lccccc} 
Aac & $<10^{\wedge} 3$ & $>10^{\wedge} 3$ & $>10^{\wedge} 4$ & $>10^{\wedge} 5$ & $>10^{\wedge} 6$ \\
gesund & 102 & 5 & 2 & 0 & 4 \\
& $90,27 \%$ & $4,42 \%$ & $1,77 \%$ & $0,00 \%$ & $3,54 \%$ \\
\hline Mukositis & 43 & 5 & 0 & 0 & 7 \\
& $78,18 \%$ & $9,09 \%$ & $0,00 \%$ & $0,00 \%$ & $12,73 \%$ \\
\hline Periimplantitis & 12 & 3 & 0 & 0 & 1 \\
& $75,00 \%$ & $18,75 \%$ & $0,00 \%$ & $0,00 \%$ & $6,25 \%$
\end{tabular}

\subsubsection{Bakteriennachweis des roten Komplexes}

Gleichermaßen waren $P g$, $T f$ und $T d$ am erkrankten Implantat wie auch am gesunden Implantat nachzuweisen. $\mathrm{Pg}$ und $\mathrm{Tf}$ waren hierbei am periimplantär erkrankten Implantat nur geringfügig erhöht. $T d$ hingegen lag zu $26 \%$ an gesunden Implantaten vor, zu $33 \%$ bei einer Mukositis und zu 50\% bei einer Periimplantitis. An gesunden Implantaten waren zu 46\% Tf und zu 62\% Pg nachweisbar. Im Falle einer Mukositis lag $\mathrm{Tf}$ zu 58\% und $\mathrm{Pg}$ zu $67 \%$ vor. An Implantaten, welche eine Periimplantitis hatten, war Tf in $63 \%$ der Fälle und $P g$ in $69 \%$ vertreten. Bei keinem der drei Bakterien des roten Komplexes war ein 
signifikanter Unterschied zwischen dem Auftreten des Bakteriums bei periimplantär erkrankten Implantaten im Vergleich zu gesunden Implantaten nachweisbar. Die folgende Abbildung 4.2 zeigt die Verteilung der Prävalenz der Bakterien des roten Komplexes an gesunden Implantaten und bei Mukositis und Periimplantitis.

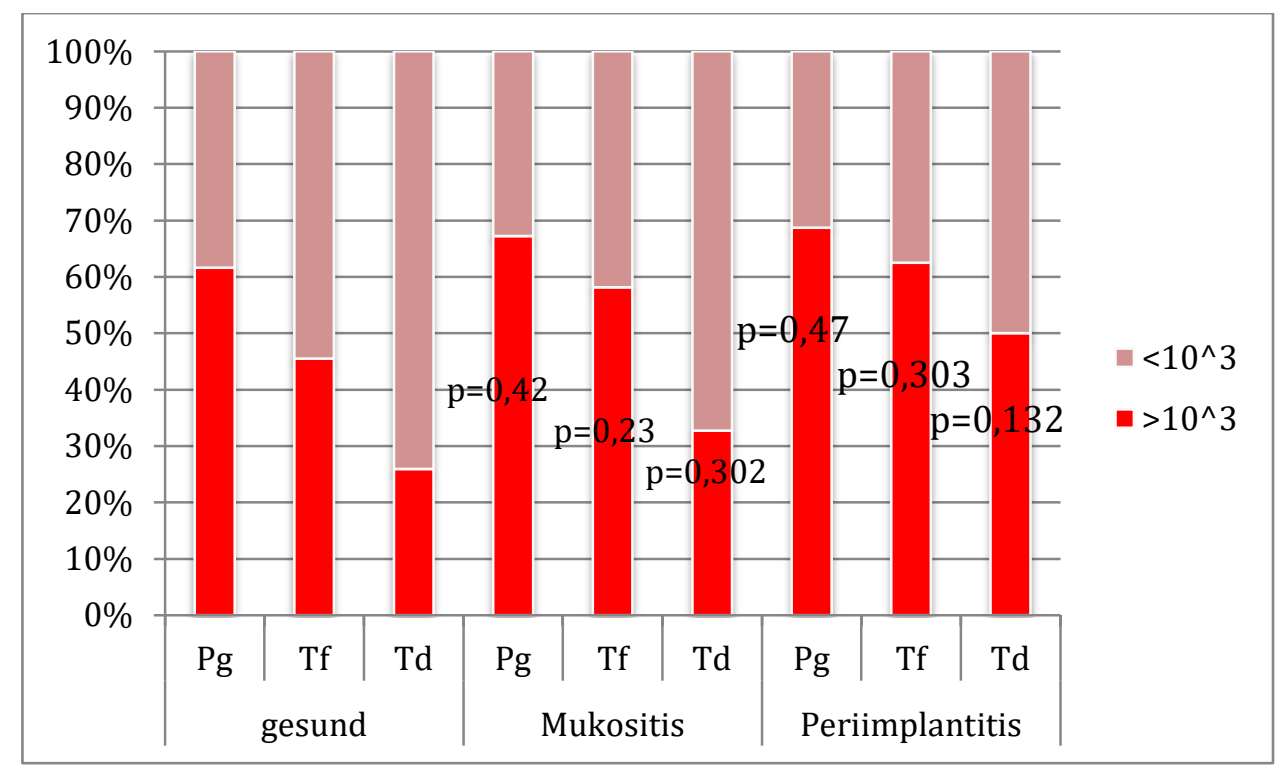

Abbildung 4.2 Verteilung der Prävalenz der Bakterien des roten Komplexes nach gesund, Mukositis und Periimplantitis

Tabelle 4.5 gibt die Verteilung der Konzentrationen des Bakteriums $P g$ an. Hierbei fällt auf, dass $P g$ sowohl am gesunden wie auch am periimplantär erkrankten Implantat deutlich häufiger oberhalb der Nachweisgrenze vorhanden ist. Es lässt sich jedoch kein signifikanter Unterschied nachweisen.

Tabelle 4.5 Verteilung der Konzentrationen für $P g$

\begin{tabular}{lccccc}
$\mathrm{Pg}$ & $<10^{\wedge} 3$ & $>10^{\wedge} 3$ & $>10^{\wedge} 4$ & $>10^{\wedge} 5$ & $>10^{\wedge} 6$ \\
gesund & 43 & 22 & 10 & 12 & 25 \\
& $38,39 \%$ & $19,64 \%$ & $8,93 \%$ & $10,71 \%$ & $22,32 \%$ \\
\hline Mukositis & 18 & 5 & 3 & 13 & 16 \\
& $32,73 \%$ & $9,09 \%$ & $5,54 \%$ & $23,64 \%$ & $29,09 \%$ \\
\hline Periimplantitis & 5 & 0 & 1 & 5 & 5 \\
& $31,25 \%$ & $0 \%$ & $6,25 \%$ & $31,25 \%$ & $31,25 \%$
\end{tabular}

Tabelle 4.6 zeigt die Verteilung der Bakterienkonzentrationen für Tf. 51\% der Bakterien wurden unterhalb der Nachweisgrenze detektiert. 49\% lagen oberhalb der Nachweisgrenze. Auch hier ließ sich kein signifikanter Unterscheid zwischen gesunden und periimplantär erkrankten Implantaten nachweisen. 
Ergebnisse

Tabelle 4.6 Verteilung der Konzentration für Tf

\begin{tabular}{lccccc} 
Tf & $<10^{\wedge} 3$ & $>10^{\wedge} 3$ & $>10^{\wedge} 4$ & $>10^{\wedge} 5$ & $>10^{\wedge} 6$ \\
gesund & 62 & 20 & 10 & 19 & 2 \\
& $54,87 \%$ & $17,70 \%$ & $8,85 \%$ & $16,81 \%$ & $1,77 \%$ \\
\hline Mukositis & 23 & 13 & 6 & 10 & 3 \\
& $41,82 \%$ & $23,64 \%$ & $10,91 \%$ & $18,18 \%$ & $5,45 \%$ \\
\hline Periimplantitis & 6 & 4 & 1 & 4 & 1 \\
& $37,50 \%$ & $25,00 \%$ & $6,25 \%$ & $25,00 \%$ & $6,25 \%$
\end{tabular}

Tabelle 4.7 spiegelt die Bakterienverteilung von $T d$ an gesunden und erkrankten Implantaten wieder. Bei $72 \%$ der Implantate lag $T d$ unterhalb der Nachweisgrenze und $28 \%$ befanden sich oberhalb dieser. Auch bei $T d$ ließ sich kein signifikanter Zusammenhang zwischen dem Vorkommen von $T d$ an gesunden bzw. erkrankten Implantaten herstellen. Der $p$-Wert lag hier bei maximal 0,063 bei der Periimplantitis im geringen Konzentrationsbereich $\left(>10^{3}\right)$.

Tabelle 4.7 Verteilung der Konzentration für $T d$

\begin{tabular}{lccccc}
$T d$ & $<10^{\wedge} 3$ & $>10^{\wedge} 3$ & $>10^{\wedge} 4$ & $>10^{\wedge} 5$ & $>10^{\wedge} 6$ \\
gesund & 84 & 11 & 13 & 5 & 0 \\
& $74,34 \%$ & $9,73 \%$ & $11,50 \%$ & $4,42 \%$ & $0,00 \%$ \\
\hline Mukositis & 37 & 7 & 5 & 5 & 1 \\
& $67,27 \%$ & $12,73 \%$ & $9,09 \%$ & $9,09 \%$ & $1,82 \%$ \\
\hline Periimplantitis & 8 & 4 & 1 & 2 & 1 \\
& $50,00 \%$ & $25,00 \%$ & $6,25 \%$ & $12,50 \%$ & $6,25 \%$
\end{tabular}

\subsubsection{Bakteriennachweis des orangen Komplexes}

Bis auf $F n(82 \%)$ lagen die Keime am gesunden Implantat mit $17 \%$ bei $P i$ und $15 \%$ bei $P m$ in geringer Konzentration vor. Allerdings war Fn auch bei 89\% der Implantate mit einer Mukositis und 94\% der Implantate mit einer Periimplantitis nachweisbar. Implantate mit einer Mukositis wiesen zu 25\% Pi und zu 24\% Pm auf. Bei einer Periimplantitis war Pi an $50 \%$ und $P m$ an $31 \%$ der Implantate nachweisbar. Einzig bei $P i$ ließ sich ein signifikanter Unterschied zwischen dem Vorkommen von $\mathrm{Pi}$ an gesunden Implantaten im Vergleich zu Implantaten mit einer Periimplantitis belegen $(p=0,031)$. Abbildung 4.3 stellt die Verteilung der Prävalenz der Bakterien des orangenen Komplexes nach gesund, Mukositis und Periimplantitis dar. 


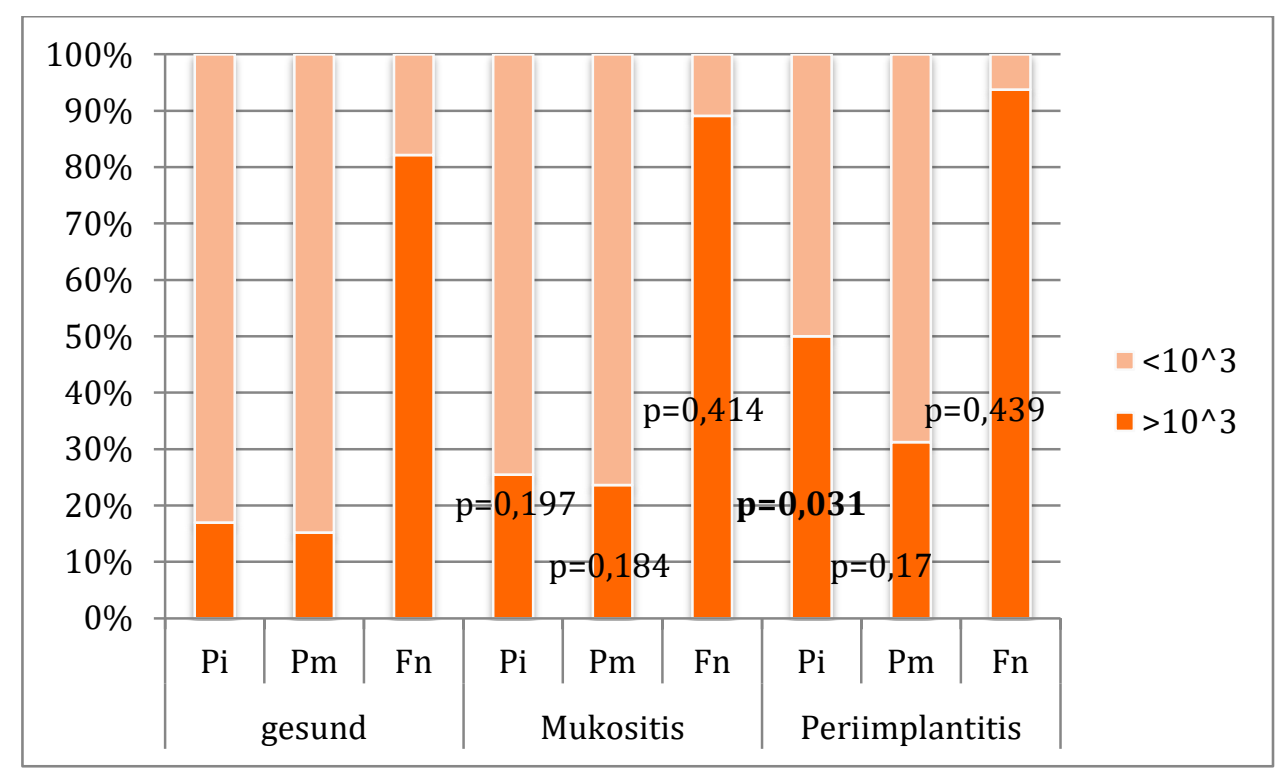

Abbildung 4.3 Verteilung der Prävalenz der Bakterien des orangenen Komplexes nach gesund, Mukositis und Periimplantitis

Die Verteilung der Konzentrationen von Pi an gesunden und erkrankten Implantaten ist in Tabelle 4.8 dargestellt. $80 \%$ der Proben lagen unterhalb der Nachweisgrenze. 20\% ließen sich oberhalb der Nachweisgrenze detektieren. Vergleicht man $\mathrm{Pi}$ im sehr stark erhöhten Konzentrationsbereich $\left(>10^{6}\right)$ an gesunden Implantaten und Implantaten mit einer Periimplantitis lässt sich ein signifikanter Unterscheid feststellen $(p=0,008)$.

Tabelle 4.8 Verteilung der Konzentration für $P i$

\begin{tabular}{lccccc} 
Pi & $<10^{\wedge} 3$ & $>10^{\wedge} 3$ & $>10^{\wedge} 4$ & $>10^{\wedge} 5$ & $>10^{\wedge} 6$ \\
gesund & 94 & 4 & 3 & 7 & 5 \\
& $83,19 \%$ & $3,54 \%$ & $2,65 \%$ & $6,19 \%$ & $4,42 \%$ \\
\hline Mukositis & 41 & 1 & 3 & 4 & 6 \\
& $74,55 \%$ & $1,82 \%$ & $5,45 \%$ & $7,27 \%$ & $10,91 \%$ \\
\hline Periimplantitis & 8 & 1 & 2 & 1 & 4 \\
& $50,00 \%$ & $6,25 \%$ & $12,50 \%$ & $6,25 \%$ & $25,00 \%$
\end{tabular}

Tabelle 4.9 gibt die Verteilung der Konzentration für $\mathrm{Pm}$ an gesunden und erkrankten Implantaten an. $82 \%$ der Proben lagen unterhalb der Nachweisgrenze und 18\% oberhalb dieser. Hier ließ sich kein signifikanter Zusammenhang zwischen der Konzentrationsverteilung von $\mathrm{Pm}$ an gesunden und periimplantär erkrankten Implantaten herstellen $(p>0,05)$. 
Ergebnisse

Tabelle 4.9 Verteilung der Konzentration für $\mathrm{Pm}$

\begin{tabular}{lccccc}
$\mathrm{Pm}$ & $<10^{\wedge} 3$ & $>10^{\wedge} 3$ & $>10^{\wedge} 4$ & $>10^{\wedge} 5$ & $>10^{\wedge} 6$ \\
gesund & 96 & 11 & 5 & 1 & 0 \\
& $84,96 \%$ & $9,73 \%$ & $4,42 \%$ & $0,88 \%$ & $0,00 \%$ \\
\hline Mukositis & 42 & 9 & 3 & 0 & 1 \\
& $76,36 \%$ & $16,36 \%$ & $5,45 \%$ & $0,00 \%$ & $1,82 \%$ \\
\hline Periimplantitis & 11 & 4 & 1 & 0 & 0 \\
& $68,75 \%$ & $25,00 \%$ & $6,25 \%$ & $0,00 \%$ & $0,00 \%$
\end{tabular}

\subsubsection{Bakteriennachweis des gelben Komplexes}

Cr lag bei 4,8\% $(n=8)$ der Implantaten oberhalb der Nachweisgrenze. Am gesunden Implantat zu 2,6\%, bei einer Mukositis zu 7,3\% und bei einer Periimplantitis zu 6,25\% oberhalb der Nachweisgrenze. Es ließ sich kein signifikanter Unterscheid zwischen dem Vorkommen von $\mathrm{Cr}$ an gesunden und periimplantär erkrankten Implantaten herstellen. En war nur an einem Implantat oberhalb der Nachweisgrenze nachweisbar und dieses Implantat war gesund. Abbildung 4.4 veranschaulicht die Verteilung der Prävalenz der Bakterien des gelben Komplexes.

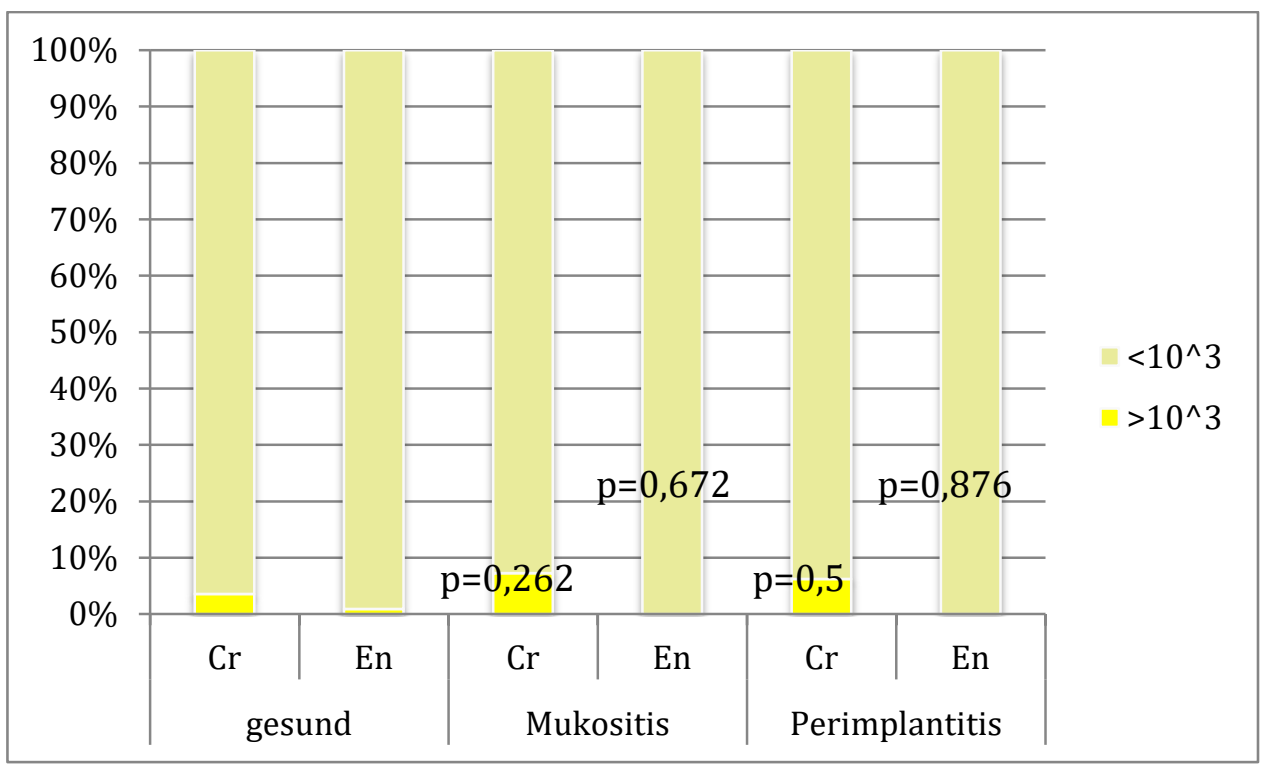

Abbildung 4.4 Verteilung der Prävalenz der Bakterien des gelben Komplexes nach gesund, Mukositis und Periimplantitis

Die folgenden Tabellen 4.10 und 4.11 geben die Verteilung der Konzentrationen von $\mathrm{Cr}$ und En an gesunden und periimplantär erkrankten Implantaten an. Hierbei wird deutlich, dass $\mathrm{Cr}$ am gesunden wie auch am periimplantär erkrankten Implantat zu über $90 \%$ unterhalb der Nachweisgrenze lag. Ähnliches gilt für En, welches sich an keinem erkrankten Implantat nachweisen ließ. Somit ließ sich kein signifikanter Unterschied von Cr und En an periimplantär erkrankten Implantaten im Vergleich zu gesunden Implantaten 
Ergebnisse

herstellen.

Tabelle 4.10 Verteilung der Konzentration für $\mathrm{Cr}$

\begin{tabular}{lccccc} 
Cr & $<10^{\wedge} 3$ & $>10^{\wedge} 3$ & $>10^{\wedge} 4$ & $>10^{\wedge} 5$ & $>10^{\wedge} 6$ \\
gesund & 109 & 3 & 1 & 0 & 0 \\
& $96,46 \%$ & $2,67 \%$ & $0,88 \%$ & $0,00 \%$ & $0,00 \%$ \\
\hline Mukositis & 51 & 3 & 1 & 0 & 0 \\
& $92,73 \%$ & $5,45 \%$ & $1,82 \%$ & $0,00 \%$ & $0,00 \%$ \\
\hline Periimplantitis & 15 & 1 & 0 & 0 & 0 \\
& $93,75 \%$ & $6,25 \%$ & $0,00 \%$ & $0,00 \%$ & $0,00 \%$
\end{tabular}

Tabelle 4.11 Verteilung der Konzentration für En

\begin{tabular}{lccccc} 
En & $<10^{\wedge} 3$ & $>10^{\wedge} 3$ & $>10^{\wedge} 4$ & $>10^{\wedge} 5$ & $>10^{\wedge} 6$ \\
gesund & 112 & 1 & 0 & 0 & 0 \\
& $99,11 \%$ & $0,89 \%$ & $0,00 \%$ & $0,00 \%$ & $0,00 \%$ \\
\hline Mukositis & 55 & 0 & 0 & 0 & 0 \\
& $100,00 \%$ & $0,00 \%$ & $0,00 \%$ & $0,00 \%$ & $0,00 \%$ \\
\hline Periimplantitis & 16 & 0 & 0 & 0 & 0 \\
& $100,00 \%$ & $0,00 \%$ & $0,00 \%$ & $0,00 \%$ & $0,00 \%$
\end{tabular}

\subsubsection{Bakteriennachweis des grünen Komplexes}

Der grüne Komplex verhielt sich ähnlich wie der gelbe Komplex. Es lag insgesamt zu 93,5\% unterhalb der Nachweisgrenze. Bei der Mukositis lagen 94,5\% und bei der Periimplantitis $93,75 \%$ unterhalb der Nachweisgrenze. Cs ließ sich an $11,91 \%$ der Implantate nachweisen. Bei einer Mukositis war Cs an 9,09\% und bei einer Periimplantitis an $6,25 \%$ der Implantate nachweisbar. Es konnte kein signifikanter Unterscheid zwischen dem Auftreten der Bakterien des grünen Komplexes an gesunden und periimplantär erkrankten Implantaten festgestellt werden. 


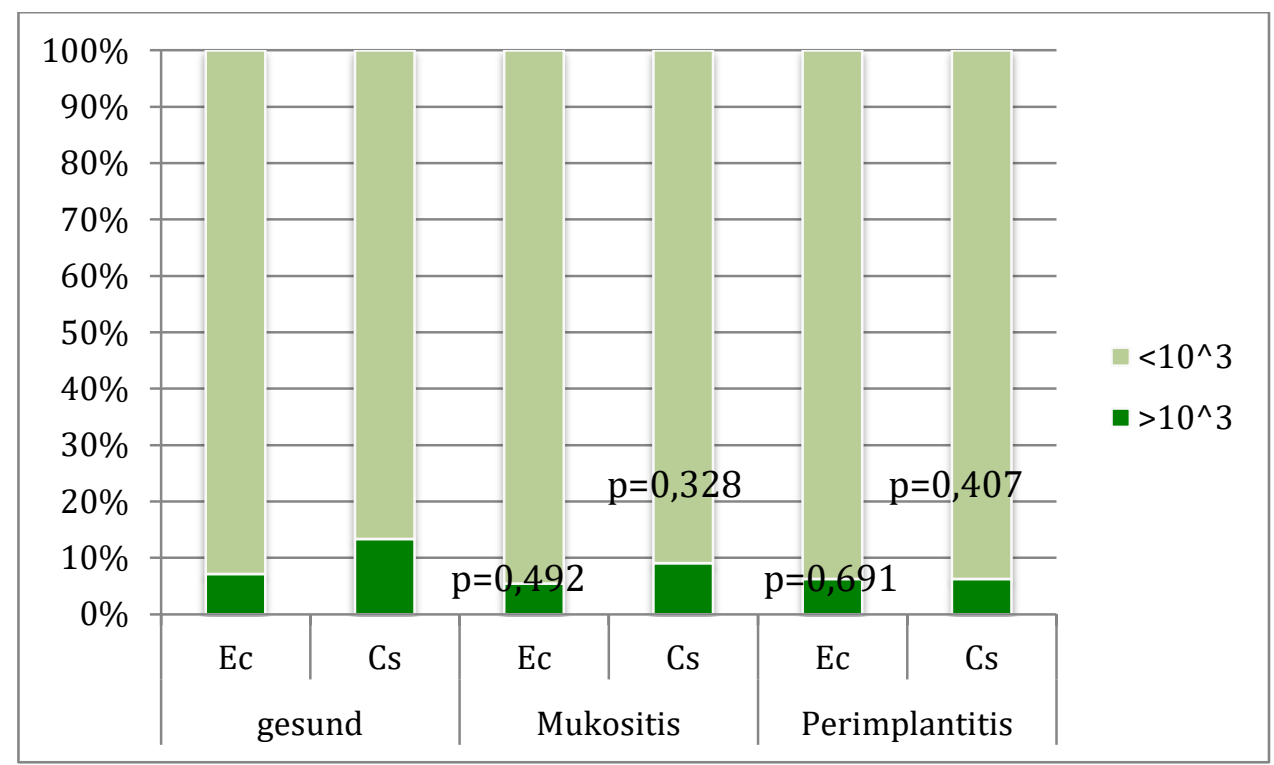

Abbildung 4.5 Verteilung der Prävalenz der Bakterien des grünen Komplexes nach gesund, Mukositis und Periimplantitis

Tabelle 4.12 und 4.13 geben die Verteilung der Konzentrationen des grünen Komplexes für $E c$ und $C s$ wieder. Hierbei fällt auf, dass die Konzentrationen im nachweisbaren Bereich bei periimplantär erkrankten Implantaten leicht abnehmen, dieses aber in keinem signifikanten Zusammenhang steht.

Tabelle 4.12 Verteilung der Konzentration für Ec

\begin{tabular}{lccccc} 
Ec & $<10^{\wedge} 3$ & $>10^{\wedge} 3$ & $>10^{\wedge} 4$ & $>10^{\wedge} 5$ & $>10^{\wedge} 6$ \\
gesund & 105 & 6 & 2 & 0 & 0 \\
& $92,92 \%$ & $5,31 \%$ & $1,77 \%$ & $0,00 \%$ & $0,00 \%$ \\
\hline Mukositis & 52 & 0 & 2 & 1 & 0 \\
& $94,54 \%$ & $0,00 \%$ & $3,64 \%$ & 1,82 & $0,00 \%$ \\
\hline Periimplantitis & 15 & 0 & 1 & 0 & 0 \\
& $93,75 \%$ & $0,00 \%$ & $6,25 \%$ & $0,00 \%$ & $0,00 \%$
\end{tabular}

Tabelle 4.13 Verteilung der Konzentration für Cs

\begin{tabular}{lccccc} 
Cs & $<10^{\wedge} 3$ & $>10^{\wedge} 3$ & $>10^{\wedge} 4$ & $>10^{\wedge} 5$ & $>10^{\wedge} 6$ \\
gesund & 98 & 11 & 3 & 1 & 0 \\
& $86,73 \%$ & $9,73 \%$ & 2,65 & 0,89 & $0,00 \%$ \\
\hline Mukositis & 50 & 4 & 1 & 0 & 0 \\
& $90,91 \%$ & $7,27 \%$ & 1,82 & $0,00 \%$ & $0,00 \%$ \\
\hline Periimplantitis & 15 & 1 & 0 & 0 & 0 \\
& $93,75 \%$ & $6,25 \%$ & $0,00 \%$ & $0,00 \%$ & $0,00 \%$
\end{tabular}


Ergebnisse

\subsection{Klinische Prävalenz von Mukositis und Periimplantitis unter Berücksichtigung von Risikofaktoren und sonstigen Einflussfaktoren}

Folgend wird zwischen gesicherten Risikofaktoren und sonstigen Einflussfaktoren unterteilt. Zu den gesicherten Risikofaktoren zählen das Rauchen, die unregelmäßige Teilnahme an Prophylaxemaßnahmen und eine parodontale Vorerkrankung. Mögliche Einflussfaktoren sind die Implantatposition, das Patientenalter, das Geschlecht und die Lage des Kiefers.

\subsubsection{Gesicherte Risikofaktoren}

Abbildung 4.6 zeigt die Prävalenz von Mukositis $(n=55)$ und Periimplantitis $(n=16)$ an Implantaten von Rauchern, Patienten ohne UPT/ PZR, Implantaten von Patienten mit einer Sys-Paro, sowie an Implantaten von Patienten ohne gesicherte Risikofaktoren.

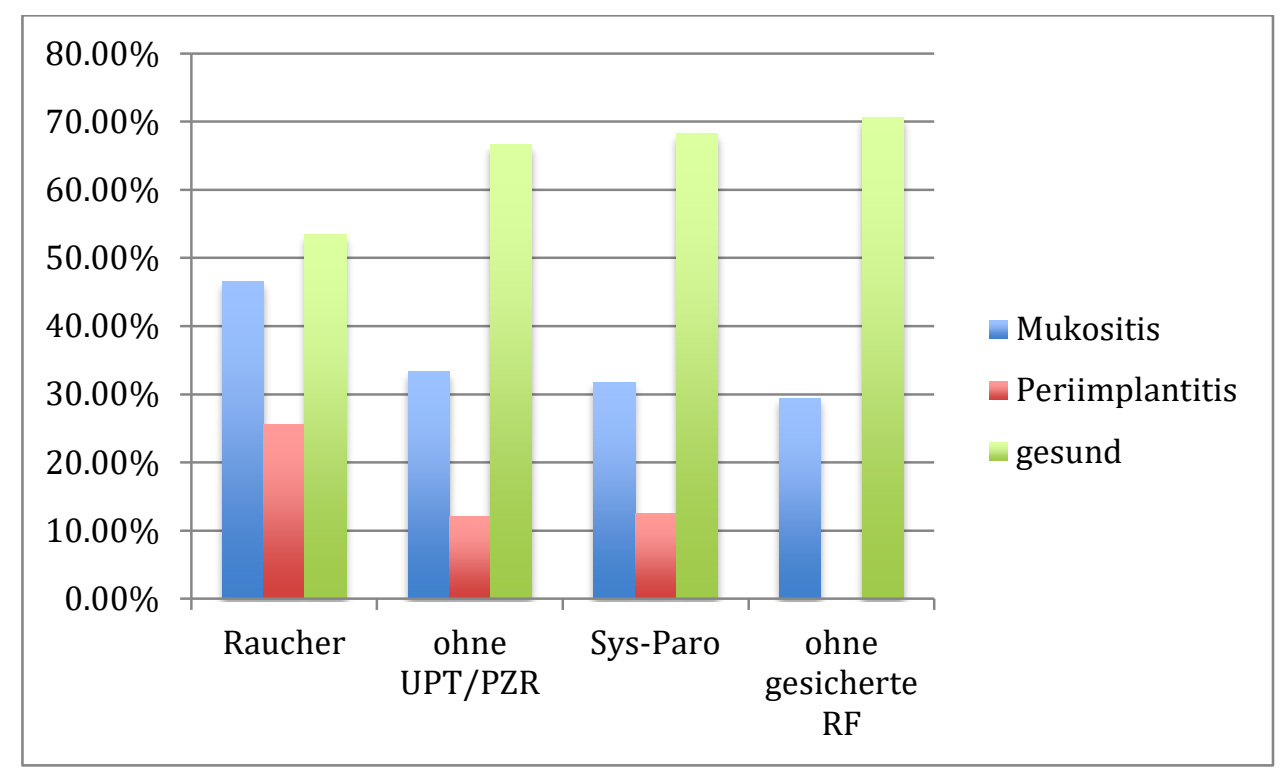

Abbildung 4.6 Prävalenz von Mukositis / Periimplantitis bezogen auf die gesicherten Risikofaktoren

Die Auswertung ergab, dass 47\% der Implantate von Rauchern eine Mukositis und 26\% eine Periimplantitis entwickelt haben. Die Implantate der Patienten mit unregelmäßiger Teilnahme am Prophylaxeprogramm hatten zu 32\% eine Mukositis und zu $12 \%$ eine Periimplantitis. Ähnlich verhält es sich bei den Implantaten der Patienten mit parodontaler Vorgeschichte, von denen $32 \%$ eine Mukositis hatten und $13 \%$ eine Periimplantitis. Als Vergleichsgruppe sind Implantate der Patienten ohne einen dieser drei Risikofaktoren aufgeführt $(n=17)$. Hierbei fällt auf, dass die Implantate der Patienten, welche nicht 
rauchten, keine parodontale Vorerkrankung hatten und regelmäßig an den Prophylaxeterminen teilnahmen keine Periimplantitis bekamen und nur 29\% eine Mukositis. Allerdings lässt sich auch kein signifikanter Unterscheid zwischen Implantaten ohne gesicherte Risikofaktoren und der Gesamtanzahl an untersuchten Implantaten feststellen ( $p^{\text {Mukositis }}=0,54, p^{\text {Perimplantitis }}=0,23$ ).

Abbildung 4.7 zeigt die Prävalenz periimplantärer Erkrankungen bei Rauchern $(n=18)$ und Nichtrauchern $(n=69)$. Im Detail zeigte sich, dass die Implantate der Raucher mit $47 \%$ deutlich häufiger eine Mukositis als die Implantate von Nichtrauchern mit $28 \%$ $(p=0,037)$ entwickelten. Noch deutlicher wird dieser Unterschied bei der Periimplantitis. Hier hatten $26 \%$ der Implantate von Rauchern und nur $4 \%$ der Implantate der Nichtraucher eine Periimplantitis. Hieraus ergibt sich ein signifikanter Unterschied zwischen Implantaten von Rauchern und Nichtrauchern und dem Auftreten periimplantärer Erkrankungen ( $\left.p^{\text {Mukositis }}=0,037, p^{\text {Perimplantitis }}=0,0002\right)$.

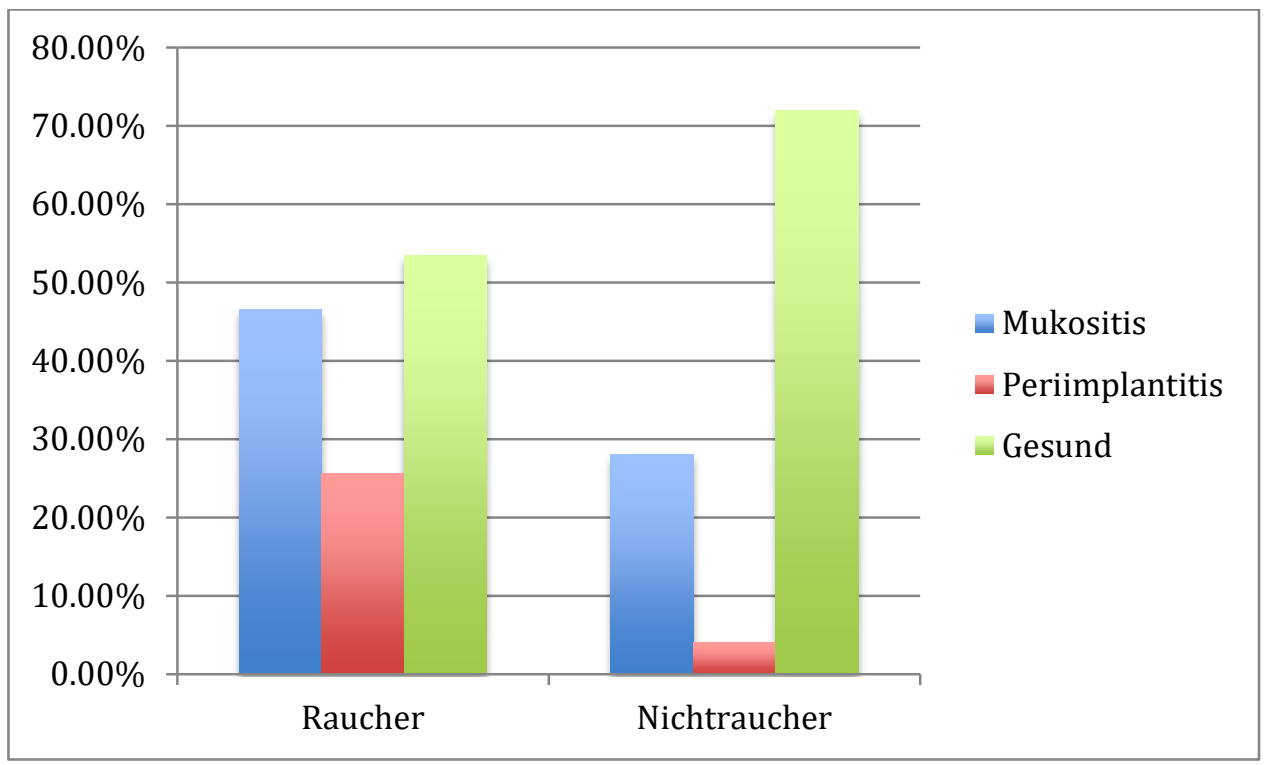

Abbildung 4.7 Prävalenz periimplantärer Erkrankungen an Implantaten von Rauchern und Nichtrauchern

Abbildung 4.8 veranschaulicht die Prävalenz periimplantärer Erkrankungen der Implantate von Patienten mit UPT bzw. PZR $(n=52)$ und denen ohne $(n=35)$. Von 75 Implantaten ohne UPT/PZR blieben 68\% gesund, 32\% entwickelten eine Mukositis und 12\% eine Periimplantitis. $67 \%$ der Implantate mit UPT/PZR blieben klinisch gesund, 33\% entwickelten eine Mukositis und $8 \%$ eine Periimplantitis. Daraus geht hervor, dass eine regelmäßige bzw. unregelmäßige Teilnahme an einer UPT/PZR in keinen signifikanten Zusammenhang zum Auftreten periimplantärer Erkrankungen steht ( $p^{\text {Mukositis }}=0,742$, $\left.p^{\text {Perimplantitis }}=0,421\right)$. 
Ergebnisse

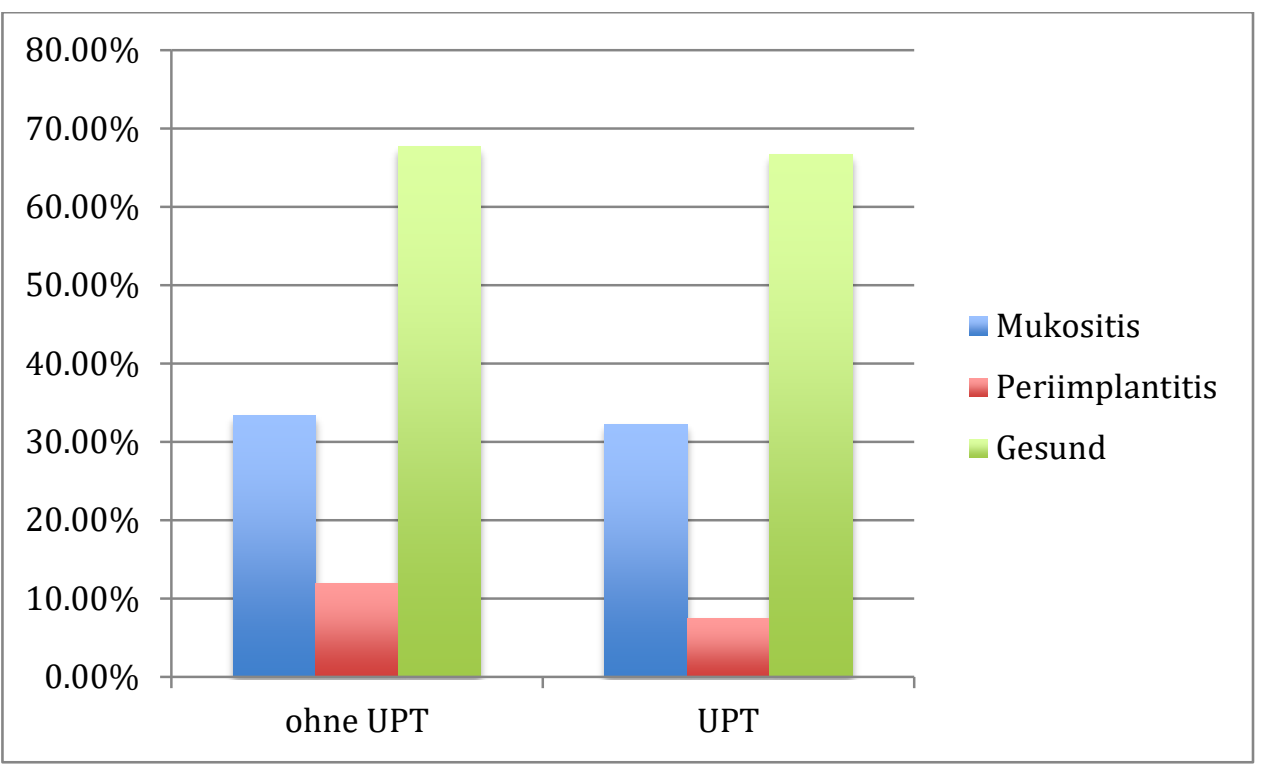

Abbildung 4.8 Prävalenz periimplantärer Erkrankungen an Implantaten mit und ohne UPT/PZR

Abbildung 4.9 vergleicht Implantate von Patienten mit einer parodontalen Vorerkrankung ( $n=54)$ und Patienten ohne Sys-Paro $(n=33)$. Die Implantate $(n=104)$ der Patienten mit parodontaler Vorerkrankung (Sys-Paro) hatten zu 32\% eine Mukositis und zu 13\% eine Periimplantitis. $68 \%$ der Implantate blieben gesund. Implantate $(n=64)$ der Patienten ohne Sys-Paro waren zu 66\% gesund, 34\% entwickelten eine Mukositis und 5\% eine Periimplantitis. Auch hier ist kein signifikanter Unterscheid zwischen Implantaten von Patienten ohne und mit Sys-Paro zu ermitteln ( $p^{\text {Mukositis }}=0,738, p^{\text {Perimplantitis }}=0,173$ ).

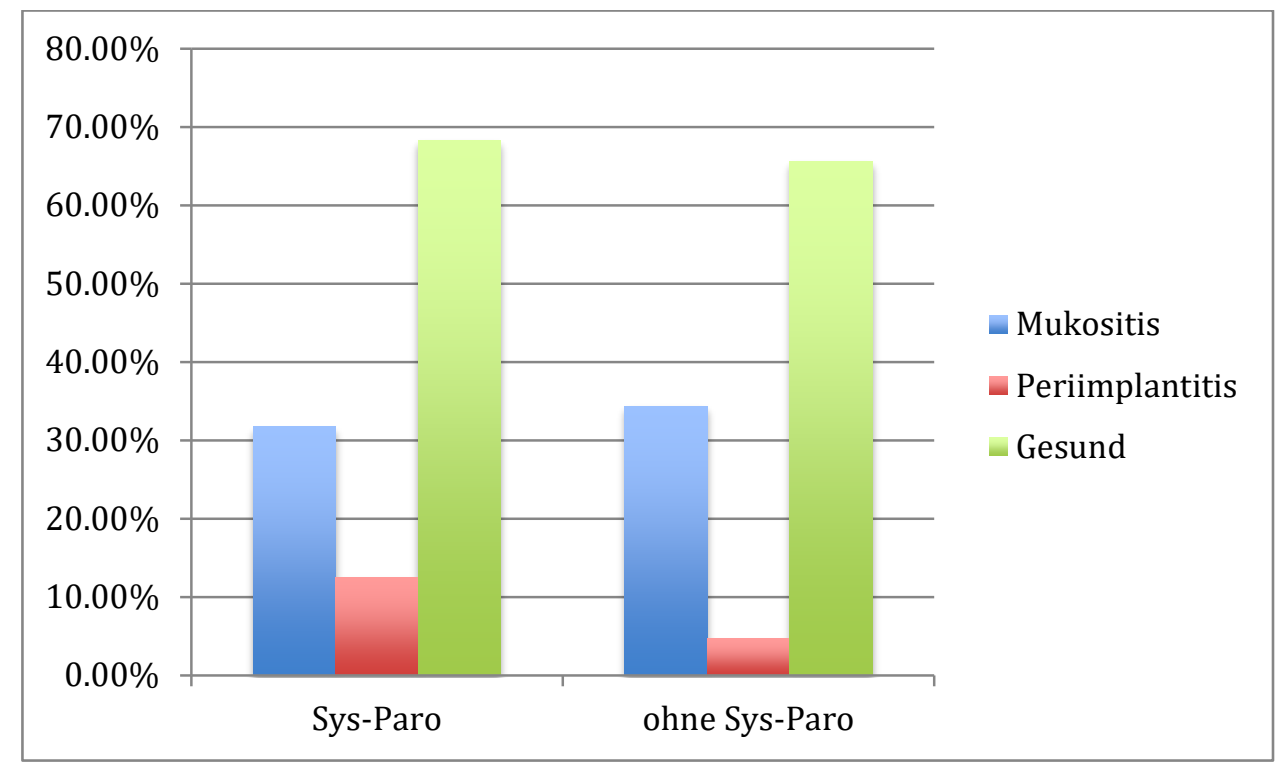

Abbildung 4.9 Prävalenz periimplantärer Erkrankungen an Implantaten von Patienten mit und ohne parodontaler Vorerkrankung 


\subsubsection{Sonstige Einflussfaktoren}

Tabelle 4.14 gibt einen Überblick über die Anzahl der Implantate bei Männern und Frauen und zeigt das Signifikanzniveau des Geschlechts bezogen auf die Gesamtzahl der Implantate. 29\% der Implantate $(n=19)$ bei Männer bekamen eine Mukositis und $6 \%$ eine Periimplantitis $(n=4)$. Bei den Implantaten der weiblichen Patienten entwickelten $35 \%$ der Implantate eine Mukositis $(n=36)$ und $12 \%$ eine Periimplantitis $(n=12)$. Wie der Tabelle zu entnehmen ist, besteht kein signifikanter Zusammenhang zwischen dem Geschlecht und Vorkommen periimplantärer Erkrankungen.

Tabelle 4.14 Signifikanzniveau bezogen auf das Geschlecht

\begin{tabular}{l|ll} 
Geschlecht & $\mathbf{p}^{\text {Mukositis }}$ & $\mathbf{p}^{\text {Perimplantitis }}$ \\
\hline männlich $(n=66)$ & 0,395 & 0,308 \\
\hline weiblich $(n=102)$ & 0,427 & 0,369
\end{tabular}

Die folgende Abbildung 4.10 stellt die Altersstufen in Zehnjahresabständen dar. Hieraus geht hervor, dass $43 \%$ der Implantate bei 37 - bis 40 -jährigen Patienten eine Mukositis entwickelten und keines eine Periimplantitis. Zwischen 41 und 70 Jahren stieg die Anzahl periimplantärer Mukositis mit zunehmendem Alter stetig an, wobei die Anzahl von Periimplantitisfällen annähernd gleich bleibt. In der ältesten Vergleichsgruppe von 71 bis 80 Jahren sank die Zahl der Mukositis auf $10 \%$ bei keinem Fall einer Periimplantitis.

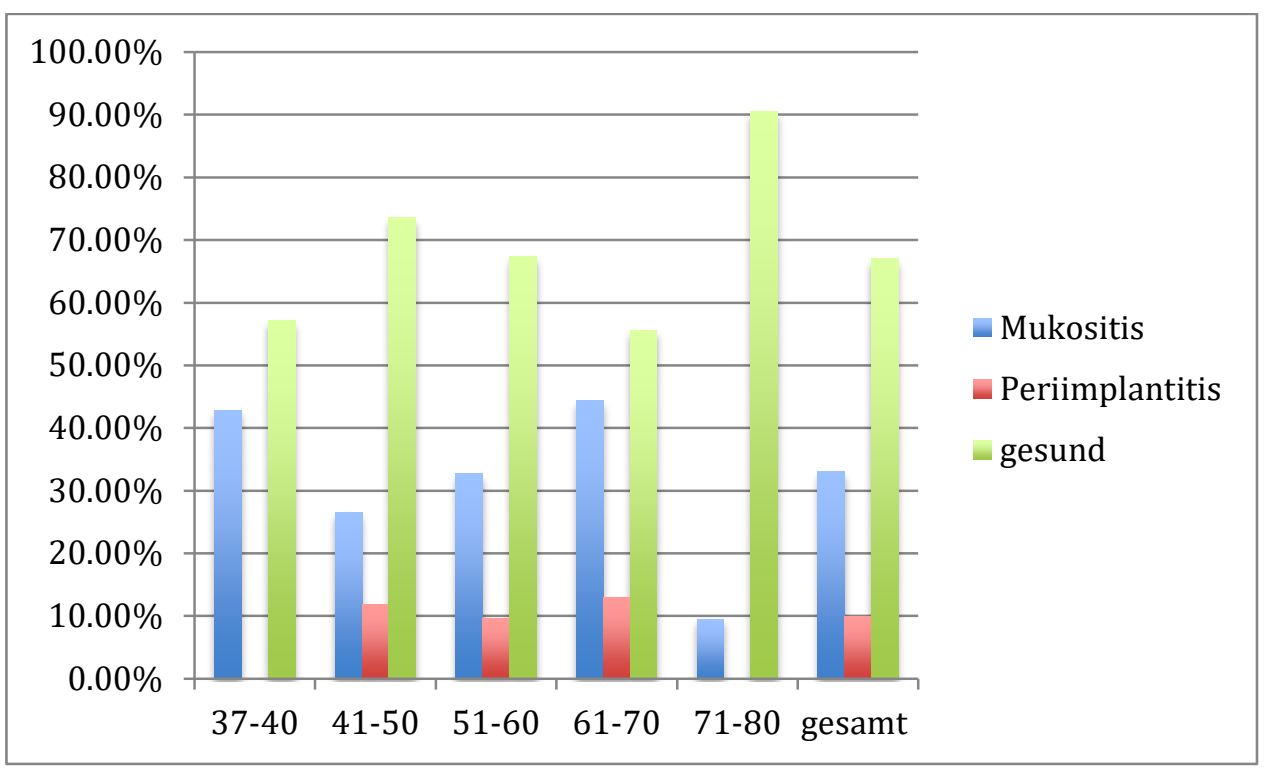

Abbildung 4.10 Mukositis und Periimplantitis bezogen auf das Patientenalter

Tabelle 4.15 gibt einen Überblick über die Verteilung in den entsprechenden Altersgruppen und deren p-Wert. Vergleicht man die periimplantären Erkrankungen der 
einzelnen Altersgruppen mit der Gesamtanzahl von Mukositis und Periimplantitis haben die Altersgruppen zwischen 51 bis 60 Jahren $(p=0,02), 61$ bis 70 Jahren $(p=0,034)$ und 71 bis 80 Jahren $(p=0,013)$ einen signifikanten Zusammenhang mit dem Auftreten einer Mukositis. Zur Periimplantitis lässt sich kein signifikanter Zusammenhang zu den einzelnen Altersgruppen herstellen.

Tabelle $4.15 p$-Werte in den Altersgruppen

\begin{tabular}{l|ll} 
Altersgruppen in Jahren & $\mathbf{p}^{\text {Mukositis }}$ & $\mathbf{p}^{\text {Perimplantitis }}$ \\
\hline $\mathbf{3 7 - 4 0}(\mathrm{n}=7)$ & 0,472 & 0,536 \\
\hline $\mathbf{4 1 - 5 0}(\mathrm{n}=34)$ & 0,378 & 0,458 \\
\hline $\mathbf{5 1 - 6 0}(\mathrm{n}=52)$ & $\mathbf{0 , 0 2}$ & 0,583 \\
\hline $\mathbf{6 1 - 7 0} \mathrm{n}=(54)$ & $\mathbf{0 , 0 3 4}$ & 0,37 \\
\hline $\mathbf{7 1 - 8 0} \mathrm{n}=(21)$ & $\mathbf{0 , 0 1 3}$ & 0,165
\end{tabular}

Die Prävalenz periimplantärer Erkrankungen bezogen auf Ober- und Unterkiefer wird in Abbildung 4.11 veranschaulicht. Von 73 Implantaten im Oberkiefer bekamen 29\% eine Mukositis und $5 \%$ eine Periimplantitis, $71 \%$ hingegen blieben klinisch gesund. Im Unterkiefer bekamen von 95 gesetzten Implantaten 13\% eine Periimplantitis, 36\% eine Mukositis und $64 \%$ blieben klinisch gesund. Mukositis wie auch Periimplantitis waren in dieser Untersuchung im Unterkiefer häufiger lokalisiert als im Oberkiefer. Es lässt sich jedoch kein signifikanter Unterscheid zwischen dem Auftreten periimplantären Erkrankungen im Ober- und Unterkiefer nachweisen $\left(p^{\text {Mukositis }}=0,408, p^{\text {Perimplantitis }}=0,177\right.$ ).

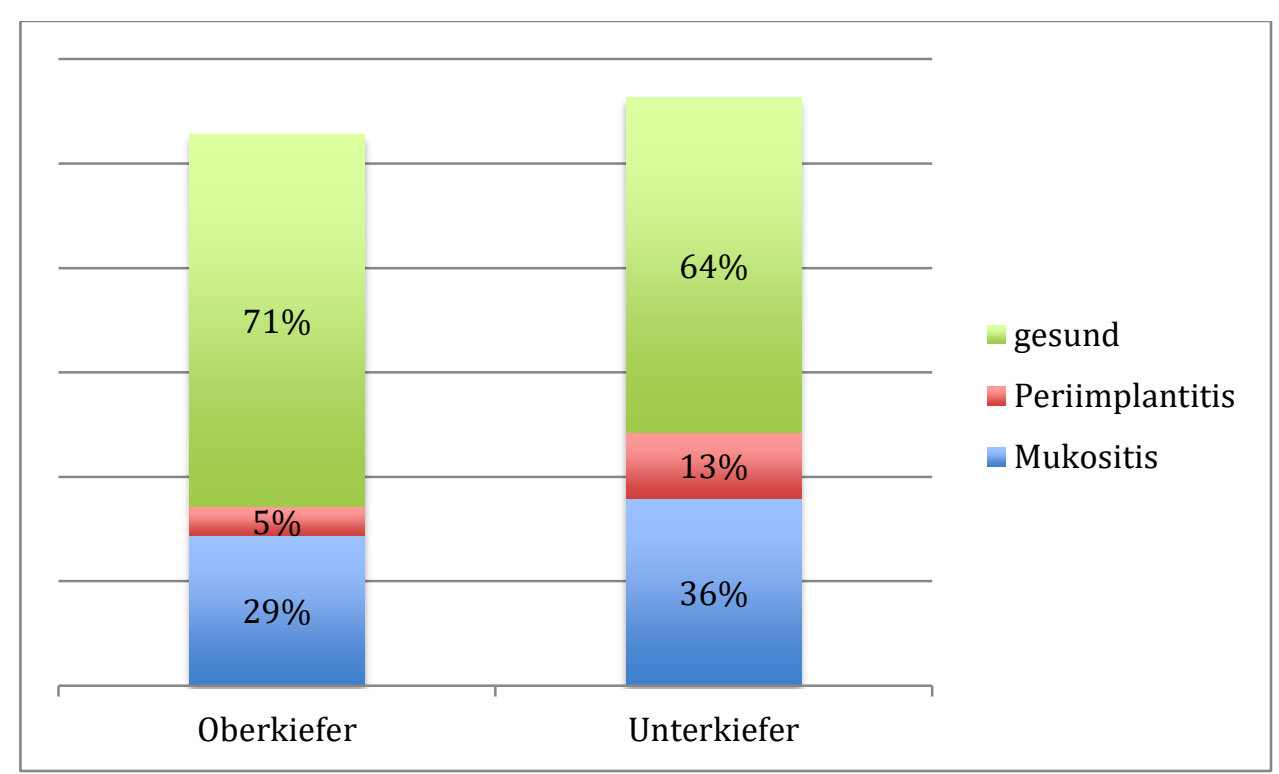

Abbildung 4.11 Prävalenz von Mukositis und Periimplantitis im Ober- und Unterkiefer 
Ergebnisse

Die nachfolgende Tabelle 4.16 stellt die Verteilung periimplantärer Erkrankungen bezogen auf ihre Implantatpositionierung dar. Dem ist zu entnehmen, dass die beiden Inzisivi zu vernachlässigen sind, da nur jeweils ein Implantat im Oberkiefer und ein Implantat im Unterkiefer gesetzt wurde. Auffällig ist jedoch, dass $45 \%$ der Implantate in der Prämolarenregion eine Mukositis entwickelten und 23\% eine Periimplantitis. Tendenziell entsteht an den Implantaten in Prämolaren-Region häufiger eine Mukositis bzw. eine Periimplantitis als an Implantaten in Molaren-Region. Allerdings ist auch hier kein signifikanter Unterscheid zwischen den periimplantären Erkrankungen in den einzelnen Regionen und den Erkrankungen bezogen auf die Gesamtanzahl der Implantate nachweisbar $(p>0,05)$.

Tabelle 4.16 Verteilung periimplantärer Erkrankungen bezogen auf die Implantatpositionierung

\begin{tabular}{ccc|cc|cc|cc} 
& & & \multicolumn{2}{|c|}{ gesund } & \multicolumn{2}{c|}{ Mukositis } & \multicolumn{2}{c}{ Periimplantitis } \\
& & $\mathrm{n}$ & $\mathrm{n}$ & $\%$ & $\mathrm{n}$ & $\%$ & $\mathrm{n}$ & $\%$ \\
\hline \multirow{2}{*}{ OK } & Inzisivi & 1 & & & 1 & 100 & & \\
& Prämolaren & 43 & 28 & 65,12 & 15 & 34,88 & 3 & 6,98 \\
& Molaren & 30 & 24 & 80 & 6 & 20 & 1 & 3,33 \\
\hline \multirow{3}{*}{ UK } & Inzisivi & 1 & 1 & 100 & & & & \\
& Prämolaren & 22 & 12 & 54,55 & 10 & 45,45 & 5 & 22,73 \\
& Molaren & 71 & 47 & 66,20 & 24 & 33,80 & 7 & 9,86
\end{tabular}


Ergebnisse

\subsection{Zusammenfassung der wichtigsten Ergebnisse}

1. Mikrobiologie

a. Einzig bei $P i$ besteht ein signifikanter Unterscheid zwischen dem Vorliegen des Bakteriums an gesunden Implantaten im Vergleich zu Implantaten mit einer Periimplantitis $(p=0,031)$.

b. Das Vorhandensein von Aac steht im sehr stark erhöhten Konzentrationsbereich in signifikantem Zusammenhang mit einer Mukositis $(p=0,026)$.

c. Ein signifikanter Zusammenhang besteht auch zwischen $\mathrm{Pi}$ im sehr stark erhöhten Konzentrationsbereich und einer Periimplantitis $(p=0,008)$.

d. Andere Bakterien sind zwar prozentual erhöht, lassen sich jedoch nicht in einen signifikanten Zusammenhang zu periimplantären Erkrankungen bringen.

2. Risikofaktoren / Einflussgrößen

a. Das Rauchverhalten steht in einem signifikanten Zusammenhang mit periimplantären Erkrankungen ( $p^{\text {Mukositis }}=0,037, p^{\text {Perimplantitis }}=0,0002$ ).

b. Bei Patienten im Alter von 51 bis 80 Jahren lässt sich ein signifikanter Zusammenhang zur Mukositis nachweisen $\quad\left(p^{51-60 J a h r e}=0,02\right.$, $\left.\mathrm{p}^{61-70 \text { Jahre }}=0,034, \mathrm{p}^{71-80 \text { Jahre }}=0,013\right)$.

c. Andere Risikofaktoren bzw. Einflussfaktoren sind zwar bei periimplantären Erkrankungen prozentual erhöht, jedoch ohne signifikanten Zusammenhang. 


\section{Diskussion}

Im Rahmen dieser Studie wurden 168 Implantate von insgesamt 87 Patienten untersucht. An diesen Implantaten wurden mit sterilen Papierspitzen Proben des subgingivalen Biofilms entnommen. Anschließend erfolgte der Nachweis der potentiell parodontalpathogenen Bakterien Aac, Pg, Td, Tf und Pi sowie Pm, Fn, Cr, En, Er und Cs mittels PCR. Es sollte geklärt werden, inwieweit diese im Zusammenhang mit dem Auftreten einer Mukositis und Periimplantitis an Implantaten stehen. Zusätzlich wurden Risikofaktoren und deren Zusammenhang mit dem Auftreten periimplantärer Erkrankungen untersucht.

\subsection{Material und Methoden}

Positiv hervorzuheben ist in dieser praxisbasierten klinischen Querschnittsstudie, dass alle Daten aus derselben allgemeinzahnärztlichen Praxis stammen und somit eine einheitliche Datenerfassung über den gesamten Beobachtungszeitraum erfolgte. Die Patienten stammen alle von einem Behandler und dementsprechend einem einheitlichen Behandlungskonzept.

Außerdem wurde ein einheitliches Implantatsystem, Ankylosimplantate der Firma Dentsply Sirona (Mannheim, Deutschland), benutzt und ein Patientenkollektiv ausgewählt, welches definierte Kriterien (3.2) zu erfüllen hatte. Durch ein einheitliches Implantatsystem konnten Unterschiede in Bezug auf die Entstehung periimplantärer Erkrankungen, welche sich aufgrund verschiedener Implantatsysteme hätten ergeben können, ausgeschlossen werden (Karoussis et al. 2004). Limitierende Faktoren einer klinischen Studie sind die Patienten, insbesondere die Abhängigkeit der Patientenverfügbarkeit und deren Zuverlässigkeit bei der Wahrnehmung ihrer Kontrolltermine innerhalb des Beobachtungszeitraumes. Bei der Auswertung der Daten fiel auf, dass es nicht möglich war, die Inzisivi in die Beurteilung als Risikofaktor bezüglich ihrer Lokalisation mit einzubeziehen, da lediglich zwei Implantate in der Region der Inzisivi inseriert wurden. Zudem erwies es sich als schwierig, genaue Aussagen über bestimmte Risikofaktoren zu treffen, da größtenteils ja/nein- Entscheidungen getroffen wurden. Dementsprechend gibt es nur Raucher und Nichtraucher, jedoch keine genaue Aussage über die Quantität bzw. Qualität der Rauchgewohnheit (pack years).

Kritisch zu bewerten sind die Anzahl der Implantate, bezogen auf die Menge der Patienten. Daher wurde eine implantatbezogene Auswertung durchgeführt. Das heißt, 
dass Patienten mit nur einem Implantat, unabhängig von deren Risikofaktoren, genauso in die Studie einbezogen wurden wie ein Patient mit sechs Implantaten. Somit könnten patientenspezifische Faktoren die statistische Auswertung beeinflusst haben.

Zum mikrobiologischen Teil der vorliegenden Arbeit muss angemerkt werden, dass auch bei der Auswertung der Daten Fehler auftreten können. So besteht bei der Durchführung einer konventionellen PCR die Gefahr einer Kontamination der Proben mit fremder DNA, da vor allem beim zweiten Teil der Amplifikation die Proben im Schüttelbad der atmosphärischen Luft ausgesetzt sind, wodurch fremde DNA aus der Luft die Proben kontaminieren könnte. In der Phase der Quantifizierung werden die Teststreifen subjektiv visuell abgelesen. Die Übergänge zur Bestimmung der Quantität der vorliegenden Bakterienmenge sind hierbei sehr fließend. Trotz der von der Firma Hain Lifescience (Nehren, Deutschland) nicht angegeben bakterienspezifischen Basenlängen der Primer bei der PCR gilt der Test jedoch als valide und wurde bereits in zahlreichen anderen Studien erfolgreich verwendet (De Boever und De Boever 2006; Ertugrul et al. 2013; Haffajee et al. 2009).

\subsection{Der Zusammenhang zwischen potentiell parodontopathogenen Bakterien und dem Auftreten periimplantärer Erkrankungen}

Im Folgenden sollen die Ergebnisse dieser Studie kritisch beleuchtet werden. Hierzu soll der Zusammenhang zwischen Bakterienkonzentration und periimplantärer Erkrankung betrachtet werden. Es soll die Hypothese überprüft werden, dass potentiell parodontopathogene Bakterien einen Zusammenhang mit dem Auftreten periimplantärer Erkrankungen aufweisen und somit negative Auswirkungen auf den dauerhaften Erfolg eines Implantats haben können.

Die Biofilmbildung auf Implantaten folgt einem ähnlichen Muster der Mikrobenbesiedlung, wie der auf Zähnen (Kalykakis et al. 1998). Patienten mit parodontaler Vorgeschichte weisen in den Taschen der Implantate eine ähnliche Mikrobiologie auf wie die an natürlichen Zähnen (Ong et al. 2008).

Die Auswertung der vorliegenden Arbeit ergab, dass ausschließlich $P i$ in einem signifikanten Zusammenhang mit einer Periimplantitis steht $(p=0,031)$. Im sehr stark erhöhten Konzentrationsbereich besteht ein signifikanter Zusammenhang von Aac und einer Mukositis $(p=0,026)$ und $P i$ und einer Periimplantitis $(p=0,008)$. Auf die einzelnen Bakterien wird im Folgenden näher eingegangen.

Aac konnte an gesunden wie auch an erkrankten Implantaten nachgewiesen werden. Dies belegen auch andere Studien, die zwar zeigen, dass Aac an erkrankten Implantaten 
geringfügig in höheren Konzentrationen nachweisbar ist, sich jedoch auch an gesunden Implantaten nachweisen lässt (Casado et al. 2011; Cortelli et al. 2013). Das Vorkommen von Aac ist daher nicht in einen unmittelbaren Zusammenhang zu periimplantären Erkrankungen zu setzen. Diese Ergebnisse werden auch in der vorliegenden Arbeit bestätigt. Zwar ist Aac prozentual bei periimplantären Erkrankungen erhöht, aufgrund des Vorkommens an gesunden Implantaten lässt sich allerdings kein statistisch signifikanter Zusammenhang nachweisen. Ausschließlich im sehr stark erhöhten Konzentrationsbereich lässt sich ein signifikanter Zusammenhang zur Mukositis erkennen. Auch $P g$ ist an gesunden und erkrankten Implantaten nachzuweisen. Allerdings liegt $P g$ deutlich häufiger als Aac auch an gesunden Implantaten vor (62\%). Folglich lässt sich kein signifikanter Zusammenhang von $P g$ und periimplantären Erkrankungen nachweisen $(p>0,05)$. Auch Galassi et al. (2012) zeigt, dass Pg zwar in erhöhten aber nicht signifikant erhöhten Keimkonzentration vorliegt. Kim et al. (2016) spricht Pg trotz fehlender Signifikanz eine entscheidende Rolle an der Entstehung periimplantärer Erkrankungen zu. Wie auch Persson und Renvert (2014), zeigt die vorliegende Arbeit jedoch, dass $P g$ bei periimplantären Erkrankungen überwiegend im stark und sehr stark erhöhten Konzentrationsbereich vorliegt. Bei der Mukositis zu 52,7\% und bei der Periimplantitis zu 63\%. Allerdings ist auch hier kein signifikanter Zusammenhang von $P g$ und dem Vorliegen einer periimplantären Erkrankung festzustellen.

Auch $T f$ nimmt mit zunehmendem Krankheitszustand an Implantaten in dieser Studie stetig zu, lässt sich aber in keinen signifikanten Zusammenhang mit periimplantären Erkrankungen bringen. Hinsichtlich $T f$ ist die Studienlage sehr kontrovers. Einige Studien zeigen keinen Zusammenhang zwischen dem Auftreten von $T f$ und periimplantären Erkrankungen (Ata-Ali et al. 2013; Casado et al. 2011), Persson und Renvert (2014) hingegen konnten eine statistische Signifikanz zu Periimplantitis feststellen. Es ist allerdings bekannt, dass $T f$ eine entzündliche Reaktion induziert, welche an der Entwicklung einer periimplantären Mukositis beteiligt ist (Ata-Ali et al. 2013). Wie schon $P g$ liegt $T f$ bei periimplantären Erkrankungen vor allem im stark und sehr stark erhöhten Konzentrationsbereich vor. Auch hier jedoch ohne signifikanten Zusammenhang.

$T d$ hat in der vorliegenden Arbeit keinen signifikanten Zusammenhang zu periimplantären Erkrankungen. Andere Studien konnten diesen Zusammenhang ebenfalls nicht belegen (Casado et al. 2011; Sato et al. 2011). Wie bei den genannten Bakterien zuvor (Aac, Pg, und $T f$ ) ist bekannt, dass $T d$ bei periimplantären Erkrankungen in erhöhter Konzentration vorliegt, dies aber in keinem signifikanten Zusammenhang mit einer Mukositis oder einer Periimplantitis steht (Persson und Renvert 2014). 
$P i$ ist vor allem bei der Periimplantitis mit $50 \%$ im Vergleich zu $17 \%$ an gesunden Implantaten erhöht und steht in einem signifikanten Zusammenhang mit dem Auftreten einer Periimplantitis $(p=0,031)$. Zur Prävalenz von $P i$ bei periimplantären Erkrankungen gibt es kaum Literatur. Was man jedoch weiß ist, dass $P i$ sehr zeitnah nach Implantatinsertion von den natürlichen Zähnen auf Implantate übergeht und eines der repräsentativsten Bakterien während der Ausbildung periimplantärer Erkrankungen zu sein scheint (Charalampakis et al. 2012; Takanashi et al. 2004). Auch Persson und Renvert (2014) beschreiben, dass Pi bei Periimplantitis in erhöhter Konzentration im Vergleich zum gesunden Implantat vorliegt. Vor allem im sehr stark erhöhten Konzentrationsbereich lässt sich in der vorliegenden Arbeit ein signifikanter Zusammenhang zur Periimplantitis herstellen $(p=0,008)$.

$P m$ ist in der vorliegenden Arbeit weitestgehend unauffällig. Zwar liegt $P m$ in leicht erhöhter Konzentration bei periimplantären Erkrankungen vor, dies lässt sich aber in keinen signifikanten Zusammenhang bringen. Auch die Verteilung der Konzentrationsbereiche lässt keinen signifikanten Zusammenhang von $P m$ und periimplantären Ekrankungen zu. Die Studienlage zu $P m$ ist sehr lückenhaft. Hier gibt es keine vergleichbare Literatur, welche sich mit der Prävalenz von $\mathrm{Pm}$ bei periimplantären Erkrankungen befasst.

Auch für $F n$ lässt sich kein signifikanter Zusammenhang zu periimplantären Erkrankungen nachweisen. Fn dient als Brückenbildner zwischen Früh- und Spätbesiedler und fördert so indirekt die Gewebedestruktion (Bolstad et al. 1996). In der vorliegenden Studie ist Fn auch bei $82 \%$ der gesunden Implantate nachweisbar. Koyanagi et al. (2013) belegt, dass Fn zwar ein sehr dominantes Bakterium ist, welches bei periimplantären Erkrankungen nochmals ansteigt, dies jedoch, wie auch in der vorliegenden Arbeit, ohne signifikanten Zusammenhang bleibt.

Da der gelbe und der grüne Komplex in der vorliegenden Arbeit in keinem signifikanten Zusammenhang zu periimplantären Erkrankungen stehen, wird auf die einzelnen Bakterien nicht näher eingegangen. Auch in der Literatur sind beide Komplexe in keinem Zusammenhang mit periimplantären Erkrankungen beschrieben. Die Literatur zu diesen beiden Komplexen bezieht sich ausschließlich auf parodontale Erkrankungen.

Obwohl das Bakterienspektrum einer Periimplantitis dem einer Parodontitis sehr ähnelt, lässt sich kein Zusammenhang dieser beiden Erkrankungen herstellen. Sowohl die Progression der einzelnen Erkrankungen, wie auch die Prävalenz der einzelnen Bakterien unterscheiden sich deutlich (Faveri et al. 2015; Lafaurie et al. 2017; Lang und Berglundh 2011). Auffällig war, dass keines der untersuchten potentiell parodontalpathogenen 
Bakterien allein als Markerkeim für periimplantäre Erkrankungen genutzt werden kann, da sie im Krankheitsbild zwar in erhöhter Konzentration auftreten, aber auch am gesunden Implantat nachweisbar sind. Zu ähnlichen Ergebnissen kamen auch Persson und Renvert (2014). Zu erwähnen bleibt allerdings, dass die Aussagen zum Signifikanzniveau bei lediglich 16 Fällen von Periimplantitis schwer einzuordnen bleiben.

Die Konsequenz der Ergebnisse ist, dass die untersuchten potentiell parodontalpathogenen Bakterien am gesunden und periimplantär erkrankten Implantat in ähnlichen Konzentrationen vorliegen. Daraus folgend erscheint der Nutzen mikrobiologischer Tests zur Differenzierung gesunder und periimplantär erkrankter Implantate fraglich.

\subsection{Risikofaktoren und deren Einfluss auf periimplantäre Erkrankungen}

Wie schon in zahlreichen anderen Studien beschrieben, steht das Rauchverhalten auch in der vorliegenden Arbeit in signifikantem Zusammenhang zur Überlebensrate bzw. zu periimplantären Erkrankungen (Bezerra Ferreira et al. 2015; Dreyer et al. 2018; Keenan und Veitz-Keenan 2016). Betrachtet man nur die 43 Implantate, welche Raucher in dieser Studie inseriert bekamen, wird deutlich, dass davon 47\% eine Mukositis und $26 \%$ eine Periimplantitis bekamen. Das bedeutet, dass annähernd jeder zweite Raucher eine Mukositis und jeder vierte eine Periimplantitis bekam. Im Vergleich zu Nichtrauchern, die in $28 \%$ der Fälle eine Mukositis und in nur $4 \%$ eine Periimplantitis bekamen, wird ein signifikanter Zusammenhang zwischen dem Auftreten einer periimplantären Erkrankung und dem Rauchverhalten ( $p^{\text {Mukositis }}=0,037, p^{\text {Perimplantitis }}=0,0002$ ) deutlich. Eine andere Studie beschreibt sogar, dass die Prävalenz von Mukositis $(8,7 \%)$ und Periimplantitis $(6,8 \%)$ bei Nichtrauchern deutlich unterhalb der des Durchschnitts periimplantärer Erkrankungen fällt (Cavalli et al. 2016). Wie auch schon in zahlreichen anderen Studien beschrieben, bestätigt sich somit der negative Einfluss des Rauchverhaltens auf periimplantäre Erkrankungen (de Araujo Nobre et al. 2014; Dreyer et al. 2018; Klokkevold und Han 2007; Sgolastra et al. 2014; Strietzel et al. 2007; Tatli et al. 2013).

Zusammenfassend kann man sagen, dass das Rauchen zwar keine absolute Kontraindikation für Implantate darstellt, das Risiko einer periimplantären Erkrankung bis hin zum Verlust des Implantats jedoch signifikant ansteigt. Diese Aussage deckt sich auch mit anderen aktuellen Studien zu diesem Thema (Bezerra Ferreira et al. 2015; Smeets et al. 2014; Stacchi et al. 2016; Takamiya et al. 2014).

Bei Patienten mit einer parodontalen Vorgeschichte lässt sich in dieser wie auch in anderen Studien kein signifikanter Zusammenhang zwischen Patienten mit und Patienten 
ohne einer vorrausgegangenen Parodontitis feststellen, insofern diese adäquat therapiert wird (Karoussis et al. 2007; Klokkevold und Han 2007; Munoz et al. 2018). 32\% der Implantate von Patienten mit einer parodontalen Vorgeschichte bekamen eine Mukositis und $13 \%$ eine Periimplantitis. Im Vergleich zur Studie von Swierkot et al. (2012), in denen Parodontitispatienten zu 56\% eine Mukositis und zu 26\% eine Periimplantitis bekamen, fällt die Prävalenz in der vorliegenden Studie geringer aus. Auch diese Patienten befanden sich in einer Parodontitistherapie, weswegen die Studie vergleichbar ist. Zwar sind die Fälle einer Periimplantitis bei Patienten mit parodontaler Vorgeschichte doppelt so hoch, dies lässt sich allerdings in keinen signifikanten Zusammenhang bringen. Andererseits stellte sich jedoch heraus, dass von den Implantaten mit einer Mukositis $60 \%$ der Patienten eine parodontale Vorerkrankung hatten. Von den Periimplantitispatienten hatten $81 \%$ eine parodontale Vorerkrankung. Somit haben drei von fünf Implantaten von Patienten mit parodontaler Vorgeschichte eine Mukositis und sogar vier von fünf Implantaten eine Periimplantitis. Andere Studien beschreiben, dass die Behandlung und demzufolge die Implantation bei Parodontitispatienten nicht kontraindiziert ist, solange eine ausreichende Infektionssteuerung und ein individualisiertes Pflegeprogramm sichergestellt wird (Anner et al. 2010; Dreyer et al. 2018; Kim und Sung 2012). Es benötigt jedoch weitere Studien, um den langfristigen Erfolg dieser Implantate zu beschreiben. Wichtig sind hierbei Langzeitstudien, da bereits bekannt ist, dass in Kurzzeitstudien kein signifikanter Zusammenhang nachweisbar ist (Schou 2008). Erste Langzeitstudien hingegen zeigen jedoch, dass das Risiko eines Implantatverlust bzw. Erkrankung des Implantats bei Parodontitispatienten langfristig signifikant ansteigt (Kim und Sung 2012).

Grundsätzlich kann man davon ausgehen, dass eine parodontale Vorgeschichte zwar keine absolute Kontraindikation darstellt, diese Patienten jedoch vorab eine adäquate PATherapie und ein regelmäßiges risikoorientiertes Recallintervall bekommen müssen, um das Risiko eines Implantatverlusts bzw. periimplantärer Erkrankungen minimieren zu können (Casado et al. 2013; Kim und Sung 2012; Marrone et al. 2013). Da das Risiko jedoch bekannt ist und demzufolge besondere Aufmerksamkeit bekommt, kann man hier durch eine individualisierte Therapie entgegenwirken. Erfolgt diese Therapie nicht, ist das Risiko einer periimplantären Erkrankung erhöht (Swierkot et al. 2012).

In dieser Studie bekamen 52 Patienten, welche eine UPT bzw. eine PZR erhielten, 93 Implantate gesetzt, wovon $32 \%$ eine Mukositis und $8 \%$ eine Periimplantitis bekamen. Die Zahlen der periimplantären Erkrankungen bei Patienten ohne therapeutische Unterstützung sind mit 33\% Mukositisfällen und 12\% Periimplantitis zwar minimal erhöht, dies lässt sich allerdings in keinen signifikanten Zusammenhang bringen. Eine andere 
Studie zeigt ähnliche Ergebnisse. Hier bekamen Patienten mit Hilfe eines regelmäßigen Recallintervalls nur halb so häufig eine Periimplantitis wie Patienten ohne regelmäßigen Recall (Costa et al. 2012). Zu ähnlichen Ergebnissen kamen auch Monje et al. (2016), die zeigen, dass vor allem die Nachsorge einen der wichtigsten Bestandteile der Implantologie einnimmt, um biologische Komplikationen zu vermeiden und somit die Langzeitprognose von Implantaten erhöht. Dennoch muss in der vorliegenden Studie berücksichtigt werden, dass die UPT bzw. PZR als alleiniger Faktor für die Compliance eines Patienten einbezogen wurde und somit unvollständig ist. Dies bestätigt auch eine Studie aus Brasilien, die beschreibt, dass die regelmäßige Teilnahme an einem Recall kein alleiniger Faktor für die Compliance eines Patienten darstellt (Ferreira et al. 2006). Hier wurde gezeigt, dass Parodontitispatienten und eine schlechte Mundhygiene negativen Einfluss auf periimplantäre Erkrankungen nehmen. Der regelmäßige Recall sagt jedoch wenig über die Mundhygiene eines Patienten aus. Außerdem wurde gezeigt, dass die Häufigkeit des Recalls keinen signifikanten Einfluss auf periimplantäre Erkrankungen nimmt (Ferreira et al. 2006). Andererseits ist auch bekannt, dass ohne eine adäquat eingestellte Mundhygiene und dementsprechend einer guten Compliance das Risiko periimplantärer Erkrankungen signifikant steigt und somit als relevanter Risikofaktor einzustufen ist (Lagervall und Jansson 2013).

$\mathrm{Zu}$ den gesicherten Risikofaktoren ist abschließend zu sagen, dass besonders die Kombination aus dem Rauchverhalten, der parodontalen Vorgeschichte und einer schlechten Mundhygiene bzw. Compliance negative Auswirkung auf den Erfolg von Implantaten hat. Schließt man andererseits diese drei Risikofaktoren aus, betrachtet man also nur Nichtraucher, Patienten ohne parodontale Vorgeschichte und Patienten mit unterstützender Therapie, bekamen davon lediglich $9 \%$ eine Mukositis und kein einziger Patient eine Periimplantitis. Dies macht die Relevanz dieser drei Faktoren letztendlich sehr deutlich.

Nachfolgend wird auf vier mögliche Einflussfaktoren näher eingegangen.

Entgegen anderer Studien, die von höheren Misserfolgsquoten im Oberkiefer sprechen (Adell et al. 1985; Esposito et al. 1998), fällt in dieser Studie auf, dass periimplantäre Erkrankungen im Unterkiefer häufiger auftraten als im Oberkiefer. An einer Mukositis erkrankten im Unterkiefer $36 \%$ der Implantate, im Oberkiefer dagegen nur 29\%. Deutlicher tritt der Unterschied bei der Periimplantitis hervor. Hier betraf es im Unterkiefer $13 \%$ und lediglich $5 \%$ der Implantate im Oberkiefer. Statistisch war hier allerdings kein signifikanter Zusammenhang zwischen dem Ober- bzw. Unterkiefer und periimplantären Ekrankungen nachweisbar $(p=0,177)$. 
Bezüglich der Position der Implantate in den entsprechenden Kiefern, das heißt Inzisivi bzw. Canini, Prämolaren oder Molaren, konnten nur die Prämolaren und die Molaren näher betrachtet und verglichen werden, da lediglich ein Implantat im Oberkiefer und ein Implantat im Unterkiefer in den Regionen der Inzisivi bzw. Canini gesetzt wurde. Den Inzisivi wird somit keine Aussagekraft zuteil. Die Auswertung ergab, dass sowohl im Oberkiefer wie auch im Unterkiefer die Implantate in den Regionen der Prämolaren häufiger eine periimplantäre Erkrankung bekamen (38\% eine Mukositis und $13 \%$ eine Periimplantitis), als Implantate in Molarenregion (29\% eine Mukositis und $8 \%$ eine Periimplantitis). Auch die Region der Implantate blieben allerdings ohne signifikanten Zusammenhang zu periimplantären Erkrankungen. Man muss jedoch beachten, dass es bisher in der wissenschaftlichen Literatur keine aussagekräftigen Studien gibt, die sich nachhaltig mit dem Thema des Einflusses der Implantatlokalisation und dessen Zusammenhang mit periimplantären Erkrankungen befassen, weshalb die vorliegenden Ergebnisse nicht in einen wissenschaftlichen Zusammenhang eingeordnet werden können.

In Bezug zum Alter zeigte sich, dass Patienten ab einem Alter von 50 Jahren ein signifikant erhöhtes Risiko einer Mukositis haben $(p<0,05)$. Das Auftreten einer Periimplantitis hingegen blieb mit steigendem Alter annähernd konstant. Die Studie von Marrone et al. (2013) zeigt zwar eine positive Korrelation zwischen Patienten ab einem Alter von 65 Jahren und einer Periimplantitis, dies ließ sich allerdings in keinen signifikanten Zusammenhang bringen. Zu einem ähnlichen Ergebnis kommt auch Dreyer et al. (2018) in seinem Review.

Das lässt sich höchstwahrscheinlich darauf zurückführen, dass Patienten mit zunehmendem Alter Mundhygieneinstruktion schwieriger befolgen können und ihre motorischen Fähigkeiten nachlassen, um einer adäquaten Mundhygiene nachzukommen. Demzufolge ist von einer erhöhten Plaqueansammlung auszugehen, welche periimplantäre Erkrankungen begünstigt (Elemek und Almas 2014; Renvert und Polyzois 2015). Weswegen nur das Mukositisaufkommen im Alter erhöht ist und nicht die Periimplantitis bleibt noch zu klären. Widersprüchlich ist hier die Altersgruppe zwischen 70 und 80 Jahren, in der 21 Implantate ausgewertet wurden. Bei diesen Patienten sinkt die Anzahl der Mukositis auf $10 \%$ bei keinem Fall einer Periimplantitis. Anzumerken ist allerdings, dass sich in dieser Gruppe kein einziger Raucher befindet. Auch zu diesem Einflussfaktor ist es schwierig, aktuelle Literatur zu finden und in einen Zusammenhang zu bringen, da sich bisher nur wenige Studien mit diesem Aspekt auseinandersetzten.

Aus dieser Arbeit geht hervor, dass Frauen doppelt so häufig an einer Periimplantitis erkrankt sind und auch der Anteil von Mukositis bei Frauen deutlich über dem der Männer 
lag. Dies lässt sich allerdings in keinen signifikanten Zusammenhang bringen. Der Einfluss des Geschlechtes zeigt in verschiedenen Studien die unterschiedlichsten Ergebnisse. So wiesen einige Studien beispielsweise nach, dass das Geschlecht keinen signifikanten Einfluss auf das Überleben des Implantates hat (Dreyer et al. 2018; Renvert et al. 2014), wohingegen eine andere Studie bestätigt, dass das weibliche Geschlecht Einfluss auf den marginalen Knochenabbau hat (Mir-Mari et al. 2012). Es fehlen jedoch auch hier ausreichend vergleichbare Studien, welche zu einem einheitlichen Ergebnis führen und den Einfluss des Geschlechts auf periimplantäre Erkrankungen untersuchen.

\section{$5.4 \quad$ Schlussfolgerung}

In dieser Studie wurden elf potentiell parodontalpathogene Bakterien bezüglich deren Zusammenhang mit dem Vorliegen periimplantärer Erkrankungen untersucht. Bis auf $\mathrm{Pi}$ $(p=0,031)$ konnte kein Bakterium in einen signifikanten Zusammenhang $z u$ periimplantären Erkrankungen gebracht werden. Zwar waren die Konzentrationen der einzelnen Bakterien am erkrankten Implantat erhöht, da sie aber auch am gesunden Implantat nachweisbar waren, ließ sich hier kein signifikanter Zusammenhang zu periimplantären Erkrankungen herstellen. Demzufolge lässt sich die Sinnhaftigkeit mikrobiologischer Tests zum Zwecke der Diagnostik bei periimplantären Erkrankungen in Frage stellen, da sie keinen diagnostischen Mehrwert hervorbringen. Hieraus lässt sich schließen, dass von einer hohen Heterogenität und Komplexität periimplantärer Biofilme auszugehen ist (Lafaurie et al. 2017). Diese erscheint deutlich komplexer, als die an Zähnen und ist nach aktuellem Kenntnisstand der Wissenschaft noch unklar (Lasserre et al. 2018). Wichtiger ist die klinische Diagnostik und eine personenbezogene Risikoanalyse, da vor allem die Kombination verschiedener Risikofaktoren negative Auswirkung auf den Erfolg der Implantate hat. Dementsprechend sollte man schon vorab bestimmte Risikofaktoren ausschließen und erst implantieren, wenn die Compliance des Patienten es zulässt. 


\section{$6 \quad$ Zusammenfassung}

Das Ziel der vorliegenden Querschnittsstudie war es, den Zusammenhang zwischen potentiell parodontopathogenen Bakterien und periimplantärer Erkrankungen wie Mukositis und Periimplantitis zu untersuchen. Außerdem wurden Risikofaktoren und Einflussfaktoren klassifiziert und deren Zusammenhang mit periimplantären Erkrankungen ausgewertet. Es sollte die Hypothese untersucht werden, dass potentiell parodontopathogene Bakterien in Zusammenhang mit dem Vorkommen periimplantärer Erkrankungen stehen.

In der vorliegenden Arbeit wurden bei 87 Patienten (51 weiblich, 36 männlich, Durchschnittsalter 57,11 \pm 10,96 Jahre) 168 Implantate des Typs Ankylos (Dentsply, Sirona, Mannheim) in teilbezahnten Kiefern und zementierter Suprakonstruktion untersucht. Der Zustand der Implantate wurde auf Grundlage der erhobenen Messwerte bewertet und in drei Kategorien eingeteilt: gesund, Mukositis und Periimplantitis. Auschlaggebend für die Beurteilung waren folgende diagnostische Kriterien: Eine Mukositis wurde definiert bei einer Taschentiefe $\geq 4 \mathrm{~mm}$ und positivem BOP. Eine Periimplantitis wurde festgelegt bei einem progressiven radiologischen Knochenverlust $\geq$ 3,5 $\mathrm{mm}$ apikal der Implantatschulter, Taschentiefen $\geq 4 \mathrm{~mm}$ und einem positiven BOP. Anschließend wurden Biofilmproben entnommen und mit Hilfe des micro-IDent ${ }^{\circledR}$ und micro-IDent ${ }^{\circledR}$ plus Tests (HAIN Lifescience, Nehren, Deutschland) das Keimspektrum potentiell parodontopathogener Bakterien mikrobiologisch ausgewertet. Folgende Bakterien wurden betrachtet: Aac, Pg, Tf, Td, Pi, Pm, Fn, Cr, En, Ec und Cs. Die semiquantitative Bestimmung der Bakterien wurde dabei subjektiv visuell über Teststreifen nach der PCR durchgeführt.

Von den 168 untersuchten Implantaten befanden sich zum Zeitpunkt der Nachuntersuchung alle in situ. 33\% $(n=55)$ hatten eine Mukositis und 10\% $(n=16)$ eine Periimplantitis. Die mikrobiologischen Untersuchungen ergaben, dass einzig $\mathrm{Pi}$ in signifikantem Zusammenhang zu periimplantären Ekrankungen stand ( $p=0,031)$. Im sehr stark erhöhten Konzentrationsbereich ließ sich außerdem ein signifikanter Zusammenhang von Aac und einer Periimplantitis herstellen. Andere Bakterien ließen sich zwar prozentual erhöht nachweisen, hier konnte jedoch kein signifikanter Zusammenhang zu periimplantären Erkrankungen hergestellt werden. Zusätzlich konnte gezeigt werden, dass das Rauchverhalten einen signifikanten Unterschied bei periimplantär erkrankten Implantaten aufweist $\left(p^{\text {Mukositis }}=0,037, p^{\text {Perimplantitis }}=0,0002\right)$. Ein zunehmendes Alter steht $\left(p^{51-60}=0,02, p^{61-70}=0,034, p^{71-80}=0,013\right)$ in signifikantem Zusammenhang mit einer Mukositis, nicht aber mit einer Periimplantitis. 
Zusammenfassung

Dementsprechend ist die Sinnhaftigkeit mikrobiologischer Tests bei periimplantären Erkrankungen in Frage zu stellen. Die klinische Diagnostik bleibt zur Feststellung periimplantärer Erkrankungen das Standardverfahren. 


\section{$7 \quad$ Abstract}

The aim of this cross-sectional study was to examine the relationship between potentially periodontopathogenic bacteria and peri-implant diseases, such as mucositis and periimplantitis. In addition, risk factors and influencing factors were classified and their relationship with peri-implant diseases was evaluated. The hypothesis was that potentially periodontopathogenic bacteria are associated with the development of peri-implant diseases.

In the present study, 168 implants of the type Ankylos (Dentsply Sirona, Mannheim) in partially-toothed jaws and cemented supraconstruction were studied in 87 patients (51 female, 36 male, mean age $57.11 \pm 10.96$ years). The condition of the implants was evaluated on the basis of the measured values and divided into three categories: healthy, mucositis and peri-implantitis. The following diagnostic criteria were decisive for the assessment: a mucositis was defined with a pocket depth $\geq 4 \mathrm{~mm}$ and positive BOP. Periimplantitis was diagnosed with a progressive radiological bone loss $\geq 3.5 \mathrm{~mm}$ apical of the implant shoulder, pocket depth $\geq 4 \mathrm{~mm}$ and a positive BOP. Subsequently, biofilm samples were removed and the microbial spectrum of periodontopathogens was evaluated by using micro-IDent ${ }^{\circledR}$ and micro-IDent $₫$ plus tests (HAIN Lifescience, Nehren, Germany). Following bacteria were considered: $\mathrm{Aac}, \mathrm{Pg}, \mathrm{Tf}, \mathrm{Td}, \mathrm{Pi}, \mathrm{Pm}, \mathrm{Fn}, \mathrm{Cr}$, En, Ec and Cs. The semiquantitative determination of the bacteria was performed subjectively visually via test strips after the PCR.

Of the 168 examined implants, all were in situ at the time of the follow-up. 33\% $(n=55)$ had a mucositis and $10 \%(n=16)$ a peri-implantitis. Microbiological studies have shown that only $P i$ is significantly associated with peri-implant diseases $(p=0.031)$. In the strongly increased concentration range, a significant association of Aac and periimplantitis could also be found. Other bacteria could be detected as a percentage increase, but no significant correlation could be established with peri-implant diseases. In addition, smoking behavior showed a significant difference in peri-implant diseases $\left(p^{\text {mucositis }}=0.037, \quad p^{\text {perimplantitis }}=0.0002\right)$. Increasing age $\left(p^{51-60}=0.02, \quad p^{61-70}=0.034\right.$, $\left.p^{71-80}=0.013\right)$ is significantly associated with mucositis, but not with peri-implantitis.

Accordingly, the usefulness of microbiological tests in peri-implant diseases is questionable. Clinical diagnostics remains the gold standard for the detection of periimplant diseases. 
Anhang

\section{$8 \quad$ Anhang}

\subsection{Tabellenverzeichnis}

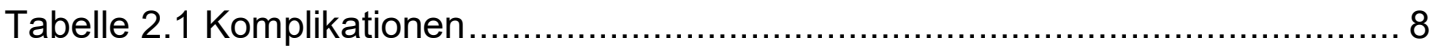

Tabelle 2.2 Inzidenz und Prävalenz von Mukositis / Periimplantitis ......................... 9

Tabelle 2.3 Parodontitistypische / nicht parodontitistypische Bakterien................. 17

Tabelle 2.4 Klinisch-diagnostische Kriterien periimplantärer Erkrankungen ........... 18

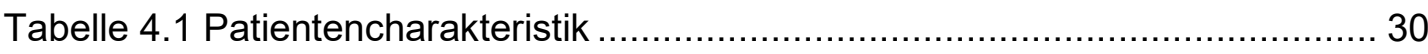

Tabelle 4.2 Positionierung der Implantate nach FDI-Schema ............................... 31

Tabelle 4.3 Verteilung der Prävalenzen der Bakterien ....................................... 31

Tabelle 4.4 Verteilung der Konzentrationen für Aac .......................................... 32

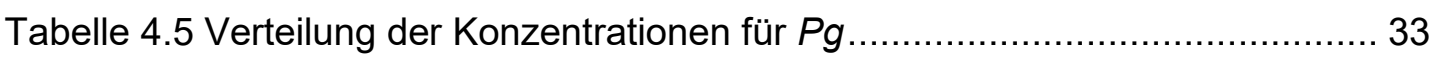

Tabelle 4.6 Verteilung der Konzentration für Tf................................................ 34

Tabelle 4.7 Verteilung der Konzentration für $T d$.............................................. 34

Tabelle 4.8 Verteilung der Konzentration für $\mathrm{Pi}$............................................... 35

Tabelle 4.9 Verteilung der Konzentration für $\mathrm{Pm}$............................................. 36

Tabelle 4.10 Verteilung der Konzentration für $\mathrm{Cr}$.......................................... 37

Tabelle 4.11 Verteilung der Konzentration für En ............................................... 37

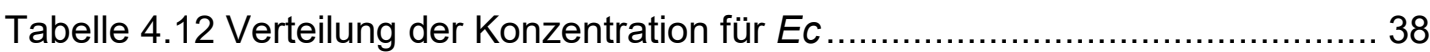

Tabelle 4.13 Verteilung der Konzentration für Cs.......................................... 38

Tabelle 4.14 Signifikanzniveau bezogen auf das Geschlecht............................ 42

Tabelle 4.15 p-Werte in den Altersgruppen...................................................... 43

Tabelle 4.16 Verteilung periimplantärer Erkrankungen bezogen auf die

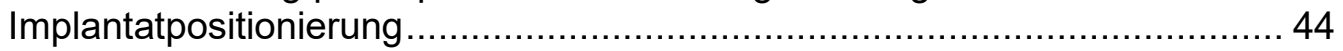




\subsection{Abbildungsverzeichnis}

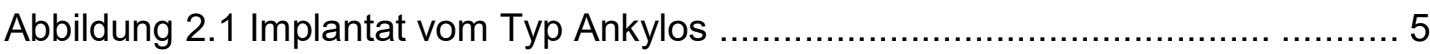

Abbildung 2.2 Ätiologisches Modell der Parodontitis ......................................... 10

Abbildung 2.3 Pathogenität der Bakterien ...................................................... 13

Abbildung 2.4 Darstellung der Bakterien in Komplexen (Socransky et al. 1998) .... 14

Abbildung 4.1 Verteilung der Prävalenz von Aggregatibacter actinomycetemcomitans ................................................................ 32

Abbildung 4.2 Verteilung der Prävalenz der Bakterien des roten Komplexes ......... 33

Abbildung 4.3 Verteilung der Prävalenz der Bakterien des orangenen Komplexes 35

Abbildung 4.4 Verteilung der Prävalenz der Bakterien des gelben Komplexes ...... 36

Abbildung 4.5 Verteilung der Prävalenz der Bakterien des grünen Komplexes ...... 38

Abbildung 4.6 Prävalenz von Mukositis / Periimplantitis bezogen auf die gesicherten

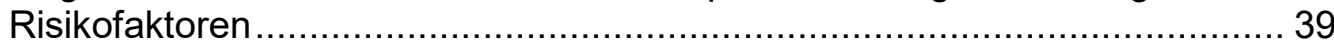

Abbildung 4.7 Prävalenz periimplantärer Erkrankungen an Implantaten von Rauchern und Nichtrauchern

Abbildung 4.8 Prävalenz periimplantärer Erkrankungen an Implantaten mit und ohne UPT/PZR

Abbildung 4.9 Prävalenz periimplantärer Erkrankungen an Implantaten von Patienten mit und ohne parodontaler Vorerkrankung

Abbildung 4.10 Mukositis und Periimplantitis bezogen auf das Patientenalter 42

Abbildung 4.11 Prävalenz von Mukositis und Periimplantitis im Ober- und Unterkiefer 


\section{$9 \quad$ Literaturverzeichnis}

Abadzhiev M, Balcheva M (2009): Diabetes and implant treatment: A case report. Biotechnol Biotechnol Equip 23, 1388-1390

Adell R, Lekholm U, Branemark PI, Lindhe J, Rockler B, Eriksson B, Lindvall AM, Yoneyama T, Sbordone L (1985): Marginal tissue reactions at osseointegrated titanium fixtures. Swed Dent J Suppl 28, 175-181

Ainamo J, Bay I (1975): Problems and proposals for recording gingivitis and plaque. Int Dent J $\underline{25}, 229-235$

Albertini M, Lopez-Cerero L, O'Sullivan MG, Chereguini CF, Ballesta S, Rios V, HerreroCliment M, Bullon P (2015): Assessment of periodontal and opportunistic flora in patients with peri-implantitis. Clin Oral Implants Res $\underline{26}$, 937-941

Albrektsson T, Donos N, Working G (2012): Implant survival and complications. The third eao consensus conference 2012. Clin Oral Implants Res 23 Suppl 6, 63-65

Altuna P, Lucas-Taule E, Gargallo-Albiol J, Figueras-Alvarez O, Hernandez-Alfaro F, Nart $J$ (2016): Clinical evidence on titanium-zirconium dental implants: A systematic review and meta-analysis. Int J Oral Maxillofac Surg 노, 842-850

Andreiotelli M, Wenz HJ, Kohal RJ (2009): Are ceramic implants a viable alternative to titanium implants? A systematic literature review. Clin Oral Implants Res 20 Suppl 4, 3247

Anner R, Grossmann Y, Anner Y, Levin L (2010): Smoking, diabetes mellitus, periodontitis, and supportive periodontal treatment as factors associated with dental implant survival: A long-term retrospective evaluation of patients followed for up to 10 years. Implant Dent $\underline{19}$, 57-64

Ata-Ali J, Candel-Marti ME, Flichy-Fernandez AJ, Penarrocha-Oltra D, Balaguer-Martinez JF, Penarrocha Diago M (2011): Peri-implantitis: Associated microbiota and treatment. Med Oral Patol Oral Cir Bucal 16, e937-943

Ata-Ali J, Flichy-Fernandez AJ, Ata-Ali F, Penarrocha-Diago M, Penarrocha-Diago M (2013): Clinical, microbiologic, and host response characteristics in patients with periimplant mucositis. Int J Oral Maxillofac Implants $\underline{28}, 883-890$

Augthun M, Conrads G (1997): Microbial findings of deep peri-implant bone defects. Int J Oral Maxillofac Implants $\underline{12}, 106-112$

Avila G, Galindo-Moreno P, Soehren S, Misch CE, Morelli T, Wang HL (2009): A novel decision-making process for tooth retention or extraction. J Periodontol $\underline{80}, 476-491$ 
Becker W, Becker BE, Newman MG, Nyman S (1990): Clinical and microbiologic findings that may contribute to dental implant failure. Int J Oral Maxillofac Implants $\underline{5}$, 31-38

Belibasakis GN (2014): Microbiological and immuno-pathological aspects of peri-implant diseases. Arch Oral Biol $\underline{59}$, 66-72

Berglundh T, Lindhe J, Jonsson K, Ericsson I (1994): The topography of the vascular systems in the periodontal and peri-implant tissues in the dog. J Clin Periodontol 21, 189193

Berglundh T, Armitage G, Araujo MG, Avila-Ortiz G, Blanco J, Camargo PM, Chen S, Cochran D, Derks J, Figuero E, et al. (2018): Peri-implant diseases and conditions: Consensus report of workgroup 4 of the 2017 world workshop on the classification of periodontal and peri-implant diseases and conditions. J Periodontol 89 Suppl 1, S313S318

Bezerra Ferreira JD, Rodrigues JA, Piattelli A, lezzi G, Gehrke SA, Shibli JA (2016): The effect of cigarette smoking on early osseointegration of dental implants: A prospective controlled study. Clin Oral Implants Res 27, 1123-1128

Bolstad Al, Jensen HB, Bakken V (1996): Taxonomy, biology, and periodontal aspects of fusobacterium nucleatum. Clin Microbiol Rev $\underline{9}, 55-71$

Buser D, Janner SF, Wittneben JG, Bragger U, Ramseier CA, Salvi GE (2012): 10-year survival and success rates of 511 titanium implants with a sandblasted and acid-etched surface: A retrospective study in 303 partially edentulous patients. Clin Implant Dent Relat $\operatorname{Res} \underline{14}, 839-851$

Calderon PS, Dantas PM, Montenegro SC, Carreiro AF, Oliveira AG, Dantas EM, Gurgel BC (2014): Technical complications with implant-supported dental prostheses. J Oral Sci $\underline{56}, 179-184$

Casado PL, Otazu IB, Balduino A, de Mello W, Barboza EP, Duarte ME (2011):

Identification of periodontal pathogens in healthy periimplant sites. Implant Dent $\underline{20}$, 226235

Casado PL, Pereira MC, Duarte ME, Granjeiro JM (2013): History of chronic periodontitis is a high risk indicator for peri-implant disease. Braz Dent J 24, $136-141$

Cavalli N, Austoni C, Corbella S, Taschieri S, Barbaro B, Azzola F, Francetti L (2016):

Retrospective analysis of the prevalence of peri-implant diseases in non-smoking patients rehabilitated with a fixed full-arch restoration, supported by two mesial axial and two distal tilted implants. Minerva Stomatol $\underline{65}, 164-175$

Charalampakis G, Belibasakis GN (2015): Microbiome of peri-implant infections: Lessons from conventional, molecular and metagenomic analyses. Virulence $\underline{6}, 183-187$ 
Charalampakis G, Leonhardt A, Rabe P, Dahlen G (2012): Clinical and microbiological characteristics of peri-implantitis cases: A retrospective multicentre study. Clin Oral Implants Res $\underline{23}$, 1045-1054

Cho-Yan Lee J, Mattheos N, Nixon KC, Ivanovski S (2012): Residual periodontal pockets are a risk indicator for peri-implantitis in patients treated for periodontitis. Clin Oral Implants Res $\underline{23}, 325-333$

Chrcanovic BR, Albrektsson T, Wennerberg A (2015): Smoking and dental implants: A systematic review and meta-analysis. J Dent $\underline{43}, 487-498$

Chrcanovic BR, Albrektsson T, Wennerberg A (2016): Dental implants in patients receiving chemotherapy: A meta-analysis. Implant Dent 25, 261-271

Chrcanovic BR, Kisch J, Albrektsson T, Wennerberg A (2017): Bruxism and dental implant treatment complications: A retrospective comparative study of 98 bruxer patients and a matched group. Clin Oral Implants Res $\underline{28}$, e1-e9

Cortelli SC, Cortelli JR, Romeiro RL, Costa FO, Aquino DR, Orzechowski PR, Araujo VC, Duarte PM (2013): Frequency of periodontal pathogens in equivalent peri-implant and periodontal clinical statuses. Arch Oral Biol $\underline{58}, 67-74$

Costa FO, Takenaka-Martinez S, Cota LO, Ferreira SD, Silva GL, Costa JE (2012): Periimplant disease in subjects with and without preventive maintenance: A 5-year follow-up. $\mathrm{J}$ Clin Periodontol $\underline{39}, 173-181$

Daubert DM, Weinstein BF, Bordin S, Leroux BG, Flemming TF (2015): Prevalence and predictive factors for peri-implant disease and implant failure: A cross-sectional analysis. $\mathrm{J}$ Periodontol $\underline{86}, 337-347$

Daugela P, Cicciu M, Saulacic N (2016): Surgical regenerative treatments for periimplantitis: Meta-analysis of recent findings in a systematic literature review. J Oral Maxillofac Res $\underline{7}$, e15

de Araujo Nobre M, Malo P, Antune E (2014): Influence of systemic conditions on the incidence of periimplant pathology: A case-control study. Implant Dent $\underline{23}, 305-310$

De Boever AL, De Boever JA (2006): Early colonization of non-submerged dental implants in patients with a history of advanced aggressive periodontitis. Clin Oral Implants Res $\underline{17}$, 8-17

de-Freitas NR, Lima LB, de-Moura MB, Veloso-Guedes CC, Simamoto-Junior PC, deMagalhaes D (2016): Bisphosphonate treatment and dental implants: A systematic review. Med Oral Patol Oral Cir Bucal 21, e644-651

Degidi M, Nardi D, Piattelli A (2012): 10-year follow-up of immediately loaded implants 
with tiunite porous anodized surface. Clin Implant Dent Relat Res $\underline{14}$, 828-838

Derks J, Tomasi C (2015): Peri-implant health and disease. A systematic review of current epidemiology. J Clin Periodontol 42 Suppl 16, S158-171

Diaz R, Ghofaily LA, Patel J, Balashova NV, Freitas AC, Labib I, Kachlany SC (2006): Characterization of leukotoxin from a clinical strain of actinobacillus actinomycetemcomitans. Microb Pathog $\underline{40}$, 48-55

Dierens M, Vandeweghe S, Kisch J, Nilner K, De Bruyn H (2012): Long-term follow-up of turned single implants placed in periodontally healthy patients after 16-22 years:

Radiographic and peri-implant outcome. Clin Oral Implants Res $\underline{23}, 197-204$

Dreyer H, Grischke J, Tiede C, Eberhard J, Schweitzer A, Toikkanen SE, Glockner S, Krause G, Stiesch M (2018): Epidemiology and risk factors of peri-implantitis: A systematic review. J Periodontal Res $\underline{53}, 657-681$

Duque AD, Aristizabal AG, Londono S, Castro L, Alvarez LG (2016): Prevalence of periimplant disease on platform switching implants: A cross-sectional pilot study. Braz Oral $\operatorname{Res} \underline{30}$

Elemek E, Almas K (2014): Peri-implantitis: Etiology, diagnosis and treatment: An update. N Y State Dent J $\underline{80}, 26-32$

Ericsson I, Berglundh T, Marinello C, Liljenberg B, Lindhe J (1992): Long-standing plaque and gingivitis at implants and teeth in the dog. Clin Oral Implants Res $\underline{3}, 99-103$

Ertugrul AS, Arslan U, Dursun R, Hakki SS (2013): Periodontopathogen profile of healthy and oral lichen planus patients with gingivitis or periodontitis. Int J Oral Sci $\underline{5}, 92-97$

Esposito M, Hirsch JM, Lekholm U, Thomsen P (1998): Biological factors contributing to failures of osseointegrated oral implants. (ii). Etiopathogenesis. Eur J Oral Sci 106, 721764

Faghri J, Moghim S, Abed AM, Rezaei F, Chalabi M (2007): Prevalence of porphyromonas gingivalis and bacteroides forsythus in chronic periodontitis by multiplex pcr. Pak J Biol Sci 10, 4123-4127

Faveri M, Figueiredo LC, Shibli JA, Perez-Chaparro PJ, Feres M (2015): Microbiological diversity of peri-implantitis biofilms. Adv Exp Med Biol $\underline{830}$, 85-96

Ferreira SD, Silva GL, Cortelli JR, Costa JE, Costa FO (2006): Prevalence and risk variables for peri-implant disease in brazilian subjects. J Clin Periodontol $\underline{33}$, 929-935

Fischer K, Stenberg T (2013): Prospective 10-year cohort study based on a randomized, controlled trial (rct) on implant-supported full-arch maxillary prostheses. Part ii: Prosthetic 
outcomes and maintenance. Clin Implant Dent Relat Res $\underline{15}$, 498-508

Galassi F, Kaman WE, Anssari Moin D, van der Horst J, Wismeijer D, Crielaard W, Laine ML, Veerman EC, Bikker FJ, Loos BG (2012): Comparing culture, real-time pcr and fluorescence resonance energy transfer technology for detection of porphyromonas gingivalis in patients with or without peri-implant infections. J Periodontal Res $\underline{47}, 616-625$

Glauser R, Zembic A, Ruhstaller P, Windisch S (2007): Five-year results of implants with an oxidized surface placed predominantly in soft quality bone and subjected to immediate occlusal loading. J Prosthet Dent $\underline{97}$, S59-68

Goh MS, Hong EJ, Chang M (2017): Prevalence and risk indicators of peri-implantitis in korean patients with a history of periodontal disease: A cross-sectional study. J Periodontal Implant Sci 47, 240-250

Gotfredsen K (2012): A 10-year prospective study of single tooth implants placed in the anterior maxilla. Clin Implant Dent Relat Res $\underline{14}$, 80-87

Granstrom G, Tjellstrom A, Branemark PI (1999): Osseointegrated implants in irradiated bone: A case-controlled study using adjunctive hyperbaric oxygen therapy. J Oral Maxillofac Surg $\underline{57}, 493-499$

Haffajee AD, Yaskell T, Torresyap G, Teles R, Socransky SS (2009): Comparison between polymerase chain reaction-based and checkerboard DNA hybridization techniques for microbial assessment of subgingival plaque samples. J Clin Periodontol $\underline{36}$, 642-649

Hardt CR, Grondahl K, Lekholm U, Wennstrom JL (2002): Outcome of implant therapy in relation to experienced loss of periodontal bone support: A retrospective 5- year study. Clin Oral Implants Res $\underline{13}$, 488-494

Heitz-Mayfield LJ (2008): Peri-implant diseases: Diagnosis and risk indicators. J Clin Periodontol $\underline{35}, 292-304$

Hultin M, Gustafsson A, Hallstrom H, Johansson LA, Ekfeldt A, Klinge B (2002): Microbiological findings and host response in patients with peri-implantitis. Clin Oral Implants Res $\underline{13}$, 349-358

Jemt T (2016): Single-implant survival: More than 30 years of clinical experience. Int J Prosthodont $\underline{29}, 551-558$

John V, Lane B, Chu G (2013): Complications associated with the placement and restoration of dental implants. J Indiana Dent Assoc 92, 46-53; quiz 55

Johnson GK, Hill M (2004): Cigarette smoking and the periodontal patient. J Periodontol $\underline{75}, 196-209$ 
Jung RE, Pjetursson BE, Glauser R, Zembic A, Zwahlen M, Lang NP (2008): A systematic review of the 5-year survival and complication rates of implant-supported single crowns.

Clin Oral Implants Res $\underline{19}, 119-130$

Jung RE, Zembic A, Pjetursson BE, Zwahlen M, Thoma DS (2012): Systematic review of the survival rate and the incidence of biological, technical, and aesthetic complications of single crowns on implants reported in longitudinal studies with a mean follow-up of 5 years. Clin Oral Implants Res $\underline{23 \text { Suppl } 6}, 2-21$

Kalykakis GK, Mojon P, Nisengard R, Spiekermann H, Zafiropoulos GG (1998): Clinical and microbial findings on osseo-integrated implants; comparisons between partially dentate and edentulous subjects. Eur J Prosthodont Restor Dent $\underline{6}$, 155-159

Karbach J, Callaway A, Kwon YD, d'Hoedt B, Al-Nawas B (2009): Comparison of five parameters as risk factors for peri-mucositis. Int J Oral Maxillofac Implants $\underline{24}$, 491-496

Karoussis IK, Salvi GE, Heitz-Mayfield LJ, Bragger U, Hammerle CH, Lang NP (2003): Long-term implant prognosis in patients with and without a history of chronic periodontitis: A 10-year prospective cohort study of the iti dental implant system. Clin Oral Implants Res 14, 329-339

Karoussis IK, Muller S, Salvi GE, Heitz-Mayfield LJ, Bragger U, Lang NP (2004):

Association between periodontal and peri-implant conditions: A 10-year prospective study. Clin Oral Implants Res $\underline{15}, 1-7$

Karoussis IK, Kotsovilis S, Fourmousis I (2007): A comprehensive and critical review of dental implant prognosis in periodontally compromised partially edentulous patients. Clin Oral Implants Res $\underline{18}$, 669-679

Keenan JR, Veitz-Keenan A (2016): The impact of smoking on failure rates, postoperative infection and marginal bone loss of dental implants. Evid Based Dent 17, 4-5

Koldsland OC, Scheie AA, Aass AM (2010): Prevalence of peri-implantitis related to severity of the disease with different degrees of bone loss. J Periodontol 81, 231-238

Kim KK, Sung HM (2012): Outcomes of dental implant treatment in patients with generalized aggressive periodontitis: A systematic review. J Adv Prosthodont $\underline{4}, 210-217$

Kim SG, Hong JY, Shin SI, Moon JH, Lee JY, Herr Y (2016): Prevalence of porphyromonas gingivalis fima genotypes in the peri-implant sulcus of koreans assessed using a new primer. J Periodontal Implant Sci $\underline{46}, 35-45$

Klinge B, Klinge A, Bertl K, Stavropoulos A (2018): Peri-implant diseases. Eur J Oral Sci 126 Suppl 1, 88-94

Klokkevold PR, Han TJ (2007): How do smoking, diabetes, and periodontitis affect outcomes of implant treatment? Int J Oral Maxillofac Implants 22 Suppl, 173-202 
Kotsovilis S, Karoussis IK, Trianti M, Fourmousis I (2008): Therapy of peri-implantitis: A systematic review. J Clin Periodontol $\underline{35}$, 621-629

Koyanagi T, Sakamoto M, Takeuchi Y, Maruyama N, Ohkuma M, Izumi Y (2013):

Comprehensive microbiological findings in peri-implantitis and periodontitis. J Clin

Periodontol $\underline{40}$, 218-226

Kremer BH, van Steenbergen TJ (2000): Peptostreptococcus micros coaggregates with fusobacterium nucleatum and non-encapsulated porphyromonas gingivalis. FEMS Microbiol Lett 182, 57-62

Lafaurie GI, Sabogal MA, Castillo DM, Rincon MV, Gomez LA, Lesmes YA, Chambrone L (2017): Microbiome and microbial biofilm profiles of peri-implantitis: A systematic review. J Periodontol $\underline{88}, 1066-1089$

Lagervall M, Jansson LE (2013): Treatment outcome in patients with peri-implantitis in a periodontal clinic: A retrospective study. J Periodontol $\underline{84}, 1365-1373$

Lang NP, Tonetti MS (2003): Periodontal risk assessment (pra) for patients in supportive periodontal therapy (spt). Oral Health Prev Dent 1, 7-16

Lang NP, Wilson TG, Corbet EF (2000): Biological complications with dental implants: Their prevention, diagnosis and treatment. Clin Oral Implants Res 11 Suppl 1, 146-155

Lang NP, Berglundh T (2011): Periimplant diseases: Where are we now?--consensus of the seventh european workshop on periodontology. J Clin Periodontol 38 Suppl 11, 178181

Lang NP, Bragger U, Walther D, Beamer B, Kornman KS (1993): Ligature-induced periimplant infection in cynomolgus monkeys. I. Clinical and radiographic findings. Clin Oral Implants Res $\underline{4}, 2-11$

Lasserre FJ, Brecx MC, Selena T (2018): Oral microbes, biofilms and their role in periodontal and peri-implant diseases. Materials (Basel) $\underline{11}$

Lee CT, Huang YW, Zhu L, Weltman R (2017): Prevalences of peri-implantitis and periimplant mucositis: Systematic review and meta-analysis. J Dent $\underline{62}, 1-12$

Leonhardt A, Berglundh T, Ericsson I, Dahlen G (1992): Putative periodontal pathogens on titanium implants and teeth in experimental gingivitis and periodontitis in beagle dogs. Clin Oral Implants Res $\underline{3}, 112-119$

Liaw K, Delfini RH, Abrahams JJ (2015): Dental implant complications. Semin Ultrasound CT MR $\underline{36}, 427-433$ 
Lin Y, Li JH, Qiu LX, Di P, Hu XL, Wang X (2006): [clinical retrospective study of 10 years implant results]. Zhonghua Kou Qiang Yi Xue Za Zhi 41, 131-135

Linkevicius T, Puisys A, Vindasiute E, Linkeviciene L, Apse P (2013): Does residual cement around implant-supported restorations cause peri-implant disease? A retrospective case analysis. Clin Oral Implants Res $\underline{24}$, 1179-1184

Marrone A, Lasserre J, Bercy P, Brecx MC (2013): Prevalence and risk factors for periimplant disease in belgian adults. Clin Oral Implants Res $\underline{24}$, 934-940

Mir-Mari J, Mir-Orfila P, Valmaseda-Castellon E, Gay-Escoda C (2012): Long-term marginal bone loss in 217 machined-surface implants placed in 68 patients with 5 to 9 years of follow-up: A retrospective study. Int J Oral Maxillofac Implants 27, 1163-1169

Mombelli A (1997): Etiology, diagnosis, and treatment considerations in peri-implantitis. Curr Opin Periodontol $\underline{4}, 127-136$

Mombelli A, Decaillet $F$ (2011): The characteristics of biofilms in peri-implant disease. J Clin Periodontol 38 Suppl 11, 203-213

Mombelli A, Lang NP (1998): The diagnosis and treatment of peri-implantitis. Periodontol $2000 \underline{17}, 63-76$

Mombelli A, Muller N, Cionca N (2012): The epidemiology of peri-implantitis. Clin Oral Implants Res $\underline{23 \text { Suppl } 6}, 67-76$

Mombelli A, van Oosten MA, Schurch E Jr, Land NP (1987): The microbiota associated with successful or failing osseointegrated titanium implants. Oral Microbiol Immunol $\underline{2}$, 145-151

Monje A, Aranda L, Diaz KT, Alarcon MA, Bagramian RA, Wang HL, Catena A (2016): Impact of maintenance therapy for the prevention of peri-implant diseases: A systematic review and meta-analysis. J Dent Res $\underline{95}$, 372-379

Moore WE, Moore LV (1994): The bacteria of periodontal diseases. Periodontol $2000 \underline{5}$, 66-77

Munoz V, Duque A, Giraldo A, Manrique R (2018): Prevalence of peri-implant disease according to periodontal probing depth and bleeding on probing: A systematic review and meta-analysis. Int J Oral Maxillofac Implants $\underline{33}$, e89-e105

Naujokat H, Kunzendorf B, Wiltfang J (2016): Dental implants and diabetes mellitus-a systematic review. Int J Implant Dent 2, 5

O'Leary TJ, Drake RB, Naylor JE (1972): The plaque control record. J Periodontol $\underline{43}$, 38 
Olsen I, Yilmaz O (2016): Modulation of inflammasome activity by porphyromonas gingivalis in periodontitis and associated systemic diseases. J Oral Microbiol $\underline{8}, 30385$

Ong CT, Ivanovski S, Needleman IG, Retzepi M, Moles DR, Tonetti MS, Donos N (2008): Systematic review of implant outcomes in treated periodontitis subjects. J Clin Periodontol $\underline{35}, 438-462$

Orth RK, O'Brien-Simpson NM, Dashper SG, Reynolds EC (2011): Synergistic virulence of porphyromonas gingivalis and treponema denticola in a murine periodontitis model. Mol Oral Microbiol 26, 229-240

Ouanounou A, Hassanpour S, Glogauer M (2016): The influence of systemic medications on osseointegration of dental implants. J Can Dent Assoc 82, g7

Ozkurt Z, Kazazoglu E (2011): Zirconia dental implants: A literature review. J Oral Implantol $\underline{37}, 367-376$

Padial-Molina M, Lopez-Martinez J, O'Valle F, Galindo-Moreno P (2016): Microbial profiles and detection techniques in peri-implant diseases: A systematic review. J Oral Maxillofac Res $\underline{7}$, e10

Papi P, Di Carlo S, Mencio F, Rosella D, De Angelis F, Pompa G (2017): Dental implants placed in patients with mechanical risk factors: A long-term follow-up retrospective study. J Int Soc Prev Community Dent $\underline{7}$, S48-S51

Park JH, Kim YS, Ryu JJ, Shin SW, Lee JY (2017): Cumulative survival rate and associated risk factors of implantium implants: A 10-year retrospective clinical study. J Adv Prosthodont $\underline{9}, 195-199$

Persson GR, Renvert S (2014): Cluster of bacteria associated with peri-implantitis. Clin Implant Dent Relat Res $\underline{16}$, 783-793

Pesce P, Canullo L, Grusovin MG, de Bruyn H, Cosyn J, Pera P (2015): Systematic review of some prosthetic risk factors for periimplantitis. J Prosthet Dent $\underline{114}, 346-350$

Pjetursson BE, Heimisdottir K (2018): Dental implants - are they better than natural teeth? Eur J Oral Sci 126 Suppl 1, 81-87

Pjetursson BE, Tan WC, Tan K, Bragger U, Zwahlen M, Lang NP (2008): A systematic review of the survival and complication rates of resin-bonded bridges after an observation period of at least 5 years. Clin Oral Implants Res $\underline{19}, 131-141$

Pjetursson BE, Thoma D, Jung R, Zwahlen M, Zembic A (2012): A systematic review of the survival and complication rates of implant-supported fixed dental prostheses (fdps) after a mean observation period of at least 5 years. Clin Oral Implants Res $\underline{23 \text { Suppl } 6}$, 2238 
Pjetursson BE, Asgeirsson AG, Zwahlen M, Sailor I (2014): Improvements in implant dentistry over the last decade: Comparison of survival and complication rates in older and newer publications. Int J Oarl Maxillofac Implants 29 Suppl, 308-324

Pontoriero R, Tonelli MP, Carnevale G, Mombelli A, Nyman SR, Lang NP (1994): Experimentally induced peri-implant mucositis. A clinical study in humans. Clin Oral Implants Res $\underline{5}, 254-259$

Puig-Silla M, Dasi-Fernandez F, Montiel-Company JM, Almerich-Silla JM (2012): Prevalence of fima genotypes of porphyromonas gingivalis and other periodontal bacteria in a spanish population with chronic periodontitis. Med Oral Patol Oral Cir Bucal $\underline{17}$, e1047-1053

Quaranta A, Lim ZW, Tang J, Perrotti V, Leichter J (2017): The impact of residual subgingival cement on biological complications around dental implants: A systematic review. Implant Dent $\underline{26}$, 465-474

Ramanauskaite A, Daugela P, Faria de Almeida R, Saulacic N (2016): Surgical nonregenerative treatments for peri-implantitis: A systematic review. J Oral Maxillofac Res $\underline{7}$, e14

Rams TE, Feik D, Listgarten MA, Slots J (1992): Peptostreptococcus micros in human periodontitis. Oral Microbiol Immunol $\underline{7}, 1-6$

Rams TE, Link CC, Jr. (1983): Microbiology of failing dental implants in humans: Electron microscopic observations. J Oral Implantol 11, 93-100

Renvert S, Aghazadeh A, Hallstrom H, Persson GR (2014): Factors related to periimplantitis - a retrospective study. Clin Oral Implants Res $\underline{25}$, 522-529

Renvert S, Persson GR, Pirih FQ, Camargo PM (2018): Peri-implant health, peri-implant mucositis, and peri-implantitis: Case definitions and diagnostic considerations. J Periodontol 89 Suppl 1, S304-S312

Renvert S, Polyzois I (2015): Risk indicators for peri-implant mucositis: A systematic literature review. J Clin Periodontol 42 Suppl 16, S172-186

Renvert S, Quirynen M (2015): Risk indicators for peri-implantitis. A narrative review. Clin Oral Implants Res 26 Suppl 11, 15-44

Rinke S, Ohl S, Ziebolz D, Lange K, Eickholz P (2011): Prevalence of periimplant disease in partially edentulous patients: A practice-based cross-sectional study. Clin Oral Implants Res $\underline{22}, 826-833$

Roccuzzo M, Bonino F, Aglietta M, Dalmasso P (2012): Ten-year results of a three arms prospective cohort study on implants in periodontally compromised patients. Part 2:

Clinical results. Clin Oral Implants Res $\underline{23}$, 389-395 
Roccuzzo M, Layton DM, Roccuzzo A, Heitz-Mayfield LJ (2018): Clinical outcomes of peri-implantitis treatment and supportive care: A systematic review. Clin Oral Implants Res 29 Suppl 16, 331-350

Rodrigo D, Martin C, Sanz M (2012): Biological complications and peri-implant clinical and radiographic changes at immediately placed dental implants. A prospective 5-year cohort study. Clin Oral Implants Res $\underline{23}, 1224-1231$

Romeo E, Storelli S (2012): Systematic review of the survival rate and the biological, technical, and aesthetic complications of fixed dental prostheses with cantilevers on implants reported in longitudinal studies with a mean of 5 years follow-up. Clin Oral Implants Res 23 Suppl 6, 39-49

Roos-Jansaker AM, Renvert H, Lindahl C, Renvert S (2006): Nine- to fourteen-year follow-up of implant treatment. Part iii: Factors associated with peri-implant lesions. J Clin Periodontol $\underline{33}, 296-301$

Sailer I, Muhlemann S, Zwahlen M, Hammerle CH, Schneider D (2012): Cemented and screw-retained implant reconstructions: A systematic review of the survival and complication rates. Clin Oral Implants Res 23 Suppl 6, 163-201

Sailer I, Philipp A, Zembic A, Pjetursson BE, Hammerle CH, Zwahlen M (2009): A systematic review of the performance of ceramic and metal implant abutments supporting fixed implant reconstructions. Clin Oral Implants Res 20 Suppl 4, 4-31

Sakanaka A, Takeuchi H, Kuboniwa M, Amano A (2015): Dual lifestyle of porphyromonas gingivalis in biofilm and gingival cells. Microb Pathog

Salvi GE, Aglietta M, Eick S, Sculean A, Lang NP, Ramseier CA (2012): Reversibility of experimental peri-implant mucositis compared with experimental gingivitis in humans. Clin Oral Implants Res $\underline{23}, 182-190$

Salvi GE, Cosgarea R, Sculean A (2017): Prevalence and mechanisms of peri-implant diseases. J Dent Res $\underline{96}$, 31-37

Sanchez GA, Acquier AB, De Couto A, Busch L, Mendez CF (2015): Association between aggregatibacter actinomycetemcomitans and porphyromonas gingivalis in subgingival plaque and clinical parameters, in argentine patients with aggressive periodontitis. Microb Pathog $\underline{82}, 31-36$

Sanchez-Garces MA, Gay-Escoda C (2004): Periimplantitis. Med Oral Patol Oral Cir Bucal 9 Suppl, 69-74; 63-69

Sanchez-Perez A, Moya-Villaescusa MJ, Caffesse RG (2011): Temperature of periimplant tissues in clinically successful implants: An observational clinical study in humans. Implant Dentistry 20, 292-298 
Sanz M, Chapple IL, Working Group 4 of the VEWoP (2012): Clinical research on periimplant diseases: Consensus report of working group 4. J Clin Periodontol 39 Suppl 12, 202-206

Sato J, Gomi K, Makino T, Kawasaki F, Yashima A, Ozawa T, Maeda N, Arai T (2011): The evaluation of bacterial flora in progress of peri-implant disease. Aust Dent J $\underline{56}, 201-$ 206

Saxer UP, Walter C, Bornstein MM, Klingler K, Ramseier CA (2007): Einfluss des Tabakkonsums auf das Parodont--ein Update. Teil 2: Klinische und radiologische Veränderungen des Parodonts sowieFolgen auf die Parodontaltherapie und orale Implantologie. Schweiz Monatsschr Zahnmed 117, 153-169

Schou S (2008): Implant treatment in periodontitis-susceptible patients: A systematic review. J Oral Rehabil 35 Suppl 1, 9-22

Schwarz F, Herten M, Sager M, Bieling K, Sculean A, Becker J (2007): Comparison of naturally occurring and ligature-induced peri-implantitis bone defects in humans and dogs. Clin Oral Implants Res $\underline{18}, 161-170$

Settem RP, El-Hassan AT, Honma K, Stafford GP, Sharma A (2012): Fusobacterium nucleatum and tannerella forsythia induce synergistic alveolar bone loss in a mouse periodontitis model. Infect Immun $\underline{80}$, 2436-2443

Sgolastra F, Petrucci A, Severino M, Gatto R, Monaco A (2014): Smoking and the risk of peri-implantitis. A systematic review and meta-analysis. Clin Oral Implants Res

Shibli JA, Melo L, Ferrari DS, Figueiredo LC, Faveri M, Feres M (2008): Composition of supra- and subgingival biofilm of subjects with healthy and diseased implants. Clin Oral Implants Res $\underline{19}$, 975-982

Smeets R, Henningsen A, Jung O, Heiland M, Hammacher C, Stein JM (2014): Definition, etiology, prevention and treatment of peri-implantitis--a review. Head Face Med $\underline{10}, 34$

Smith MM, Knight ET, Al-Harthi L, Leichter JW (2017): Chronic periodontitis and implant dentistry. Periodontol $2000 \underline{74}, 63-73$

Socransky SS, Haffajee AD, Cugini MA, Smith C, Kent RL Jr. (1998): Microbial complexes in subgingival plaque. J Clin Periodontol $\underline{25}, 134-144$

Stacchi C, Berton F, Perinetti G, Frassetto A, Lombardi T, Khoury A, Andolsek F, Di Lenarda R (2016): Risk factors for peri-implantitis: Effect of history of periodontal disease and smoking habits. A systematic review and meta-analysis. J Oral Maxillofac Res $\underline{7}$, e3

Strietzel FP, Reichart PA, Kale A, Kulkarni M, Wegner B, Kuchler I (2007): Smoking interferes with the prognosis of dental implant treatment: A systematic review and meta- 
analysis. J Clin Periodontol $\underline{34}$, 523-544

Swierkot K, Lottholz P, Flores-de-Jacoby L, Mengel R (2012): Mucositis, peri-implantitis, implant success, and survival of implants in patients with treated generalized aggressive periodontitis: 3- to 16-year results of a prospective long-term cohort study. J Periodontol $\underline{83}, 1213-1225$

Tagger Green N, Machtei EE, Horwitz J, Peled M (2002): Fracture of dental implants: Literature review and report of a case. Implant Dent 11, 137-143

Takamiya AS, Goiato MC, Gennari Filho H (2014): Effect of smoking on the survival of dental implants. Biomed Pap Med Fac Univ Palacky Olomouc Czech Repub 158, 650-653

Takanashi K, Kishi M, Okuda K, Ishihara K (2004): Colonization by porphyromonas gingivalis and prevotella intermedia from teeth to osseointegrated implant regions. Bull Tokyo Dent Coll $\underline{45}$, 77-85

Tanner A, Maiden MF, Lee K, Shulman LB, Weber HP (1997): Dental implant infections. Clin Infect Dis 25 Suppl 2, S213-217

Tatli U, Damlar I, Erdogan O, Esen E (2013): Effects of smoking on periimplant health status and il-1beta, tnf-alpha, and pge2 levels in periimplant crevicular fluid: A crosssectional study on well-maintained implant recall patients. Implant Dent $\underline{22}, 519-524$

Timmerman MF, van der Weijden GA (2006): Risk factors for periodontitis. Int J Dent Hyg $\underline{4}, 2-7$

Tomasi C, Derks J (2012): Clinical research of peri-implant diseases--quality of reporting, case definitions and methods to study incidence, prevalence and risk factors of periimplant diseases. J Clin Periodontol 39 Suppl 12, 207-223

Tomita S, Komiya-Ito A, Imamura K, Kita D, Ota K, Takayama S, Makino-Oi A, Kinumatsu T, Ota M, Saito A (2013): Prevalence of aggregatibacter actinomycetemcomitans, porphyromonas gingivalis and tannerella forsythia in japanese patients with generalized chronic and aggressive periodontitis. Microb Pathog 61-62, 11-15

Torrungruang K, Jitpakdeebordin S, Charatkulangkun O, Gleebbua Y (2015):

Porphyromonas gingivalis, aggregatibacter actinomycetemcomitans, and treponema denticola / prevotella intermedia co-infection are associated with severe periodontitis in a thai population. PLoS One $\underline{10}$, e0136646

Turkyilmaz I (2010): One-year clinical outcome of dental implants placed in patients with type 2 diabetes mellitus: A case series. Implant Dent $\underline{19}$, 323-329

van Steenberghe D, Klinge B, Linden U, Quirynen M, Herrmann I, Garpland C (1993): Periodontal indices around natural and titanium abutments: A longitudinal multicenter study. J Periodontol $\underline{64}, 538-541$ 
van Velzen FJ, Ofec R, Schulten EA, Ten Bruggenkate CM (2015): 10-year survival rate and the incidence of peri-implant disease of 374 titanium dental implants with a sla surface: A prospective cohort study in 177 fully and partially edentulous patients. Clin Oral

Wang HL, Garaicoa-Pazmino C, Collins A, Ong HS, Chudri R, Giannobile WV (2016): Protein biomarkers and microbial profiles in peri-implantitis. Clin Oral Implants Res $\underline{27}$, $1129-1136$

Wehrbein H (1994): Enossale Titanimplantate als orthodontische Verankerungselemente. Experimentelle untersuchungen und klinische Anwendung. Fortschr Kieferorthop $\underline{55}$, 236250

Weng D (2011): Cementum excess as cause for peri-implantitis - a case report. Implantologie 19, 171-177

Yang NY, Zhang Q, Li JL, Yang SH, Shi Q (2014): Progression of periodontal inflammation in adolescents is associated with increased number of porphyromonas gingivalis, prevotella intermedia, tannerella forsythensis, and fusobacterium nucleatum. Int J Paediatr Dent 24, 226-233 
Danksagung

\section{Danksagung}

Mein herzlichstes Dankeschön geht an:

Herrn Prof. Dr. med. dent. Dirk Ziebolz und Herrn PD Dr. Sven Rinke für die Vergabe des Themas und die sehr gute Betreuung im Rahmen meiner Dissertation.

Frau Monika Hoch für die große Hilfe während des experimentellen Teils der Arbeit. istep: 
Lebenslauf 